\author{
UNIVERSIDADE DE SÃO PAULO \\ ESCOLA DE ENFERMAGEM DE RIBEIRÃO PRETO
}

\author{
CINTHIA MIDORI SASSAKI
}

FATORES PREDITIVOS PARA O RESULTADO DE TRATAMENTO DA TUBERCULOSE PULMONAR NO MUNICÍPIO DE RECIFE-PE: uma contribuição para as ações de vigilância epidemiológica.

Ribeirão Preto 


\section{FATORES PREDITIVOS PARA O RESULTADO DE TRATAMENTO DA TUBERCULOSE PULMONAR NO MUNICÍPIO DE RECIFE-PE: uma contribuição para as ações de vigilância epidemiológica.}

Tese apresentada à Escola de Enfermagem de Ribeirão Preto da Universidade de São Paulo para obtenção do título de Doutor em Enfermagem em Saúde Pública, junto ao Departamento de Enfermagem Materno-Infantil e Saúde Pública, inserida na Linha de Pesquisa: Práticas, Saberes e Políticas de Saúde.

Orientadora: Profa. Dra. Tereza Cristina Scatena Villa 
AUTORIZO A REPRODUCÃO E DIVULGACÃO TOTAL OU PARCIAL DESTE TRABALHO, POR QUALQUER MEIO CONVENCIONAL OU ELETRÔNICO, PARA FINS DE ESTUDO E PESQUISA, DESDE QUE CITADA A FONTE.

FICHA CATALOGRÁFICA

Sassaki, Cinthia Midori.

FATORES PREDITIVOS PARA O RESULTADO DE TRATAMENTO DA TUBERCULOSE PULMONAR NO MUNICÍPIO DE RECIFE-PE: uma contribuição para as ações de vigilância epidemiológica./ Cinthia Midori Sassaki; orientadora Tereza Cristina Scatena Villa. Ribeirão Preto, 2006.

123 f. : fig.

Tese (Doutorado - Programa de Pós-Graduação em Saúde Pública. Área de concentração: Saúde Pública) - Escola de Enfermagem de Ribeirão Preto da Universidade de São Paulo.

1. Tuberculose. 2. Resultado de tratamento. 3. Sistemas de informação. 4. Vigilância Epidemiológica. 5. Eqüidade. 6. Enfermagem em saúde pública. I. Título. 


\section{FOLHA DE APROVAÇÃO}

Cinthia Midori Sassaki

FATORES PREDITIVOS PARA O RESULTADO DE TRATAMENTO DA TUBERCULOSE PULMONAR NO MUNICÍPIO DE RECIFE-PE: uma contribuição para as ações de vigilância epidemiológica.

Tese apresentada à Escola de Enfermagem de Ribeirão Preto da Universidade de São Paulo para obtenção do título de Doutor em Enfermagem em Saúde Pública. Linha de Pesquisa: Práticas, Saberes e Políticas de Saúde.

Aprovado em:

\section{Banca Examinadora}

Prof. Dr.

Instituição:

Assinatura:

Prof. Dr.

Instituição: Assinatura:

Prof. Dr.

Instituição: Assinatura:

Prof. Dr. Instituição: Assinatura:

Prof. Dr. Instituição: Assinatura: 
Este trabalho é dedicado:

Em primeiro lugar, a Deus e também a todos aqueles enviados por "Ele" que zelaram e intercederam por mim nesta etapa da minha vida. Agradeço pela força que me fez incansável; por todas as portas, pontes e elos; pela ânsia inesgotável de querer e sonhar; pelos horizontes sempre à frente e pela capacidade de buscar e inovar.

Aos meus queridos pais, Mário e Katsuko, pela formação que me deram, pelo exemplo de vida e por todo amor que me inspira a ir adiante para realização dos meus sonhos. Que Deus em sua infinita bondade e sabedoria os abençoe sempre e ilumine os seus caminhos. 


\section{HOMENAGEM ESPECIAL}

À minha orientadora Profa. Dra. Tereza Cristina Scatena Villa, "Tite”, agradeço pela acolhida que tive desde o início da minha caminhada na pesquisa, por ter acreditado em mim, pelo apoio e ensinamentos extremamente valiosos que levarei comigo para sempre. Muito obrigada! 


\section{AGRADECIMENTOS}

Ao Dr. Antonio Ruffino-Netto, Dra. Ione Carvalho Pinto, Dra. Lúcia Marina Scatena e Dra. Roxana Isabel Cardozo Gonzales, membros da banca examinadora, pela dedicação na análise da pró-forma e pelas sugestões que certamente qualificaram este estudo.

À Dra. Lúcia Marina Scatena pela assessoria estatística, por sua incalculável disposição e apoio e por ter contribuído em grande parte para realização deste trabalho.

Às minhas queridas irmãs Myrian e Alessandra que me motivaram carinhosamente com suas mensagens e palavras de incentivo.

Ao meu querido sobrinho Matheus, que na sua infância inquieta, me traz alegria e esperança de um futuro melhor.

À Aline Monroe, Cláudia Gazetta, Danuza Firmino, Elisangela Assis, Jordana Nogueira, Livia Módulo, Lurdinha, Márcia Zanutto, Maria Eugênia Brunelo, Mayra Oliveira, Patrícia Pazini, Paula Hino, Paula Nogueira, Renata Silveira, Ricardo Arcêncio, Roxana, Rubia Andrade e Silvia Vendramini que compartilharam com dedicação, alegria e entusiasmo essa trajetória. Obrigada pelas palavras de incentivo, pela adorável atenção em todos os momentos de dificuldades, pelos ensinamentos transmitidos e pela gentil amizade de cada um de vocês.

Aos queridos amigos Alan Esperança, Daniela Lanfredi, Elísio Machado Filho, Fabiana Mendes, Fernando Petrilli Filho, Paulo Telles Filho, Priscilla Hortense, Ricardo Reges e Terezinha Yano que em algum momento desta minha trajetória me deram atenção, força e apoio. Obrigada pelo carinho de cada um de vocês que ficarão guardados para sempre em meu coração.

Aos membros do GEOTB-REDE-TB, cujas experiências compartilhadas comigo resultaram em valiosas contribuições.

À Maria Júlia Barros Vilela, à Daisy Maria da Silva e a toda equipe do DEAB-Recife/PE, indispensáveis para a realização deste estudo, pela colaboração e confiança em ceder-me dados e materiais básicos para o desenvolvimento desta investigação, pelo acolhimento e carinho que me foram atribuídos. 
Ao Prof. Dr. Moacyr Lobo da Costa Júnior, que desde o início da minha pós-graduação, auxiliou-me nas pesquisas, disponibilizando seu tempo, conhecimento e dedicação.

Ao Prof. Dr. Ricardo Arraes de Alencar Ximenes, pelos esclarecimentos e valiosas contribuições prestados durante a execução deste trabalho.

Aos funcionários da EERP, Adriana, Andréia, Augusto, Olânia, Rosana, Bernadete, Lurdes, por serem sempre prestativos e atenciosos e por todo o suporte que me proporcionaram.

À Coordenação de Aperfeiçoamento de Pessoal de Nível Superior (CAPES) pelo apoio financeiro para a realização desta pesquisa.

\section{Esperança}

Vamos dividir nossos problemas,

Vamos dividir nossos conhecimentos, Vamos dividir nossas posses, Vamos dividir nossos poderes, Vamos dividir nossas inquietações, Vamos dividir nossas experiências,

Vamos dividir tudo que somos.

E, ao assim dividir,

Vamos somar nossas esperanças,

Vamos somar nossas expectativas

Vamos somar nossas vidas

E poder perceber

Que o amor que daí resulta

É maior que a soma

De todos os divisores

Que poderão existir no Universo

Antonio Ruffino-Netto 


\section{AGRADECIMENTO ESPECIAL}

Ao meu querido Thiago, "razão da minha vida”, pela sua capacidade de compreender minha ausência, pelo carinho, paciência e por todas as suas atitudes e palavras de amor, apoio e tranqüilidade.

"A imortalidade de que se reveste a natureza humana faz o homem sempre presente: presente pelo conhecimento que transmitiu, pela amizade que conquistou, pelo exemplo que legou e pelo amor que dedicou” 


\section{RESUMO}

SASSAKI, C. M. FATORES PREDITIVOS PARA O RESULTADO DE TRATAMENTO DA TUBERCULOSE PULMONAR NO MUNICÍPIO DE RECIFE-PE: uma contribuição para as ações de vigilância epidemiológica. 2006. 123 f. Tese (Doutorado) - Escola de Enfermagem de Ribeirão Preto, Universidade de São Paulo, Ribeirão Preto, 2006.

O objetivo desta investigação foi identificar e analisar fatores preditivos para o resultado favorável de tratamento dos casos de tuberculose pulmonar, diagnosticados no período de 2001 a 2004 e residentes no município de Recife-PE. Inicialmente, foi realizado um estudo exploratório para identificar dados perdidos (brancos, ignorados e inconsistentes) nos dados selecionados no Sistema de Informação de Agravos de Notificação (SINAN): ano do diagnóstico; município de residência; desfecho do tratamento; idade; sexo; escolaridade; ocupação; distrito de residência; forma clínica; tipo de entrada; tratamento supervisionado; data diagnóstico, início e encerramento do tratamento; distrito da unidade de saúde; HIV e outros agravos. Observou-se registros em branco nos dados Outros Agravos (42,85\%) e Ocupação (82,10\%); ignorados, nos dados Escolaridade (39,40\%), Outros Agravos (39,73\%) e Tratamento Supervisionado (63,96\%) e inconsistentes, nos dados Ocupação (2,53\%), Data do diagnóstico (0,98\%), Data do início do tratamento $(9,94 \%)$ e Data do encerramento do tratamento $(17,66 \%)$. Posteriormente, foram identificados e analisados os fatores preditivos ao resultado favorável de tratamento por meio de métodos estatísticos uni e multivariado de regressão logística. $\mathrm{Na}$ análise univariada, as variáveis que apresentaram associação foram: sexo; idade; escolaridade; tipo de entrada; tratamento supervisionado; Tempo 1; Tempo 2 e distrito da unidade de saúde. As variáveis que permaneceram no modelo multivariado ajustado final foram: Idade, "0 a 9 anos" ( $\mathrm{OR}=4,27 ; \mathrm{p}=0,001)$ e "10 a 19 anos" $(\mathrm{OR}=1,78 ; \mathrm{p}=0,011)$ que tiveram maior chance de cura do que "mais de 60 anos"; Escolaridade, "8 a 11 anos" $(\mathrm{OR}=1,52 ; \mathrm{p}=0,049)$ que teve maior chance de cura do que "nenhuma escolaridade"; Tipo de entrada, "casos novos" (OR=3,31; $p<0,001)$ e "recidiva" $(O R=3,32 ; p<0,001)$ que tiveram maior chance de cura do que "reingresso pós abandono"; Tempo 2, "5-16 meses" (OR=9,15; $p<0,001)$; "6 -19 meses" ( $O R=27,28 ; p<0,001)$ e "Mais de 9 meses" $(\mathrm{OR}=24,78 ; p<0,001)$ que tiveram maior chance de cura do que aqueles que o fizeram em tempo menor; Distrito da Unidade de Saúde, "DS I" $(\mathrm{OR}=1,60 ; p=0,018)$ e "DS IV" $(\mathrm{OR}=2,87 ; \mathrm{p}<0,001)$ que tiveram maior chance de cura do que "DS VI". Sugere-se desenvolver nos serviços de saúde uma organização de assistência voltada às necessidades individuais priorizando os grupos com menor chance de cura garantindo a equidade da atenção e conseqüentes transformações nos indicadores epidemiológicos da tuberculose no município de Recife.

Palavras-chave: Tuberculose. Resultado de tratamento. Sistemas de informação. Vigilância epidemiológica. Eqüidade. Enfermagem em saúde pública. 


\title{
ABSTRACT
}

\author{
SASSAKI, C. M. PREDICTIVE FACTORS OF PULMONARY \\ TUBERCULOSIS TREATMENT OUTCOMES IN RECIFE-PE: a \\ contribution to epidemiological surveillance actions. 2006. $123 \mathrm{f}$. \\ Doctoral Thesis - University of São Paulo at Ribeirão Preto College of \\ Nursing, Ribeirão Preto, 2006.
}

This study aimed to identify and analyze predictive factors of favorable treatment outcome related to pulmonary tuberculosis cases residing in Recife and diagnosed between 2001 and 2004. Initially, an exploratory study was carried out to identify lost data (blank, unknown and inconsistent) in the selected data in the Reportable Health Events Information System (SINAN): year of diagnosis; city of residence; treatment outcome; age; gender; education level; occupation; district of residence; form; type of entry; Supervised Treatment; date of diagnosis, start and end of treatment; health unit district; HIV and other health problems. Blank registers were found for Other Health Problems (42.85\%) and Occupation (82.10\%); unknown data were found for Education level (39.40\%), Other Health Problems (39.73\%) and Supervised Treatment (63.96\%); and inconsistent data for Occupation $(2.53 \%)$, Date of diagnosis $(0.98 \%)$, Treatment start date $(9.94 \%)$ and Treatment end date (17.66\%). Then, we identified and analyzed predictive factors of favorable treatment outcome by means of uni and multivariate logistic regression methods. In univariate analysis, the following variables were associated with favorable treatment outcome: gender; age; education level; type of entry; supervised treatment; Time 1; Time 2 and health unit district. The variables that remained in the final adjusted multivariate model were: Age, " 0 to 9 years" $(\mathrm{OR}=4.27 ; \mathrm{p}=0.001)$ and "10 to 19 years" $(\mathrm{OR}=1.78 ; \mathrm{p}=0.011)$ had a greater chance of cure than those "older than 60 years"; Education, " 8 to 11 years" $(\mathrm{OR}=1.52 ; \mathrm{p}=0.049)$ had greater chance of cure than "no education"; Type of entry, "new cases" (OR=3.31; $p<0.001)$ and "relapse" $(\mathrm{OR}=3.32 ; \mathrm{p}<0.001)$ had a greater chance of cure than "reentry after abandonment"; Time 2, "5 -6 months" (OR=9.15; $p<0.001)$; " $6 \multimap-19$ months" (OR=27.28; $p<0.001)$ and "More than 9 months" $(O R=24,78$; $p<0,001)$ had greater chance of cure than patients who terminated treatment in less time; Health Unit District, "DS I" $(\mathrm{OR}=1.60 ; \mathrm{p}=0.018)$ and "DS IV" $(\mathrm{OR}=2.87 ; p<0.001)$ had a greater chance of cure than "DS VI". We suggest that health services develop a care organization that is directed at individual needs, prioritizing groups with lower chances of cure, guaranteeing equity and consequent transformations in the city's epidemiological TB indices.

Key words: Tuberculosis. Treatment outcome. Information systems. Epidemiological surveillance. Equity. Public health nursing. 


\section{RESUMÉN}

SASSAKI, C. M. FACTORES ASOCIADOS PARA EL RESULTADO DE TRATAMIENTO DE LA TUBERCULOSIS PULMONAR EN EL MUNICIPIO DE RECIFE-PE: una contribución para las acciones de vigilancia epidemiológica. 2006. 123 f. Tesis (Doctorado) - Escuela de Enfermería de Ribeirão Preto, Universidad de São Paulo, Ribeirão Preto, 2006.

El objetivo del estudio fue identificar y analisar factores asociados al resultado favorable de tratamiento del casos de tuberculosis pulmonar, diagnosticados en el período de 2001 a 2004 y residentes en el município de Recife-PE. Inicialmente, fue realizado un estudo exploratório para identificar datos perdidos (blancos, ignorados e inconsistentes) en el Sistema de Información de Agravos de Notificación (SINAN) en relación al año del diagnóstico; municipio de residencia; resultado del tratamiento; edad; sexo; escolaridad; ocupación; distrito de residencia; forma; tipo de entrada; Tratamiento Supervisado; fecha de diagnóstico, início y conclusión del tratamiento; distrito de la unidad de salud; VIH y otros agravos. Se observó registros en blanco en Otros Agravos (42,85\%) y Ocupación (82,10\%); ignorados en Escolaridad (39,40\%), Otros Agravos (39,73\%) y Tratamiento Supervisado $(63,96 \%)$ e inconsistentes en Ocupación (2,53\%), Fecha del diagnóstico (0,98\%), Fecha del início del tratamiento $(9,94 \%)$ y Fecha de conclusión del tratamiento (17,66\%). Posteriormente, fueron identificados y analizados los factores asociados al resultado favorable de tratamiento por medio de métodos estadísticos uni y multivariado de regresión logística. En el análisis univariado, las variábles que presentaron asociación fueron: sexo; edad; escolaridad; tipo de entrada; tratamiento supervisado; Tiempo 1; Tiempo 2 y distrito de la unidad de salud. Las variables que permanecieron en el modelo multivariado ajustado final fueron: edad, "0 a 9 años" (OR=4,27; $p=0,001)$ y "10 a 19 años" (OR=1,78; $p=0,011$ ) presentaron mayor chance de cura de que "más de 60 años"; Escolaridad, "8 a 11 años" $(\mathrm{OR}=1,52 ; \mathrm{p}=0,049)$ presentó mayor chance de cura de que "ninguna escolaridad"; Tipo de entrada, "casos nuevos" (OR=3,31; $p<0,001)$ y "recidiva" $(O R=3,32 ; p<0,001)$ presentaron mayor chance de cura de que "reingreso após abandono"; Tiempo 2 , " $5-16$ meses" (OR=9,15; $p<0,001)$; "6 6 - 9 meses" ( $O R=27,28 ; p<0,001)$ y "Más de 9 meses" ( $O R=24,78$; $p<0,001)$ presentaron mayor chance de cura de que aquellos que lo hicieron en el menor tiempo; Distrito de la Unidad de Salud, "DS I" $(\mathrm{OR}=1,60$; $p=0,018)$ y "DS IV" $(O R=2,87 ; p<0,001)$ presentaron mayor chance de cura de que "DS VI". Se recomienda desarrollar en los servicios de salud una organización de asistencia orientada a las necesidades individuales priorizando los grupos con menor chance de cura garantizando la equidad y consecuentes transformaciones en los indicadores epidemiológicos de la TB en el municipio.

Descriptores: Tuberculosis. Resultado de tratamiento. Sistemas de información. Vigilancia epidemiológica. Equidad. Enfermería salud pública. 


\section{LISTA DE ILUSTRAÇÕES}

Figura 1 - Número de casos novos e coeficiente de incidência (100.000 habitantes) de tuberculose segundo o ano de ocorrência. Recife, 1998 - 2003

Figura 2 - Percentual de casos de tuberculose segundo forma 04 clínica. Recife, 1998 - 2003

Figura 3 - Número de óbitos e coeficiente de mortalidade (100.000 habitantes) de tuberculose segundo o ano de ocorrência. Recife, 1998 - 2002

Figura 4 - Coeficiente de incidência (100.000 habitantes) de 06 tuberculose segundo Distrito Sanitário. Recife, 1998 2003

Figura 5 - Situação no encerramento dos casos novos de 07 tuberculose segundo ano de ocorrência. Recife, 1998 2002

Figura 6 - Fluxo de documentos recomendado pelo Ministério da 16 Saúde

Figura 7 - Evolução das equipes do Programa de Saúde da 46 Família. Recife, 1998 - 2005

Figura 8 - Total de Unidades de Saúde da Família em funcionamento por Distrito Sanitário. Recife, 1998 - 2005

Figura 9 - Rede de Serviços de Saúde do Programa de Controle 48 da Tuberculose. Recife, 2003

Mapa 1 - Divisão político-administrativa do município de Recife 43

Mapa 2 - Mapa de áreas pobres no município de Recife 


\section{LISTA DE TABELAS}

Tabela 1 - Freqüência de dados perdidos dos casos de TB pulmonar, diagnosticados no período de 2001 a 2004, residentes em Recife e registrados no banco de dados do SINAN

Tabela 2 - Distribuição dos casos de TB pulmonar, diagnosticados no período de 2001 a 2004 e residentes em Recife, segundo resultados de tratamento (cura, abandono, óbito e TB-multirresistente)

Tabela 3 - Análise univariada da associação entre resultado favorável e variáveis independentes dos casos de TB pulmonar, diagnosticados no período de 2001 a 2004 e residentes em Recife

Tabela 4 - Análise multivariada da associação entre resultado favorável e variáveis independentes dos casos de TB pulmonar, diagnosticados no período de 2001 a 2004 e residentes em Recife 


\section{LISTA DE GRÁFICOS}

Gráfico 1 - Distribuição das categorias do dado TRATAMENTO

(Tipo de entrada). SINAN-TB, Recife-PE, 2001-2004

Gráfico 2 - Distribuição das categorias do dado HIV. SINAN-TB,

60 Recife-PE, 2001-2004

Gráfico 3 - Distribuição dos casos com inconsistência no dado 62 DT_INIC_TR (Data do início do tratamento) segundo resultado de tratamento. SINAN-TB, Recife-PE, 20012004 


\section{LISTA DE ABREVIATURAS E SIGLAS}

AIDS

CAPS

CHETRE

$\mathrm{CNPq}$

DOTS

DS

FII

FIN

GEOTB

IBGE

IC

LOS

MS

NOB

OMS

OR

PACS

PCT

PIB

PNCT

PSF

REDE-TB

RPA

$\mathrm{SIH}$
(Acquired Immunological Deficiency Syndrome) Síndrome da Imunodeficiência Adquirida

Centro de Atenção Psicossocial

Center for Health Equity, Training, Research and Evaluation

Conselho Nacional de Desenvolvimento Científico e Tecnológico

(Directly Observed Therapy Short Course) Tratamento Diretamente Observado de Curta Duração

Distrito Sanitário

Ficha Individual de Investigação

Ficha Individual de Notificação

Grupo de Estudos Epidemiológico-Operacionais em Tuberculose

Instituto Brasileiro de Geografia e Estatística

Intervalo de Confiança

Leis Orgânicas da Saúde

Ministério da Saúde

Normas Operacionais Básicas

Organização Mundial de Saúde

Odds Ratio

Programa de Agentes Comunitários de Saúde

Programa de Controle da Tuberculose

Produto Interno Bruto

Plano Nacional de Controle da Tuberculose

Programa de Saúde da Família

Rede Brasileira de Pesquisa em Tuberculose

Regiões Político Administrativas

Sistema de Informações sobre Internações Hospitalares 
SIL-TB

SIM

SINAN

SIS

SNVE

SPSS

SUS

TA

TB

TS

USF

UST

ZEIS
Sistema de Informação de Laboratório em Tuberculose

Sistema de Informações de Mortalidade

Sistema de Informação de Agravo de Notificação

Sistemas de Informações em Saúde

Sistema Nacional de Vigilância Epidemiológica

Statistical Package for the Social Sciences

Sistema Único de Saúde

Tratamento Auto-administrado

Tuberculose

Tratamento Supervisionado

Unidades de Saúde da Família

Unidades de Saúde Tradicionais

Zonas Especiais de Interesse Social 


\section{SUMÁRIO}

\section{APRESENTAÇÃO}

1. CONSTRUINDO O OBJETO DE ESTUDO 01

1.1. A situação epidemiológica da tuberculose no Recife (1998- 02 2003)

1.2. A situação operacional do controle da tuberculose no Recife 08 (2001-2004)

1.3. Epidemiologia e Planejamento de Saúde 11

1.4. A interface do Sistema de Informação em Saúde com a 13 Vigilância Epidemiológica

1.5. O problema da investigação 18

2. OBJETIVO DO ESTUDO 24

3. HIPÓTESE 26

4. QUADRO TEÓRICO 28

5. METODOLOGIA 40

5.1. O campo de investigação 41

5.1.1. Caracterização do local de estudo 41

5.1.2. O sistema de serviços de saúde para assistência à 45 tuberculose no município de Recife

5.2. Técnica de coleta e análise dos dados 49

5.2.1. Fase Exploratória $\quad 50$

5.2.2. Fase Univariada 52

5.2.3. Fase Multivariada $\quad 55$

5.3. Aspectos éticos da pesquisa 56

6. RESULTADOS 58

6.1. Fase Exploratória $\quad 59$

6.2. Fase Univariada 63

6.3. Fase Multivariada 68

7. ANÁLISE E DISCUSSÃO DOS DADOS 70

7.1. Fase Exploratória 71

7.2. Fases Univariada e Multivariada 80 
8. CONSIDERAÇÕES FINAIS 


\section{APRESENTAÇÃO}

interesse na temática da tuberculose (TB) emergiu durante o processo da minha formação profissional e, principalmente, da minha participação no Grupo de Estudos Epidemiológico-Operacionais em Tuberculose (GEOTB), cadastrado e certificado no diretório de grupos do Conselho Nacional de Desenvolvimento Científico e Tecnológico (CNPq) em 2002 ${ }^{1}$, com inserção na Rede Brasileira de Pesquisa em Tuberculose (REDE-TB) $)^{2}$.

Este estudo teve início durante a elaboração do livro "TUBERCULOSE. Implantação do DOTS em algumas regiões do Brasil: Histórico e peculiaridades regionais" (RUFFINO-NETTO; VILLA, 2006), em 2005, que considerou o município de Recife-PE como um dos locais de estudo.

A TB esteve presente como problema de saúde pública no Brasil durante todo século XX, ficando conhecida como a "calamidade negligenciada" (RUFFINO-NETTO, 2002). Atualmente, o país ocupa o $16^{\circ}$

${ }^{1}$ Coordenado pelo Prof. Dr. Antonio Ruffino Netto da Faculdade de Medicina de Ribeirão Preto da Universidade de São Paulo (FMRP-USP) e pela Profa. Dra. Tereza Cristina Scatena Villa da Escola de Enfermagem de Ribeirão Preto da Universidade de São Paulo (EERP-USP).

${ }^{2}$ Site da REDE TB: www.redetb.usp.br 
lugar entre os 22 países com a mais alta carga de TB notificada no mundo, com incidência estimada para o ano de 2004 de 60/ 100.000 habitantes por todas as formas (WHO, 2006). A TB, uma doença que tem cura, ainda mata pelo menos 6 mil pessoas por ano no Brasil. O percentual de cura é de 72,2 \% e a taxa de abandono está em torno de 11,7\% (WHO, 2005).

Segundo o Ministério da Saúde (MS), o Estado de Pernambuco ocupa $02^{\circ}$ lugar na região nordeste do Brasil, em número de casos de TB, perdendo apenas para a Bahia (BRASIL, 2005a). Em 2003, foram registrados no Estado 4.222 casos novos da doença, o coeficiente de incidência foi de 51,7/ 100.000 habitantes. Em Pernambuco existem 15 municípios prioritários para o Programa Nacional de Controle da Tuberculose (PNCT), entre eles, o município de Recife, uma vez que este apresenta um coeficiente de incidência bastante elevado, 113,95/ 100.000 habitantes (SINAN/ SMS, 2004), número acima do observado no Estado de Pernambuco e Brasil. A gravidade deste quadro ainda é demonstrada pelo alto coeficiente de mortalidade de 9,91/ 100.000 habitantes (SIM/ SMS, 2003). Quanto ao resultado de tratamento, o município vem apresentando taxa de abandono em torno de $15 \%$ e percentual de cura na faixa de $60 \%$ (RECIFE, 2005). Tal situação mostra que o município ainda está longe de alcançar as metas propostas pela Organização Mundial de Saúde (OMS) (WHO, 2005) de curar pelo menos $85 \%$ dos casos diagnosticados e manter o abandono de tratamento em percentuais considerados aceitáveis (5\%).

Nesse cenário, surgiu a necessidade de estudar a temática da TB a partir de alguns dados disponíveis no Sistema de Informação de Agravo de 
Notificação (SINAN) a fim de produzir informações que subsidiem as ações de vigilância epidemiológica para o controle da TB no município de RecifePE. Além disso, podem servir de informações que auxiliem no processo de formulação de políticas, planejamento, programação, organização e avaliação das ações de controle da doença no município. Para o desenvolvimento deste estudo, foram levantados os casos de TB pulmonar, diagnosticados no período de 2001 a 2004 e residentes no município de Recife. Inicialmente, procurou-se através de um estudo exploratório, analisar a qualidade dos dados disponíveis no SINAN-WINDOWS (no agravo "Tuberculose") e seu impacto para as ações de vigilância epidemiológica. A partir de dados selecionados no SINAN, foram definidas variáveis dependentes e independentes, utilizados métodos estatísticos uni e multivariado a fim de identificar e analisar os fatores preditivos para o resultado favorável de tratamento dos casos em estudo gerando deste modo, conhecimentos sobre os principais obstáculos ao sucesso do tratamento e os grupos prioritários do ponto de vista de um acompanhamento diferenciado.

Um dos propósitos deste trabalho foi otimizar o aproveitamento de dados sobre TB no Recife já coletados pelo sistema de vigilância epidemiológica utilizado na rotina do sistema de serviço de saúde municipal, sem que fosse necessário introduzir novos instrumentos ou despender mais recursos. Os dados estão disponíveis nos diferentes sistemas de informação, entretanto, poucos são habitualmente analisados de modo a 
fornecer suporte no processo de formulação de políticas, planejamento, organização e avaliação das ações de controle da TB no município. 
1. CONSTRUINDO O OBJETO DE ESTUDO 


\subsection{A situação epidemiológica da tuberculose no Recife $(1998-2003)^{5}$}

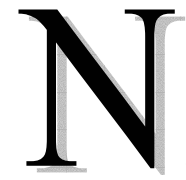

o período de 1998 a 2003 foram atendidos 9.893 casos de TB residentes no Recife. Destes, 1.488 relataram história de tratamento anterior para TB (15,04\%), 8.301 foram casos novos (83,91\%) e 104 entraram por transferência $(1,05 \%)$.

O coeficiente de incidência manteve-se em níveis elevados nesse mesmo período, com coeficiente de incidência médio de 97,60 casos de TB por 100.000 habitantes. Entre os anos de 1998 e 2001 houve um decréscimo anual de 8,65\% na detecção de casos, já em 2001 a 2003 verificou-se tendência crescente, correspondendo a uma elevação de $21,62 \%$ na detecção dos casos de TB (Figura 1).

O número total de casos novos esperados de TB, residentes no município, para o ano de 2003 era de 1.649 casos. O percentual de casos detectados foi de $93,45 \%$ superando o percentual da meta Nacional de diagnosticar pelo menos $70 \%$ dos casos esperados.

\footnotetext{
${ }^{5}$ PREFEITURA DO RECIFE. Secretaria de Saúde. Política de controle da Tuberculose: Plano de Ação de Tuberculose - Ano: 2004/ 2005. Recife, 2004. Versão Preliminar. Disponibilizado em setembro/ 2005.
} 
Figura 1: Número de casos novos e coeficiente de incidência $(100.000$ habitantes) de tuberculose segundo o ano de ocorrência. Recife, 1998 2003*

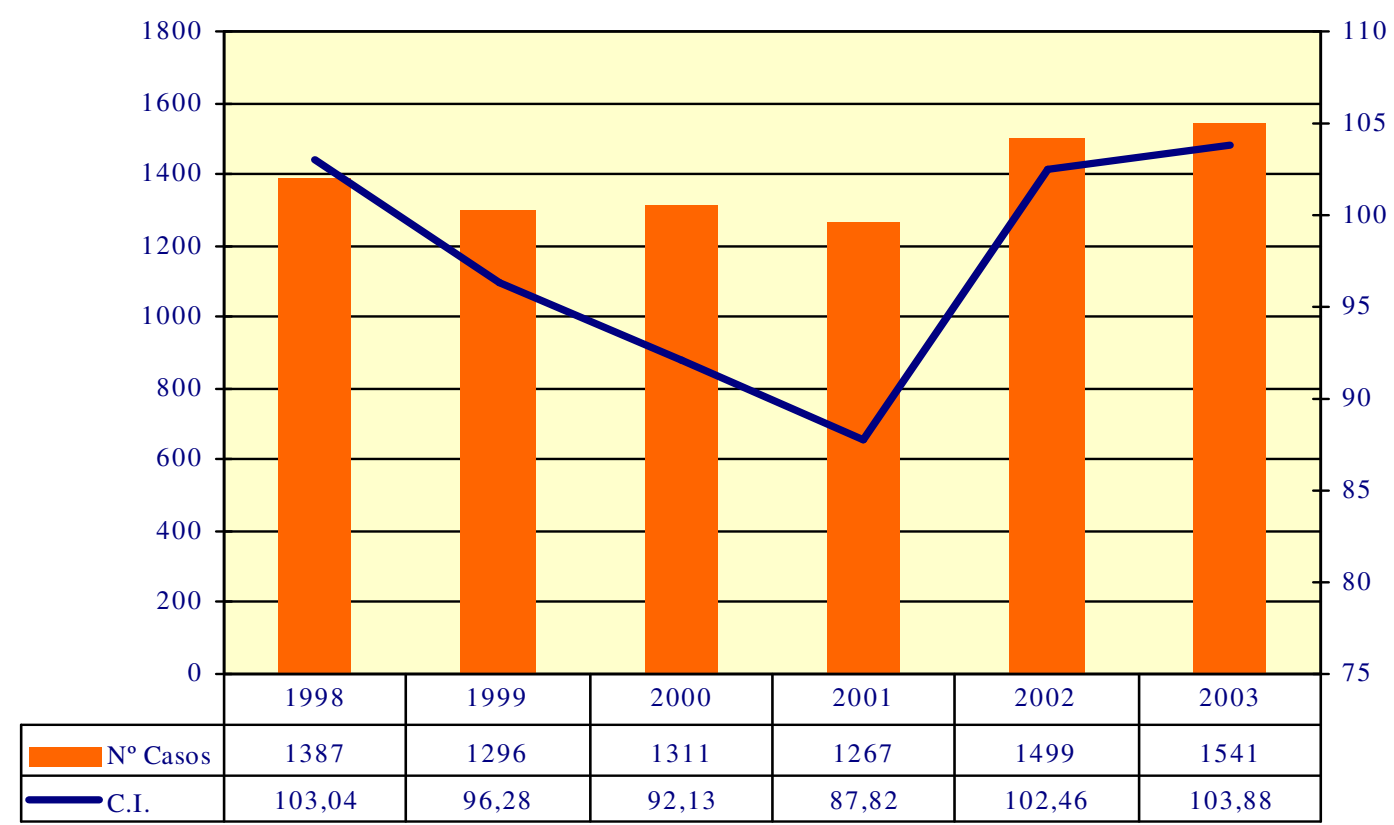

Fonte: SINAN/DIEVS - Secretaria de Saúde de Recife

* Dados provisórios

O sexo masculino foi o mais atingido no período de 1998 a 2003 com $64,21 \%$ (5.330 casos). Quanto ao grupo populacional, o mais atingido foi o de 20 a 59 anos, faixa etária produtiva, representando $84,14 \%$ dos casos; observou-se que o grupo etário de 40 - 59 anos, com 160,33/ 100.000 habitantes, vem apresentando maior incidência de casos.

Quanto à forma clínica, a mais freqüente foi à forma pulmonar (incluindo as formas pulmonar + extrapulmonar) com 7.242 casos, representando $87,24 \%$ dos casos em todas as formas (Figura 2). 
Figura 2: Percentual de casos de tuberculose segundo forma clínica. Recife, $1998-2003^{\star}$

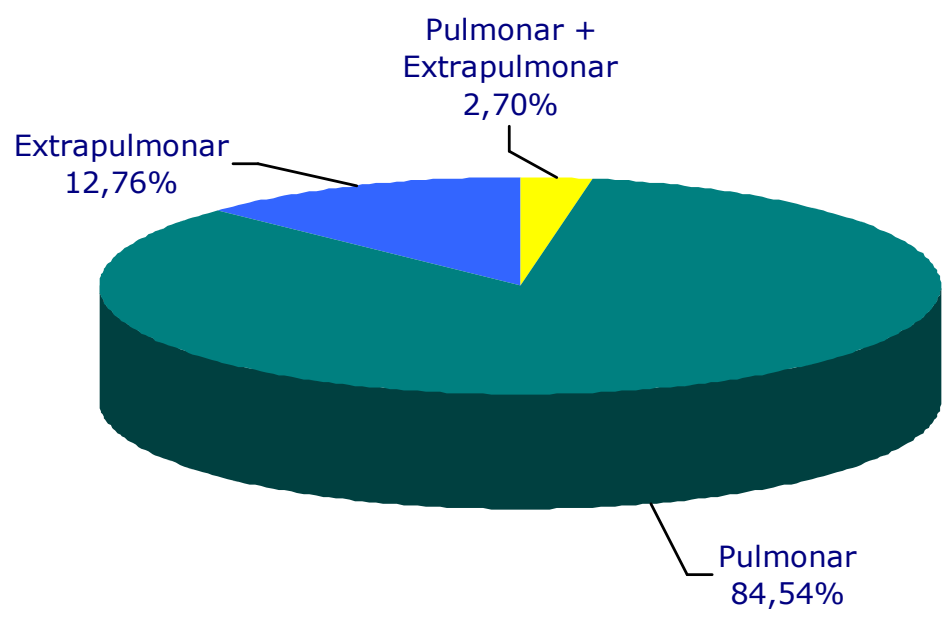

Fonte: SINAN/DIEVS - Secretaria de Saúde de Recife

* Dados provisórios

A gravidade da TB no município se traduz também pela alta mortalidade causada pela doença. As mortes oficialmente atribuídas à TB somaram 807 no período de 1998 a 2002, cerca de 160 pessoas por ano, sem levar em conta os casos de TB associados a outras doenças como AIDS, diabetes e outras (Figura 3). As faixas etárias mais atingidas, no período de 1998 a 2002, foram as de 40 a 59 anos (42,38\%) e as de 60 anos e mais $(35,44 \%)$, porém os coeficientes mostraram que na faixa etária superior a 60 anos, a mortalidade é mais elevada $(40,47 / 100.000$ habitantes), quase duas vezes mais do que a referente à faixa etária de $40 \mathrm{a}$ 59 anos de idade (23,07/ 100.000 habitantes). 
Figura 3: Número de óbitos e coeficiente de mortalidade $(100.000$ habitantes) de tuberculose segundo o ano de ocorrência. Recife, 1998 2002

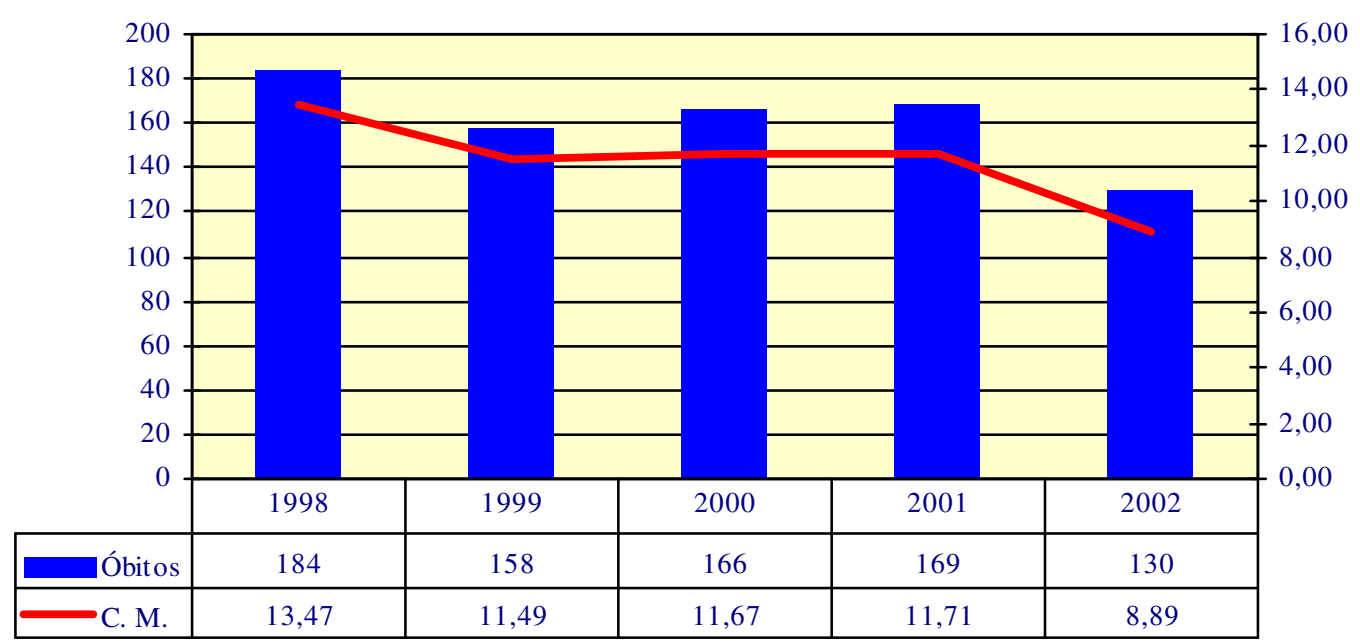

Fonte: SIM/DIEVS - Secretaria de Saúde de Recife

No período de 1998 a 2003, o maior coeficiente de incidência foi encontrado no Distrito Sanitário (DS) I com 170,57 casos por 100.000 habitantes, seguido do DS II com 113,31 casos por 100.000 habitantes. Ambos com coeficiente acima da média do município $(97,60 / 100.000$ habitantes) no período (Figura 4). 
Figura 4: Coeficiente de incidência (100.000 habitantes) de tuberculose segundo Distrito Sanitário. Recife, 1998 - 2003*

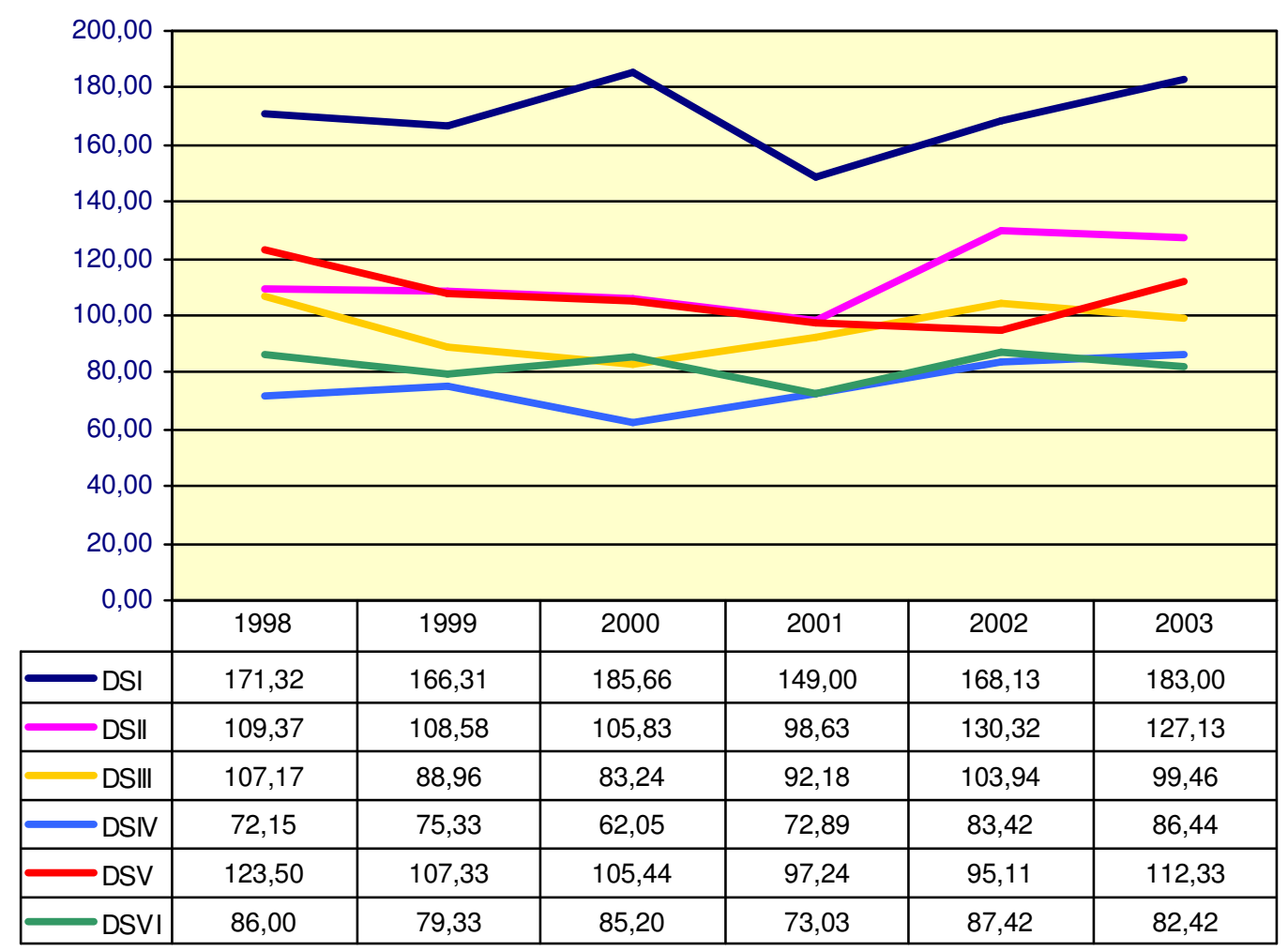

Fonte: SINAN/DIEVS - Secretaria de Saúde de Recife

* Dados provisórios

Em relação aos resultados de tratamento (situação no encerramento), o município apresentou entre 1998 e 2002 taxas de abandono e de cura distantes do preconizado pelo MS (Figura 5). 
Figura 5: Situação no encerramento dos casos novos de TB segundo ano de ocorrência. Recife, 1998 - 2002

\begin{tabular}{|c|c|c|c|c|c|c|c|c|c|c|}
\hline \multirow{2}{*}{$\begin{array}{c}\text { Situação no } \\
\text { Encerramento }\end{array}$} & \multicolumn{2}{|c|}{1998} & \multicolumn{2}{|c|}{1999} & \multicolumn{2}{|c|}{2000} & \multicolumn{2}{|c|}{2001} & \multicolumn{2}{|c|}{2002} \\
\hline & № & $\%$ & № & $\%$ & № & $\%$ & № & $\%$ & № & $\%$ \\
\hline Cura & 824 & 59,41 & 760 & 58,64 & 674 & 51,41 & 577 & 45,54 & 632 & 42,16 \\
\hline Abandono & 208 & 14,99 & 194 & 14,97 & 163 & 12,43 & 178 & 14,05 & 172 & 11,47 \\
\hline Óbito & 166 & 11,97 & 127 & 9,80 & 237 & 18,08 & 105 & 8,29 & 91 & 6,07 \\
\hline Transferência & 41 & 2,96 & 65 & 5,02 & 102 & 7,78 & 55 & 4,34 & 137 & 9,14 \\
\hline Mudança de Diagnóstico & 4 & 0,29 & 7 & 0,54 & 3 & 0,23 & 4 & 0,31 & 13 & 0,87 \\
\hline TB Multiresistente & 0 & - & 0 & - & 0 & - & 0 & - & 2 & 0,13 \\
\hline Ignorado/Branco & 144 & 10,38 & 143 & 11,03 & 132 & 10,07 & 348 & 27,47 & 452 & 30,16 \\
\hline Total & 1387 & 100,00 & 1296 & 100,00 & 1311 & 100,00 & 1267 & 100,00 & 1499 & 100,00 \\
\hline
\end{tabular}

Fonte: SINAN/DIEVS - Secretaria de Saúde de Recife 


\subsection{A situação operacional do controle da tuberculose no Recife (2001-} 2004)

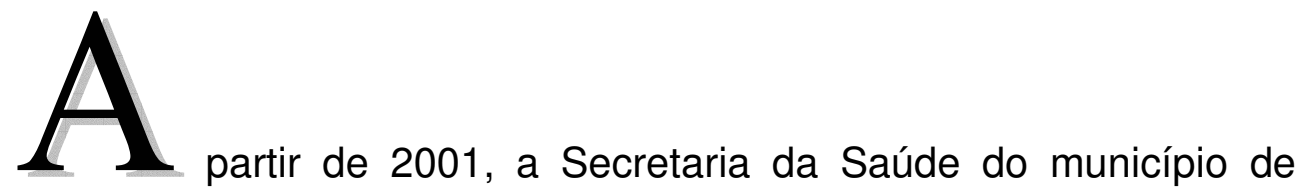

Recife iniciou a política de controle da TB com base na descentralização das ações para a rede de unidades básicas, tendo como principal estratégia o desenvolvimento de ações do Programa de Controle da Tuberculose (PCT) pelo Programa de Saúde da Família (PSF) e pelo Programa de Agentes Comunitários de Saúde (PACS) adotando os mesmos como porta de entrada do sistema de saúde.

Com a expansão do PSF, foi desencadeado em 2002, um processo de supervisão compartilhada (nível central/ DS) com a finalidade de fortalecer o acompanhamento e orientação do processo de trabalho das equipes nas Unidades de Saúde da Família (USF), compatibilizar ações e procedimentos básicos, atualizar e informar aos supervisionados sobre as mudanças técnicas e administrativas em torno das ações de TB.

O processo deu-se inicialmente através de capacitação das equipes de saúde do PSF e PACS oferecido pelos DS, abordando aspectos como: missão e papel do PACS/PSF, concepção do território, princípios do Sistema Único de Saúde (SUS), estigma, ética, sinais e sintomas, modo de transmissão, meios de diagnóstico, tratamento e vigilância epidemiológica. No tópico do tratamento, foi dada ênfase à questão do medicamento, dose supervisionada e importância da integralidade na atenção ao doente. No 
campo do diagnóstico foi explorado o papel do laboratório no apoio diagnóstico, especialmente no que tange à realização de baciloscopia e cultura. Na vigilância, foi abordado o controle de faltosos e contatos, o adequado preenchimento dos instrumentos alimentadores do SINAN, o fluxo destes entre as unidades de saúde, DS e Diretoria de Epidemiologia e Vigilância à Saúde, bem como os demais instrumentos e alguns documentos do PCT (PERNAMBUCO, 2004).

Em 2003, na VI Conferência Municipal de Saúde, ficou estabelecida a TB como um problema prioritário em Recife, sendo necessária a reorganização das ações de controle da doença no sentido de reverter os indicadores a médio e a longo prazo, tendo para isto, utilizado o Planejamento Estratégico e a Epidemiologia como norteadores do processo que resultou na construção do Plano Municipal de Tuberculose (2004-2005) cujas principais linhas de ação coincidem com os cinco elementos da estratégia Directly Observed Therapy Short-course (DOTS): 1. Compromisso governamental nas atividades básicas de controle da TB; 2. Detecção de casos por baciloscopia em todo paciente sintomático respiratório que espontaneamente procure o serviço de saúde; 3. Esquemas de tratamento padronizados de seis a oito meses para, pelo menos, todo caso bacilifero, com tratamento diretamente supervisionado durante no mínimo os dois meses iniciais; 4. Suprimento regular e ininterrupto dos medicamentos padronizados; 5 Um sistema de registro e notificação de casos que permitam o acompanhamento dinâmico dos resultados de tratamento de cada paciente 
e do PCT como um todo. (ORGANIZAÇÃO PANAMERICANA DA SAÚDE, 1997).

$\mathrm{Na}$ assistência farmacêutica, foi implantada planilha para facilitar a programação mensal de medicamentos, assim como tornado obrigatório a vinculação da notificação à liberação dos medicamentos, tornando este setor um importante produtor de dados para o gerenciamento e distribuição dos medicamentos do programa. Ficou acordado que a medicação anti-TB para tratamento dos casos no PACS/ PSF não ficariam disponíveis na farmácia da unidade de saúde local, devendo ser solicitados aos DS após descoberta dos casos. Apenas as unidades de referência dispõe de um quantitativo de medicamento para início de tratamento de novos casos. Quanto ao laboratório, foram implantados a cultura de Bacilo de Koch e o Sistema de Informação de Laboratório em Tuberculose (SIL-TB), que produz dados dos exames realizados em cada paciente desde a descoberta até a cura.

A partir de 2004, as ações de gestão e coordenação do PCT no município de Recife foram intensificadas e a estratégia DOTS começou a ser implantada de forma gradual a partir do Plano Municipal de Tuberculose (2004-2005). 


\subsection{Epidemiologia e Planejamento de Saúde}

1 aproximação entre a epidemiologia, o planejamento e a organização dos serviços começou a ocorrer nos anos 80 , a partir do Seminário sobre "Usos e perspectivas da Epidemiologia", realizado em Buenos Aires, que colocava em discussão a contribuição da epidemiologia no desenvolvimento dos programas de saúde e os usos da epidemiologia na avaliação, na planificação dos serviços e na vigilância e controle das enfermidades em geral (ORGANIZACIÓN PANAMERICANA DE LA SALUD, 1984).

Contemporaneamente, a Epidemiologia tem colocado em sua agenda de debates um conjunto de temas que implicam um certo "redirecionamento teórico, metodológico e operacional da disciplina" que traz, como uma das implicações possíveis, a redefinição dos objetos e métodos de análise de situações de saúde e a transformação das estratégias de intervenção sobre determinantes, riscos e danos à saúde de populações, grupos e indivíduos. Com isso, a prática de planejamento tende a diversificar (TEIXEIRA, 2003).

Castellanos (1994) propõe a articulação de "níveis de análise da situação de saúde" com "espaços de ação transformadora" das políticas e práticas de saúde. Assim, pode-se considerar a existência de três níveis, correspondentes a identificação e intervenção sobre problemas em termos das variações individuais: "epidemiologia do que" e fundamenta a 
implementação das chamadas "estratégias de alto risco", ações focalizadas sobre indivíduos, que por suas características biológicas e sociais encontram-se expostos a riscos específicos de adoecimento e morte. A identificação de problemas que constituam variações da situação de saúde e das condições de vida de grupos sociais corresponde a "epidemiologia do quem" e orienta a adoção de "estratégias populacionais", voltadas à melhoria das condições ambientais, econômicas e socioculturais desses grupos. Finalmente, o reconhecimento de problemas de saúde como variações entre diferentes modelos econômicos e processos políticos constitui um nível de análise que se vincula à formulação de políticas de saúde em geral.

A epidemiologia aparece como uma disciplina que fornece subsídios ao processo de planejamento, em vários momentos, desde a identificação e descrição dos problemas, até a seleção de tecnologias de intervenção e avaliação dos resultados alcançados em termos da melhoria dos níveis de saúde e/ou alteração do quadro epidemiológico (TEIXEIRA, 2003).

O atual SUS incorporou o Sistema Nacional de Vigilância Epidemiológica (SNVE), definido em seu texto legal (Lei 8.080/90) a vigilância epidemiológica como "um conjunto de ações que proporciona o conhecimento, a detecção ou prevenção de qualquer mudança nos fatores determinantes e condicionantes de saúde individual ou coletiva, com a finalidade de recomendar e adotar as medidas de prevenção e controle das doenças ou agravos".

A vigilância epidemiológica tem como propósito fornecer orientação técnica permanente para os profissionais de saúde que têm a 
responsabilidade de decidir sobre a execução de ações de controle de doenças e agravos, tornando disponíveis, para esse fim, informações atualizadas sobre a ocorrência dessas doenças e agravos, bem como dos fatores que a condicionam, numa área geográfica ou população definida (BRASIL, 2005b).

O cumprimento das funções de vigilância epidemiológica depende da disponibilidade de dados que sirvam para subsidiar o processo de produção de informação para implementar processos de decisões, planejamento, organização, bem como para a normatização de atividades técnicas correlatas.

\subsection{A interface do Sistema de Informação em Saúde com a Vigilância Epidemiológica}

s Sistemas de Informações em Saúde (SIS), estruturados como instrumentos para adquirir, organizar e analisar os dados, têm sido utilizados pela epidemiologia sob diversos enfoques, seja para o diagnóstico da situação de saúde, como também para a avaliação das ações e do impacto das políticas públicas no estado de saúde da população (LESSA et al., 2000).

Segundo Goldbaum (1993) a prática da epidemiologia nos serviços de saúde pode ocorrer em dois níveis: no plano político e no plano gerencial. 
No plano político da epidemiologia, a elaboração de análises de situação de saúde e de suas tendências, proporcionadas a partir das condições de vida da população, pode responder às necessidades interpostas para a produção de informação epidemiológica, visando à orientação e planejamento estratégicos da saúde nas suas concepções mais gerais.

No plano gerencial, a elaboração de análises epidemiológicas sobre a avaliação do impacto da prestação de serviços de saúde encontra sua lógica. A avaliação de serviços, programas e tecnologias, complementando o plano político, constitui-se igualmente em instrumento de alta utilidade para prover elementos de contínua avaliação das políticas gerais e específicas de saúde.

A implantação de SIS veio colaborar com a perspectiva tanto política quanto gerencial da epidemiologia. O uso de dados secundários para análises epidemiológicas teve maior difusão com a implantação dos principais sistemas de informações de âmbito nacional. Entre os sistemas gerenciados pelo MS, apenas o SINAN foi estruturado para subsidiar as ações de vigilância epidemiológica.

Os sistemas de informações disponíveis para o Programa Nacional de Controle da Tuberculose e para os demais programas de controle de doenças no Brasil são o SINAN, o SIM - Sistema de Informações de Mortalidade e o SIH - Sistema de Informações sobre Internações Hospitalares. 
O SINAN é adaptado à municipalização dos serviços de vigilância epidemiológica, o que possibilita a coleta e o trabalho com informações desde a unidade de saúde. Foi desenvolvido no início da década de 90 , tendo como objetivo a coleta e processamento de dados relacionados às doenças e agravos de notificação compulsória em todo o território nacional, fornecendo informações para a análise do perfil da morbidade contribuindo, dessa forma, para a tomada de decisões nos níveis municipal, estadual e federal (BRITO, 1993). A concepção do SINAN foi norteada pela padronização de definição de caso, pela transmissão de dados a partir da organização hierárquica das três esferas de governo, pelo acesso à base de dados necessária à análise epidemiológica e pela possibilidade de disseminação rápida dos dados gerados na rotina do SNVE do SUS. Além disso, o sistema deveria ser utilizado como a principal fonte de informação para estudar a história natural de um agravo ou doença e estimar a sua magnitude como problema de saúde na população, detectar surtos ou epidemias, bem como elaborar hipóteses epidemiológicas a serem testadas em ensaios específicos (LAGUARDIA, 2004).

O formulário padrão contém duas partes: a Ficha Individual de Notificação (FIN), que deve ser preenchida por profissionais das unidades assistenciais da rede privada, conveniada e pública para cada paciente quando há suspeita da ocorrência de um problema de saúde de notificação obrigatória e encaminhada pela unidade de saúde notificadora aos órgãos responsáveis pela vigilância epidemiológica nos níveis local, regional ou estadual; e a Ficha Individual de Investigação (FII), que, em geral, é 
preenchida pelo responsável da investigação e contém os elementos necessários ao conhecimento da situação epidemiológica relacionada com o caso notificado (MOTA; CARVALHO, 2003). Apresenta-se na Figura 6, o fluxo de documentos recomendado pelo MS.

Figura 6 - Fluxo de documentos recomendado pelo Ministério da Saúde

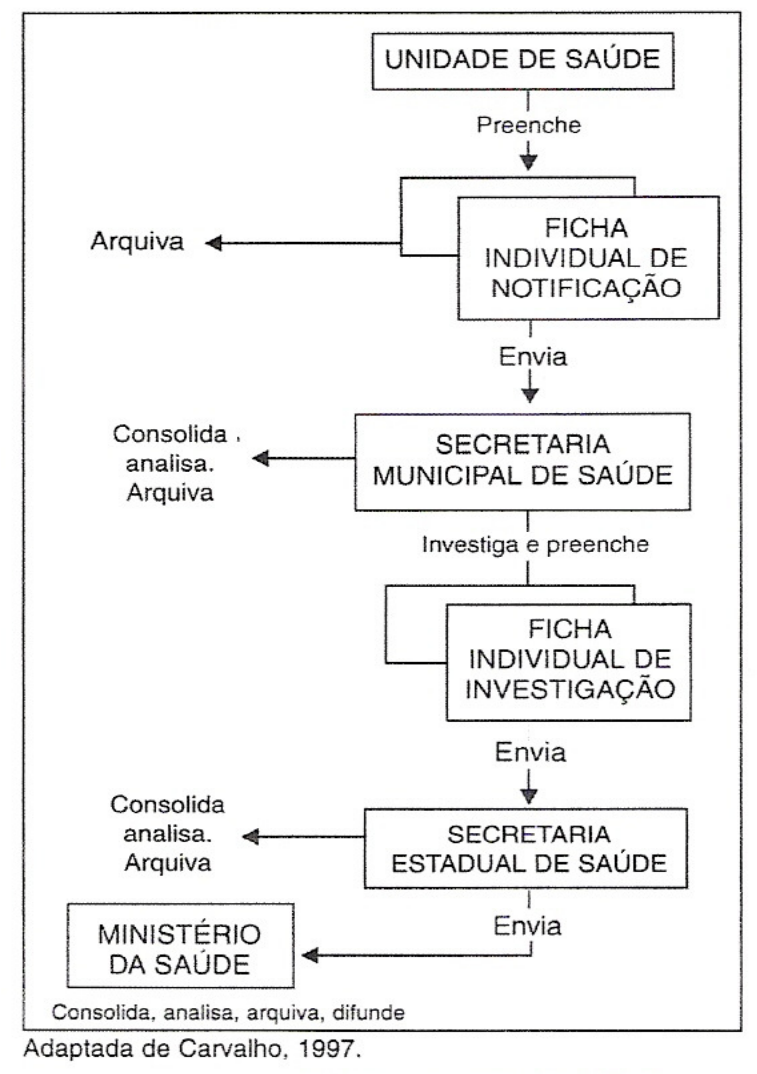

Apesar da obrigatoriedade da notificação de casos de doenças como consta na Lei 6.259/1975, que instituiu o SNVE, regulamentada pelo Decreto 78.231/ 1976, há o viés da qualidade dos dados do SINAN, uma vez que se trabalha com dados secundários. Além de ser "acometido" por um plausível grau de sub-notificação de casos, apresenta baixa qualidade no que se 
refere à informação dos dados que o alimentam. Adicionalmente, verifica-se que a notificação inicial de um caso não é necessariamente feito pelo serviço de saúde da área de residência do paciente e, quando este paciente é referido para o serviço de saúde de sua área, é gerada nova notificação, resultando em duplicidade de casos (SOUZA, 2003).

É necessário considerar a sensibilidade do processo de notificação de casos e o registro sistemático e oportuno no SINAN para avaliar a representatividade dos dados $\mathrm{e}$ isso depende essencialmente da organização e cobertura das atividades de vigilância epidemiológica. 0 desenvolvimento dessas atividades nas unidades de saúde não se restringe à notificação, mas integram o sistema de vigilância epidemiológica, além disso, envolve todos os profissionais de saúde possibilitando maior consistência e melhor qualidade dos dados.

A oportunidade, atualidade, disponibilidade e cobertura são características que determinam a qualidade da informação, fundamentais para que todo o sistema de vigilância epidemiológica apresente bom desempenho (BRASIL, 2005b). 


\subsection{O problema da investigação}

1 situação epidemiológica da TB no Recife aponta para a necessidade de redirecionamento das estratégias de operacionalização do Programa no sentido de potencializar as atividades de diagnóstico precoce do doente com TB, tratamento oportuno assegurando a conclusão do mesmo e conseqüentemente a cura, a prevenção da resistência bacteriana e interrupção da transmissão da doença.

Segundo o Programa Nacional de Controle da Tuberculose (BRASIL, 2004) o objetivo é reduzir a morbidade, mortalidade e transmissão da TB. Dentre suas metas destacam-se: curar pelo menos $85 \%$ dos casos diagnosticados e manter o abandono de tratamento em percentuais considerados aceitáveis (5\%).

Os registros sobre os resultados de tratamento dos doentes com TB permitem analisar a qualidade das atividades de controle desenvolvidas nas unidades básicas de saúde. A análise realizada no nível local permite redirecionar as estratégias de controle mais rapidamente, aprimorando, dessa forma, a vigilância à TB (BRASIL, 2002b).

Albuquerque et al. (2001) referem o tratamento supervisionado (TS) como um procedimento diferenciado de acompanhamento que deve ser implementado de forma a fortalecer o controle da TB em nível local. Contudo, para que sejam implementados procedimentos de acompanhamento diferenciados, é necessária a avaliação sistemática do 
tratamento da TB nas unidades de saúde mediante a identificação dos principais obstáculos ao sucesso do tratamento e dos grupos prioritários.

Atualmente, o maior problema apontado no tratamento da TB é o não cumprimento à terapêutica $(\mathrm{WHO}, 2003)$ que diminui a chance de cura e aumenta os indicadores de mortalidade e multirresistência (WHO, 2004). Nesse contexto, torna-se relevante analisar fatores associados ao resultado de tratamento, pois pode contribuir no direcionamento de ações específicas para o controle da doença.

Em um estudo realizado por Oliveira, Marin-León e Gardinali (2005), analisou-se o resultado do tratamento para TB nos serviços públicos de saúde de Campinas-SP em 2002. Os resultados mostraram que a taxa de sucesso foi de $68,6 \%$, sendo $72,3 \%$ nos pacientes sem AIDS e $57,6 \%$ nos com AIDS. Nos casos novos, o grupo sem AIDS teve 2,2 vezes mais chance de resultados favoráveis. No grupo com AIDS, não se observou diferença entre novos e retratamentos. Nos insucessos, apenas a letalidade apresentou diferença, $18,9 \%$ nos com AIDS e $8,0 \%$ nos sem AIDS.

Em um estudo caso-controle realizado por Albuquerque et al. (2001) em 297 pacientes do Hospital das Clínicas da Universidade Federal de Pernambuco, entre 1994 e 1999, identificou que os fatores prognósticos para o insucesso do tratamento da TB pulmonar entre os indivíduos estudados estavam inter-relacionados, sendo de natureza biológica, clínica e social. A ingestão excessiva de álcool, a co-infecção pelo HIV, a história de tratamento anterior para TB e a presença de resistência a duas ou mais 
drogas anti-TB foram fatores de risco para o insucesso do tratamento da TB pulmonar bacilífera entre os indivíduos estudados.

Algumas variáveis demográficas e socioeconômicas como idade, sexo, raça, ocupação, estado civil, renda e educação são freqüentemente incluídas nos estudos sobre tuberculose como importantes indicadores de não-adesão (BARNHOORN; ADRIAANSE, 1992; MANGTANI et al., 1995).

No estudo de Gonçalves et al. (1999) foi abordada a questão da adesão ao tratamento da TB dentro do universo composto por homens e mulheres doentes e as conexões e conseqüências da doença no seu modo de vida e resultado final do tratamento, concluindo-se que as características sociais imputadas aos gêneros estão por trás de comportamentos que afetam diretamente a forma como os pacientes lidam com seu tratamento, seu corpo, com o fato de estarem doentes e conviverem socialmente. 0 momento de vida em que cada paciente se encontra impõe relações e atitudes que, por vezes, favorecem a não-adesão ao tratamento.

É importante destacar que alguns estudos epidemiológicos consideram os tradicionais enfoques sobre indivíduos de risco como insuficientes. É necessária a identificação de áreas de risco prioritárias a fim de subsidiar o planejamento de intervenções no nível dos serviços locais de saúde.

Segundo Jacobi (1990), a distribuição da população no espaço urbano segue padrões de desigualdades. De um lado, a periferia da cidade, sem infra-estrutura urbana básica, é ocupado por grupos menos privilegiados de baixa renda e piores condições de saúde. Do outro, áreas 
com acesso total às facilidades urbanas ocupadas por grupos de alta renda, vivendo em moradias satisfatórias e com melhores padrões de saúde.

A falta de eqüidade social no âmbito da saúde manifesta-se tanto nos diferenciais encontrados nas taxas de morbi-mortalidade como no adoecimento mais precoce das camadas menos favorecidas (MARMOT et al., 1987). Os elevados coeficientes de morbi-mortalidade de velhos problemas de saúde pública, como é o caso da TB, em determinadas áreas urbanas revelam a necessidade de entender as relações entre ambiente urbano/ pobreza urbana e a existência de quadros sanitários superpostos (SOUZA et al., 2000).

Um outro fator que pode estar associado ao resultado de tratamento da TB, refere-se ao tempo de tratamento. Quanto maior o tempo do tratamento, maior é a probabilidade de abandono, com suas implicações biológicas, econômicas, psicológicas e sociais (WORKSHOP - REDE BRASILEIRA DE PESQUISA EM TUBERCULOSE, 2002).

Um estudo exploratório realizado por Sassaki et al. (2002) analisou o tempo de tratamento da TB de pacientes inscritos no PCT de um serviço de saúde do município de Ribeirão Preto-SP, no período de janeiro de 1998 a dezembro de 1999. Os resultados mostraram que dos 140 pacientes em estudo, 25\% não curaram (abandono, óbito, mudança de diagnóstico, transferência), destes 25,71\% não curaram após 6 meses de tratamento. Verificou-se que as intercorrências ao longo do tratamento ocasionam desvios como o não-cumprimento do esquema terapêutico, aumentando o 
tempo de tratamento, o risco de abandono e conseqüentemente o agravamento do quadro clínico e até mesmo o óbito.

Em relação à resistência na $T B$, torna-se extremamente grave para os pacientes com tratamento prévio, levando ao insucesso do tratamento. Para muitos destes pacientes as lesões tuberculosas pulmonares avançam por reativações repetidas e por tratamentos inadequados, os quais favorecem o aparecimento de cepas mutantes resistentes do $M$. tuberculosis a uma ou mais drogas (CAMPOS et al., 2000; DAVIDSON, 1987). Um estudo realizado em Recife-PE, em 2001, revela que o retratamento para TB apresenta percentual total de resistência em torno de 39,7\% (ALBUQUERQUE et al., 2001).

Outros trabalhos sobre fatores preditivos para o resultado de tratamento da TB foram realizados em diferentes regiões do mundo como a África, Índia, Egito, Alemanha, México e Inglaterra (HARGREAVES et al., 2001; SANTHA et al., 2002; SINGLA, et al., 2005; MORSY et al., 2003; DIEL; NIEMANN, 2003; BUSTAMANTE-MONTES et al., 2000; PRITCHARD et al., 2003).

O insucesso do tratamento além de causar danos individuais, põe em risco a saúde pública porque pode levar a um prolongamento da infecciosidade aumentando a probabilidade de transmissão de bacilos multiresistentes. A análise sistemática dos fatores associados ao resultado de tratamento da TB é necessária, pois pode contribuir para as ações de vigilância epidemiológica mediante identificação dos grupos prioritários do ponto de vista de um acompanhamento diferenciado e dos principais 
obstáculos ao sucesso do tratamento. Além disso, podem servir de informações que auxiliem no processo de formulação de políticas, planejamento, programação, organização e avaliação das ações de controle da TB no município. 
2. OBJETIVO DO ESTUDO 
Identificar e analisar fatores preditivos para o resultado favorável de tratamento dos casos de TB pulmonar, diagnosticados no período de 2001 a 2004 e residentes no município de Recife-PE. 
3. HIPÓTESE 
entro do universo composto por doentes de TB existe uma diversidade de características individuais de diferentes naturezas que estão associadas ao resultado favorável ou desfavorável do tratamento da doença. 
4. QUADRO TEÓRICO 


\section{A eqüidade nas ações de controle da tuberculose}

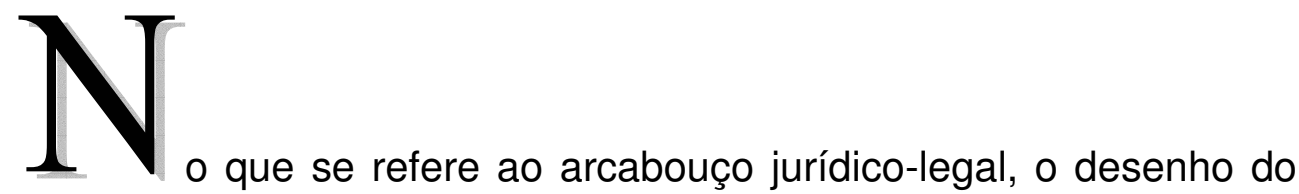
sistema de saúde brasileiro é apreendido na Constituição Federal de 1988, no capítulo sobre seguridade social, e detalhado nas Leis Orgânicas da Saúde (LOS) que tratam das condições para viabilizar o direito definido constitucionalmente:

- a lei 8.080 , de 19 de setembro de 1990, que regulamenta o SUS em todos os níveis, dispõe sobre as condições para a promoção, proteção e recuperação da saúde, a organização e o funcionamento dos serviços correspondentes e dá outras providências;

- a lei 8.142, promulgada em 28 de dezembro de 1990, que dispõe sobre a participação da comunidade na gestão do SUS, define, em linhas gerais, as formas de transferências intergovernamentais de recursos financeiros na área da saúde e dá outras providências.

Essa legislação tem sido operacionalizada por meio de diversas portarias do MS, particularmente as que originaram as Normas Operacionais Básicas - NOB's - de 1991, 1993 e 1996. Segundo o ministério, as NOB's 
definem as estratégias e movimentos que orientam a operacionalidade do SUS.

A Constituição de 1988, em seu artigo 196, define a saúde como "direito de todos e dever do Estado, garantido mediante políticas sociais e econômicas que visem à redução do risco de doenças e outros agravos e ao acesso universal igualitário para sua promoção, proteção e recuperação".

A lei 8.080 , nos artigos 20 e 30 das disposições gerais, reafirma esse direito, admite a existência de fatores determinantes e condicionantes da saúde, explicitando que os níveis de saúde expressam a organização econômica e social do país e inclui, como relacionadas com a saúde, todas as ações e medidas que interferem nestes fatores.

Assim, a legislação sanitária brasileira atual é avançada no conceito de eqüidade que incorpora, pelo menos no que se refere a dois eixos: o acesso universal e igualitário (eqüidade de oportunidade) e a ação sobre os determinantes dos níveis de saúde (eqüidade de condições).

Marsiglia, Silveira e Carneiro Júnior (2005) afirmam que o princípio da universalidade tem contribuído para o incremento do acesso aos serviços de saúde, porém não tem criado condições para o estabelecimento da eqüidade, necessitando para isso reformulação e adaptação de programas e ações em saúde.

O princípio da eqüidade é o tema central em todos os debates sobre as reformas dos sistemas de saúde no mundo ocidental (TEIXEIRA, 2002a). O princípio doutrinário da eqüidade considera: 
- Todo cidadão é igual perante o SUS e será atendido conforme as suas necessidades.

- $\quad$ Os serviços de saúde devem considerar que em cada população existem grupos que vivem de forma diferente, ou seja, cada grupo ou classe social ou região tem seus problemas específicos, tem diferenças no modo de viver, de adoecer e de ter oportunidades de satisfazer suas necessidades de vida.

- Os serviços de saúde devem saber quais são as diferenças dos grupos da população e trabalhar para cada necessidade, oferecendo mais a quem mais precisa, diminuindo as desigualdades existentes.

- O SUS não pode oferecer o mesmo atendimento à todas as pessoas, da mesma maneira, em todos os lugares. Se isto ocorrer, algumas pessoas vão ter o que não necessitam e outras não serão atendidas naquilo que necessitam.

- O SUS deve tratar desigualmente os desiguais de modo alcançar a igualdade de oportunidade de sobrevivência, de desenvolvimento pessoal e social entre os membros de uma dada sociedade. 
Le Grand (1988) chama atenção para a quantidade e complexidade de questões envolvidas na aplicação, no sistema sanitário, do conceito de eqüidade, mais próximo da concepção de justiça do que de igualdade.

A literatura internacional vem adotando como ponto de partida para novas definições do conceito de eqüidade em saúde aquele desenvolvido por Whitehead (1992), segundo o qual eqüidade implica que idealmente todos deveriam ter justa oportunidade de obter seu pleno potencial de saúde e ninguém deveria ficar em desvantagem de alcançar o seu potencial, se isso puder ser evitado.

O Center for Health Equity, Training, Research and Evaluation CHETRE (2000) apresenta uma boa síntese conceitual desenvolvida a partir da definição de Whitehead (1992). Segundo o CHETRE, o conceito de eqüidade sugere que pessoas diferentes deveriam ter acesso a recursos de saúde suficientes para suas necessidades de saúde. A iniqüidade ocorre quando diferentes grupos, definidos por suas características sociais e demográficas como, por exemplo, renda, educação, ou etnia, têm acesso diferenciado a serviços de saúde ou diferenças nas condições de saúde. Essas diferenças são consideradas iníquas se elas ocorrem porque as pessoas têm escolhas limitadas, acesso a mais ou menos recursos para saúde ou exposição a fatores que afetam a saúde, resultantes de diferenças que expressam desigualdades injustas.

Turner (1986) diferencia quatro tipos diferentes de eqüidade: ontológica, de oportunidade, de condições e de resultados. 
A eqüidade ontológica se refere à igualdade fundamental entre as pessoas. Varia das abordagens religiosas de igualdade perante Deus. A concepção ontológica trata de um debate mais inserido no campo dos sistemas morais e religiosos.

O segundo tipo, diz respeito à eqüidade de oportunidade de se alcançar os objetivos almejados. Esta concepção, herança das revoluções francesa e americana, é uma característica da doutrina política do liberalismo clássico, que considera ser possível uma mobilidade social perfeita, a partir da igualdade de oportunidades. Uma vez garantida a universalidade dos direitos fundamentais à vida, à liberdade e à propriedade, todos têm, independente de sua origem, as mesmas oportunidades de alcançar as mais altas posições individuais. Assim, de acordo com esta concepção, as posições na estrutura ocupacional da sociedade são preenchidas apenas pelo mérito pessoal, a partir da igualdade de oportunidades para o ingresso nas instituições sociais.

A eqüidade de condições, segundo Turner, está ligada à igualdade de oportunidade. Para haver, de fato, oportunidades iguais para todos os membros da sociedade, a eqüidade precisa ser observada também no "ponto de partida": apenas pessoas submetidas às mesmas condições de vida podem vir a ser consideradas "em igualdade" para competir com base em habilidades e méritos individuais. Esta é uma concepção que possibilita a inclusão de aspectos estruturais na determinação do grau de mobilidade das diferentes classes sociais. 
O quarto tipo é a eqüidade de resultados. Nele, a legislação e outras medidas políticas procuram compensar os efeitos das desigualdades entre os indivíduos. Mecanismos de discriminação positiva precisam operar em favor de grupos menos privilegiados que têm, assim, suas oportunidades aumentadas, assegurando a eqüidade nos resultados.

A conformação de um sistema de saúde equânime pode se modificar muito, dependendo da definição adotada para o termo. Do ponto de vista conceitual, a temática da eqüidade tem produzido um amplo debate. Longe de um consenso, diferentes concepções alimentam as teorias sobre justiça social desenvolvidas pelas diversas correntes de pensamento. Embora uma discussão aprofundada não faça parte do escopo deste trabalho, é importante lembrar que as opções conceituais, inerentes aos desenhos de sistema de saúde, orientam a escolha dos indicadores utilizados para avaliar o grau de eqüidade e a interpretação dos resultados em relação à efetividade do sistema.

No caso da TB, cada doente ou grupo de doentes possuem características e problemas específicos com diferenças nas oportunidades de satisfazer suas necessidades e obter resultado favorável do tratamento. Alguns doentes de TB, por exemplo, não dispõe de condições educacionais e culturais que facilitem o diálogo com os profissionais de saúde, o que pode refletir na dificuldade de entendimento e aprendizado acerca do comportamento que deve adotar para tornar coadjuvante do processo do tratamento, prevenção de riscos e de recuperação da sua saúde. Tais problemas devem ser identificados e considerados pelos profissionais de 
saúde de modo a satisfazer suas necessidades durante o processo da terapêutica e garantir a cura da doença.

O ponto de partida da noção de eqüidade é o reconhecimento da desigualdade entre os indivíduos e o reconhecimento de que muitas dessas desigualdades são injustas e devem ser superadas. Em saúde, especificamente, as diversidades se apresentam como desigualdades diante do adoecer e do morrer, reconhecendo-se a possibilidade de redução dessas desigualdades, de modo a garantir condições de vida e saúde mais iguais para todos (TEIXEIRA, 2002a).

Le Grand (1988) afirma que as políticas e as ações devem estar voltadas para minimizar os fatores que produzem as desigualdades nos perfis de morbi-mortalidade. Segundo o autor nem todas as diferenças em saúde são inevitáveis e inaceitáveis, dependendo da liberdade de escolha que o indivíduo tem ao submeter-se a situações de risco sanitário reconhecido. Diferenciais na distribuição de doenças decorrentes de hábitos que dependem de "escolhas pessoais", como fumar ou beber em demasia não podem ser considerados injustos.

Giovanella et al. (1996) considera desnecessárias e injustas portanto iniqüidades - aquelas diferenças determinadas por: comportamentos que podem causar danos à saúde, quando a liberdade de escolha de estilos de vida é restrita; exposição a condições de vida e trabalho estressantes e doentias; acesso inadequado a serviços públicos essenciais, entre eles os de saúde. 
No entanto, o modo de viver e de pensar dos indivíduos não pode ser desconsiderado no processo do tratamento da TB. O ponto de vista do doente e o envolvimento do contexto social no seu comportamento ampliam a discussão (GONÇALVES et al, 1999). As pesquisas sociais e comportamentais sobre as pessoas que continuam ou não seu tratamento são importantes também para acompanhar e atuar nas mudanças epidemiológicas da doença (SUMARTOJO, 1993). A adesão compreende que todos pacientes têm uma autonomia para aceitar ou não as recomendações médicas; algumas vezes, o termo tem a conotação de desresponsabilizar ou amenizar o dever da prática médica, enquanto participante ativo do processo de cura. Assim sendo, se o paciente não adere ao tratamento é porque ele assim escolheu, não é de responsabilidade do sistema, do PCT, dos profissionais de saúde. Entretanto, a auto-regulação do tratamento não desresponsabiliza a saúde pública, pelo contrário, exige que uma política adequada de atendimento e cura seja oferecida ao doente (GONÇALVES et al, 1999). Com a comprovação de que alguns indivíduos doentes não respondem às recomendações terapêuticas por diferentes motivos, necessita-se identificálos, reformular e adaptar programas e ações em saúde criando desta forma condições para o estabelecimento da eqüidade.

Em termos gerais, pode-se dizer que as abordagens contemporâneas em torno do tema da justiça social (RAWLS, 1997; SEN, 1997; WALZER, 1983) centram-se na valorização da noção de eqüidade como igualdade no alcance de objetivos finais, bem como no 
reconhecimento explícito de fatores determinantes das diferenças existentes na sociedade, que dizem respeito a aspectos biológicos, sociais e políticoorganizacionais.

Almeida et al. (1999) também relacionam eqüidade em saúde com justiça social, sendo as desigualdades consideradas justas ou injustas conforme as distintas interpretações das determinações da estratificação social. Para essas autoras, as iniqüidades estão fundadas nas relações sociais que determinam as chances da população obter acesso aos recursos materiais e aos produtos sociais resultantes daqueles recursos.

Nessa direção, cabe uma distinção entre eqüidade em saúde e eqüidade nos cuidados de saúde, à medida que suas determinações não são as mesmas. Eqüidade em saúde refere-se às necessidades em saúde que são socialmente determinadas e que transcende o escopo das ações dos serviços da área, à medida que os cuidados de saúde são apenas um entre os inúmeros fatores que contribuem para as desigualdades em saúde (Almeida et al., 1999). Nesse sentido, como afirmam Giovanella et al. (1996), a ação isolada dos serviços de saúde não é suficiente para resolver o conjunto das iniqüidades em saúde, mas certamente pode contribuir para reduzi-las. Já em relação à eqüidade no uso de serviços de saúde, é preciso considerar que a utilização dos serviços, além de influenciada pelo perfil de necessidades de cada grupo populacional, também está condicionada por inúmeros outros fatores, internos e externos ao setor, relacionados tanto à oferta dos serviços quanto às preferências e possibilidades dos usuários. Assim, "para além da determinação biológica e social das necessidades, são 
considerados como fatores explicativos de uso de serviços aqueles relacionados com a efetiva implementação da política de saúde" (ALMEIDA et al., 1999: 11).

É imperativo que as ações de controle da TB estejam integradas a uma política que forneça suporte social, garanta direitos universais e eqüitativos e que permita aos diferentes grupos de doentes 0 desenvolvimento de suas capacidades. Caso contrário, tais ações acabam por reproduzir desigualdades nas oportunidades de obter resultado favorável do tratamento da doença.

A contribuição que um sistema de serviços de saúde pode dar à superação das desigualdades implica redistribuição da oferta de ações e serviços, e na redefinição do perfil dessa oferta, de modo a priorizar a atenção e enfatizar ações específicas para determinados grupos e pessoas que apresentem riscos diferenciados de adoecer e morrer por determinados problemas (TEIXEIRA, 2002a).

Todo município deve promover a eqüidade na atenção à saúde, considerando as diferenças individuais e de grupos populacionais, por meio da adequação da oferta às necessidades como princípio da justiça social, e ampliação do acesso de populações em situação de desigualdade, respeitadas as diversidades. Além disso, deve com apoio dos Estados, identificar as necessidades dos indivíduos, fazer um reconhecimento das iniqüidades, oportunidades e recursos. A partir da identificação das necessidades, todo município deve desenvolver um processo de 
planejamento, regulação, programação pactuada e integrada da atenção à saúde, monitoramento e avaliação (BRASIL, 2006). 
5. METODOLOGIA 


\subsection{O campo de investigação}

\subsubsection{Caracterização do local de estudo ${ }^{7}$}

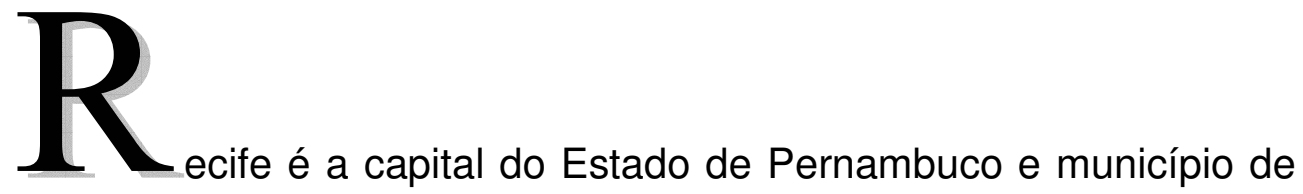
referência da Região Metropolitana do Recife que é composta por 14 municípios. A população residente no Recife, registrada pelo Censo 2000 do Instituto Brasileiro de Geografia e Estatística (IBGE), foi de 1.422 .905 pessoas distribuídas num espaço totalmente urbano, sendo 661.690 (46,5\%) do sexo masculino e 761.215 (53,5\%) do sexo feminino. Nos grupos etários, existe uma predominância das faixas etárias mais jovens, pois $26,2 \%$ dessa população está na faixa de 0 a 14 anos e 38,2\% na faixa de 10 a 29 anos. A população com idade acima de 60 anos, é em torno de 9,4\%. A densidade demográfica é de $80,37 \mathrm{hab} / \mathrm{km}^{2}$. O Estado tem uma participação no Produto Interno Bruto (PIB) nacional de $2,7 \%$ e sua economia se baseia em produtos agrícolas como mandioca, feijão, cana-de-açúcar e milho; rebanhos bovinos e caprinos; produtos minerais como calcário; indústrias de transformação de minerais não metálicos, confecções, mobiliário e curtume. Os setores comerciais de ponta são: pólo médico, pólo de informática e pólo turístico.

\footnotetext{
${ }^{7}$ PREFEITURA DO RECIFE. Secretaria de Saúde. Recife: Mais trabalho, melhor qualidade de vida. Recife, 2005. Plano Plurianual 2006-2009. v. 1. Lei 17.111/2005.
} 
Recife é subdivida em 94 bairros $^{8}$, que compõem 6 Regiões Político Administrativas (RPA), no setor saúde estas regiões representam os DS. Cada RPA ou DS é subdivida em 3 Microrregiões que agregam bairros com maiores semelhanças territoriais (Mapa 1).

\footnotetext{
${ }^{8}$ Os 94 bairros do município são: Recife, Santo Amaro, Boa Vista, Soledade, Santo Antônio, Paissandu, Ilha do Leite, Coelhos, Ilha Joana Bezerra, São José, Cabanga, Torreão, Encruzilhada, Rosarinho, Ponto de Parada, Hipódromo, Campo Grande, Peixinhos, Campina do Barreto, Arruda, Bomba do Hemetério, Alto Santa Terezinha, Água Fria, Fundão, Cajueiro, Porto da Madeira, Beberibe, Linha do Tiro, Dois Unidos, Derby, Graças, Espinheiro, Aflitos, Jaqueira, Tamarineira, Parnamirim, Santana, Casa Forte, Poço, Monteiro, Alto do Mandu, Casa Amarela, Mangabeira, Alto José do Pinho, Morro da Conceição, Alto José Bonifácio, Vasco da Gama, Macaxeira, Apipucos, Sítio dos Pintos, Dois Irmãos, Córrego do Jenipapo, Nova Descoberta, Brejo do Beberibe, Brejo da Guabiraba, Passarinho, Guabiraba, Pau Ferro, Ilha do Retiro, 0 - Madalena, Prado, Zumbi, Torre, Cordeiro, Torrões, Engenho do Meio, Iputinga, Caxangá, Várzea, Curado, San Martim, Bongi, Mustardinha, Mangueira, Afogados, Jiquiá, Estância, Jardim São Paulo, Cidade Universitária, Sancho, Totó, Coqueiral, Tejipió, Barro, Areias, Caçote, Cohab, Jordão, Ibura, Ipsep, Boa Viagem, Imbiribeira, Pina, Brasília Teimosa.
} 


\section{Mapa 1- Divisão político-administrativa do município de Recife}

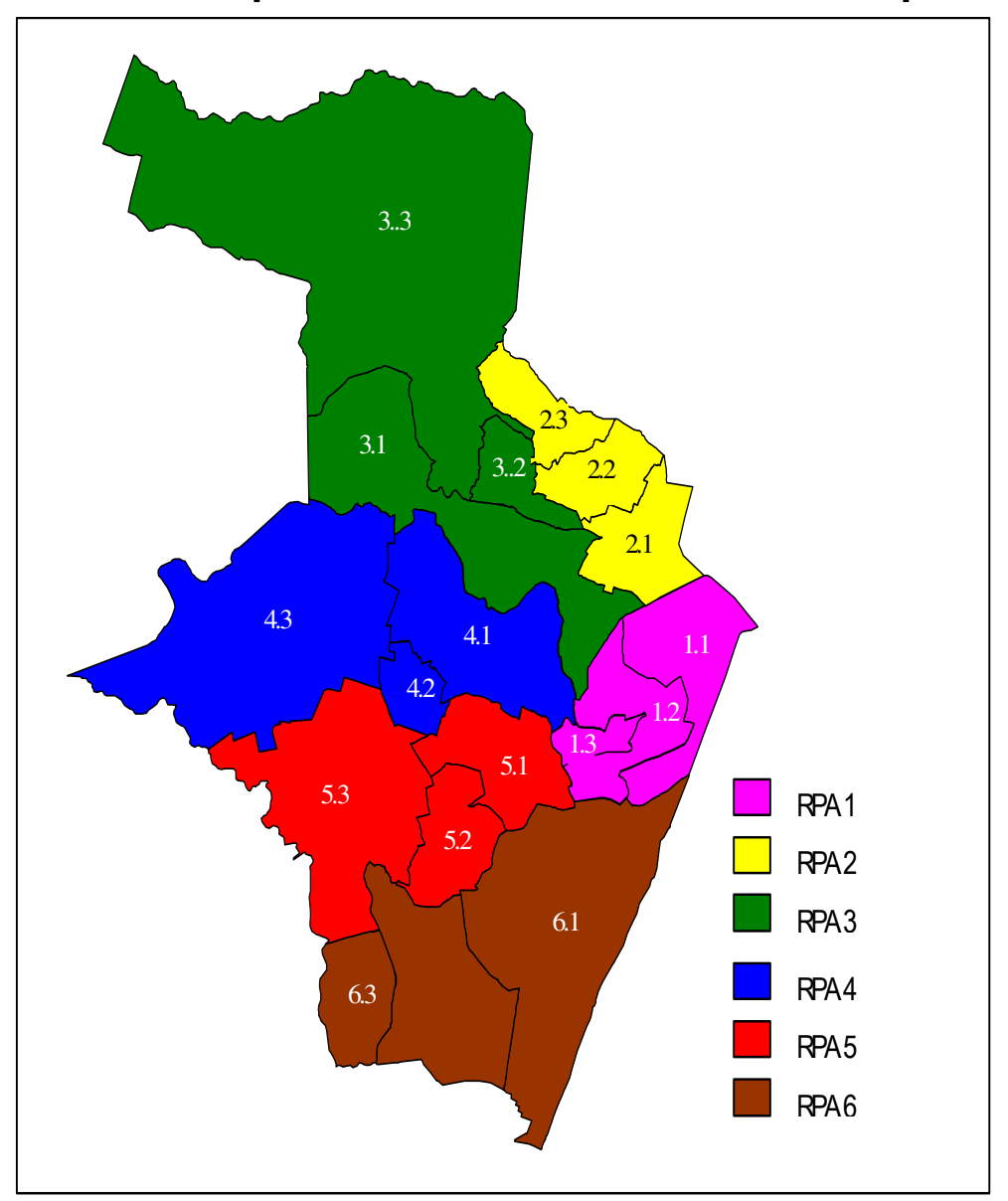

Fonte: DEAB - Secretaria Municipal de Saúde

Recife possui uma extensão territorial de $209 \mathrm{Km}^{2}$ apresenta um ambiente natural diversificado com planície, morros, estuário e praia. Nos alagados da planície que circundam a região central e nos morros das regiões Norte, Noroeste, Sudoeste e Sul do município localizam-se assentamentos populares, caracterizados por uma população pobre, áreas, na sua grande maioria, não legalizadas, mas com uma longa história de posse (Mapa 2). 


\section{Mapa 2 - Mapa de áreas pobres no município de Recife}

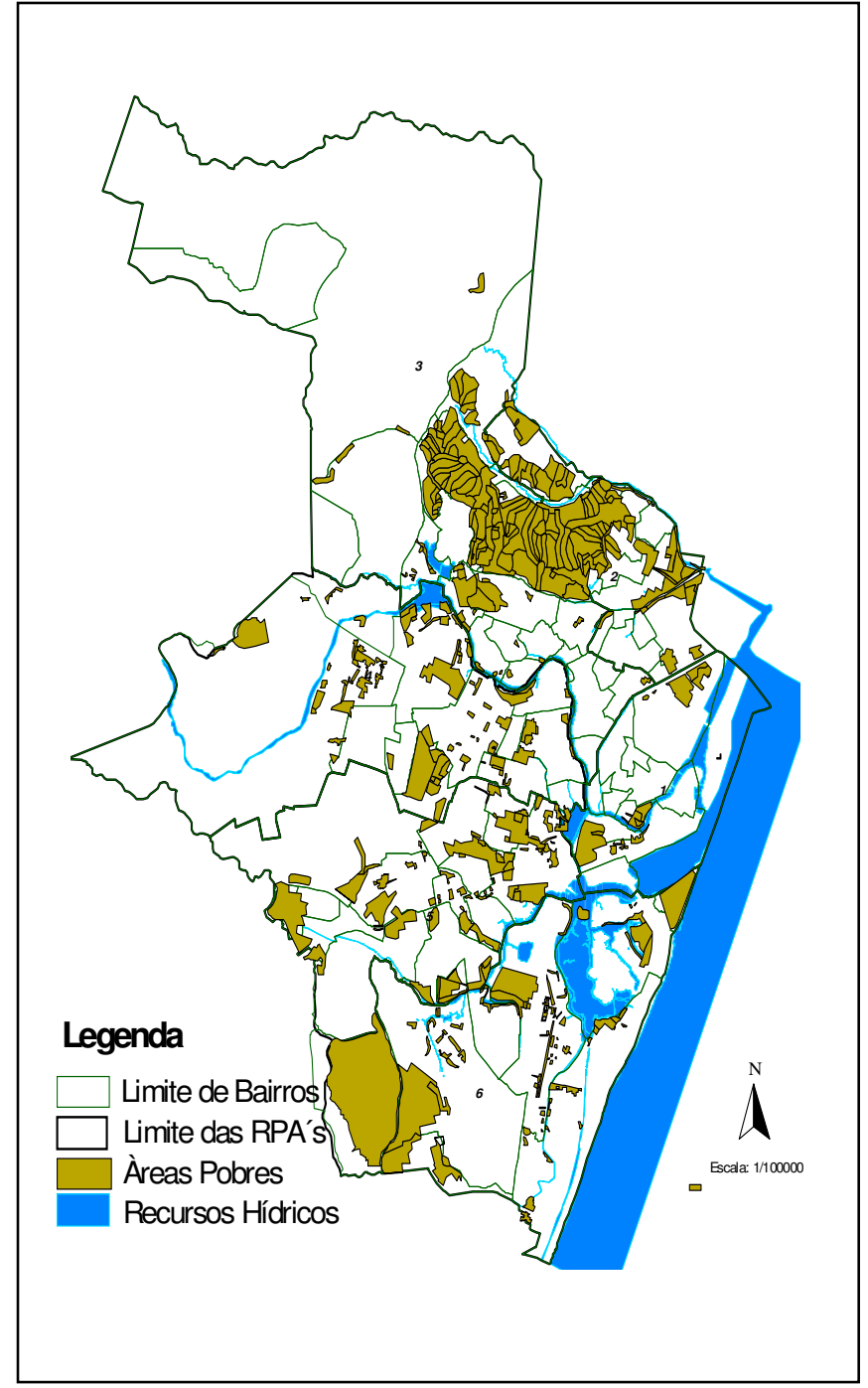

Fonte: Prefeitura do Recife, 2005

Conforme os dados secundários, $31,51 \%$ da população é pobre e a expectativa de vida é de 68,62 anos de idade. A taxa de alfabetização é de $86,6 \%$ e com relação ao saneamento básico constata-se que $88,5 \%$ da população tem água no domicílio e $41,1 \%$ tem esgoto. A taxa de mortalidade infantil é $18,47 \%$, a taxa bruta de natalidade (número de nascidos vivos por mil habitantes) é de 17,94\% e 9,21\% dos recém nascidos apresentam baixo 
peso ao nascer $(<2.500 \mathrm{~g})$. O número de consultas médicas básicas por habitante/ ano é de 1,37.

O perfil de morbidade no Recife é bastante diversificado. Incidem sobre a população do município doenças imunopreveníveis (a maioria sob controle, apesar de persistirem casos de coqueluche, de tétano acidental e de meningites), doenças de veiculação hídrica (hepatite A, leptospirose), de transmissão vetorial (filariose, dengue) e doenças transmitidas entre pessoas (TB, hanseníase, AIDS, sífilis congênita).

\subsubsection{O sistema de serviços de saúde para assistência à tuberculose no município de Recife}

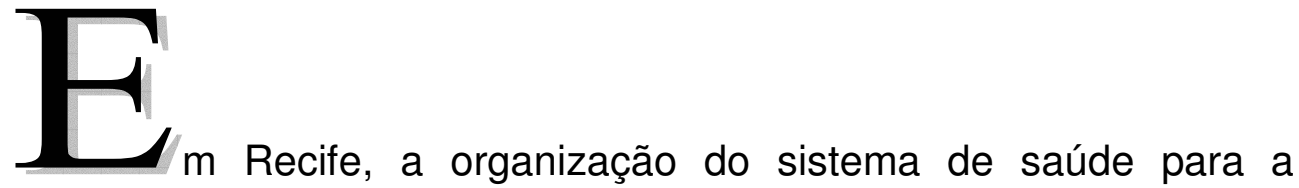
assistência à TB contempla um serviço de referência para internação, onde a maior parte dos casos é detectada ao nível hospitalar. Outro importante número de casos é descoberto através das emergências da rede geral (cerca de 30\%) revelando uma distorção da porta de entrada do usuário com TB e o retardo no diagnóstico dos casos.

Em nível ambulatorial, a assistência à TB vem sendo estruturada com ênfase na Atenção Básica. O município conta com 05 Unidades de Saúde Tradicionais (UST) e 101 USF (213 equipes) onde vêm sendo desenvolvidas ações de mobilização social junto aos diversos atores do microterritório (escolas, grupos, rádios comunitárias, outros). Também vem 
sendo estruturada a rede de referência (policlínicas), em número de oito (08), presentes em todos os distritos. Em cada uma delas, há um especialista (pneumologista) e uma equipe multidisciplinar que tem por finalidade oferecer suporte e educação continuada (reuniões clínicas) às equipes da Atenção Básica, além disso, é referência para diagnóstico dos casos de TB pulmonar negativo e extrapulmonar.

Em 1998, existiam 22 equipes de PSF aumentando para 213 em 2005 (Figura 7). O número de USF também aumentou de 14 (1998) para 101 (2005) (Figura 8).

Figura 7 - Evolução das equipes do Programa de Saúde da Família. Recife, 1998 - 2005

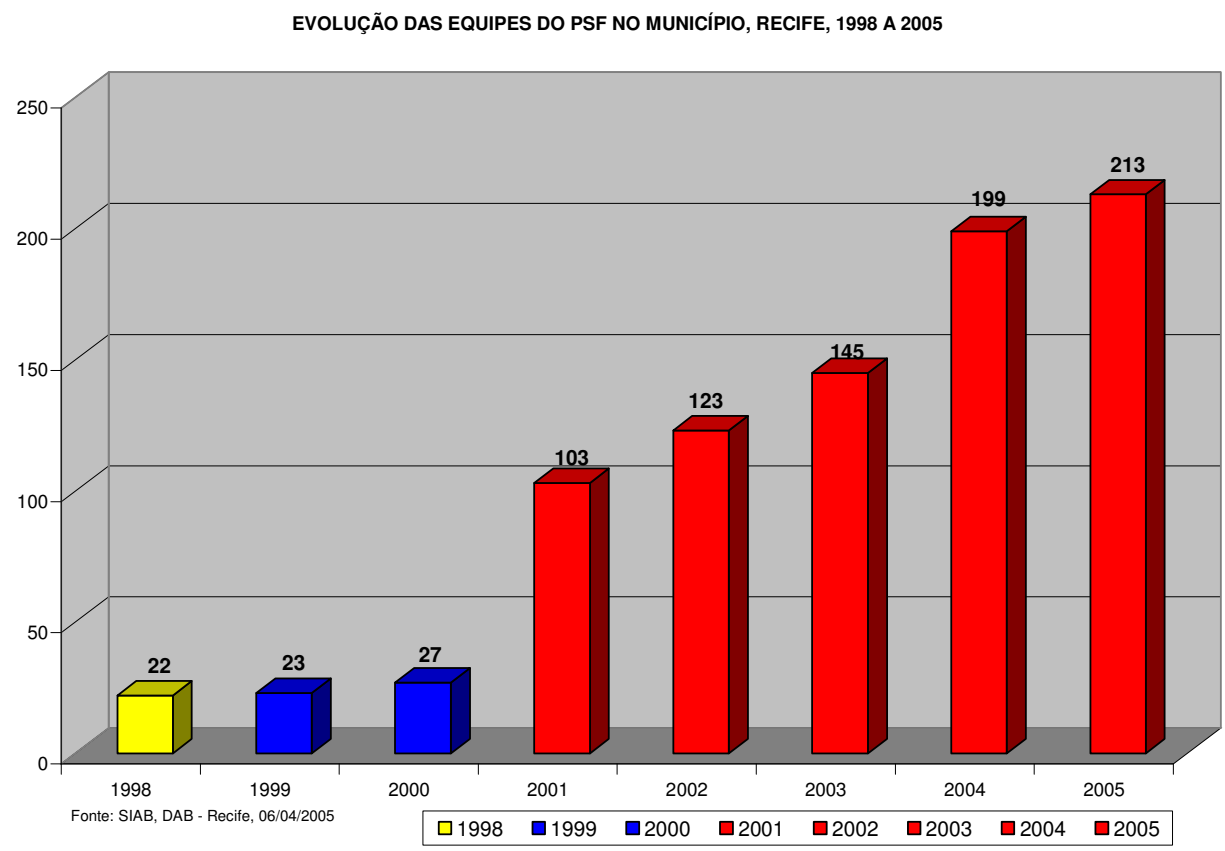


Figura 8 - Total de Unidades de Saúde da Família em funcionamento por Distrito Sanitário. Recife, 1998 - 2005

\begin{tabular}{|c|c|c|c|c|c|c|c|c|}
\hline DISTRITO & $\mathbf{1 9 9 8}$ & $\mathbf{1 9 9 9}$ & $\mathbf{2 0 0 0}$ & $\mathbf{2 0 0 1}$ & $\mathbf{2 0 0 2}$ & $\mathbf{2 0 0 3}$ & $\mathbf{2 0 0 4}$ & $\mathbf{2 0 0 5}$ \\
\hline DS I & 1 & 1 & 1 & 5 & 6 & 7 & 8 & 8 \\
\hline DS II & 2 & 2 & 4 & 11 & 14 & 14 & 16 & 17 \\
\hline DS III & 4 & 4 & 4 & 14 & 16 & 17 & 19 & 21 \\
\hline DS IV & 1 & 1 & 1 & 11 & 13 & 14 & 16 & 16 \\
\hline DS V & 2 & 2 & 2 & 7 & 7 & 8 & 12 & 12 \\
\hline DS VI & 4 & 4 & 4 & 10 & 13 & 15 & 20 & 27 \\
\hline TOTAL & $\mathbf{1 4}$ & $\mathbf{1 4}$ & $\mathbf{1 6}$ & $\mathbf{5 8}$ & $\mathbf{6 9}$ & $\mathbf{7 5}$ & $\mathbf{9 1}$ & $\mathbf{1 0 1}$ \\
\hline
\end{tabular}

Fonte: SIAB, DEAB - Recife, 06/04/2005

A figura abaixo apresenta a descentralização na Atenção Básica por DS, com a referida cobertura. 
Figura 9 - Rede de Serviços de Saúde do Programa de Controle da Tuberculose. Recife, 2003

\begin{tabular}{|c|c|c|c|c|c|c|c|}
\hline \multirow[b]{3}{*}{ DS } & \multicolumn{7}{|c|}{ REDE DE SAÚDE } \\
\hline & \multicolumn{6}{|c|}{ Atenção Básica } & \multirow{2}{*}{ 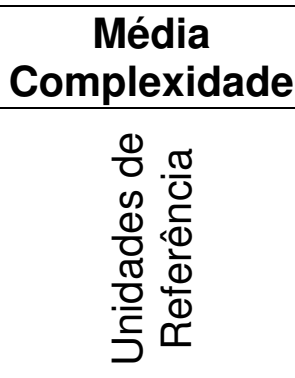 } \\
\hline & 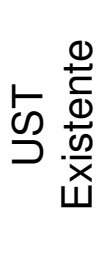 & $\stackrel{\leftarrow}{\mathscr{D}}$ & 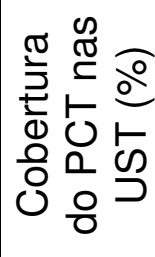 & 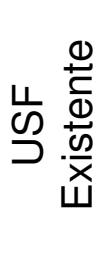 & 岁 & 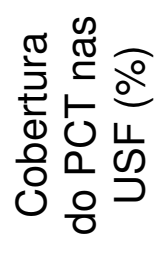 & \\
\hline I & 3 & 1 & 33,3 & 8 & 8 & 100,0 & 1 \\
\hline II & 3 & 3 & 100,0 & 14 & 14 & 100,0 & 1 \\
\hline III & 8 & 1 & 12,5 & 17 & 15 & 88,2 & 2 \\
\hline IV & 5 & - & 0,0 & 14 & 14 & 100,0 & 1 \\
\hline V & 5 & 1 & 20,0 & 8 & 7 & 87,5 & 1 \\
\hline VI & 8 & 2 & 25,0 & 16 & 14 & 87,5 & 2 \\
\hline $\begin{array}{l}\frac{1}{5} \\
\frac{5}{6}\end{array}$ & 32 & 8 & 25,0 & 77 & 72 & 90,9 & 8 \\
\hline
\end{tabular}

DS: Distrito Sanitário; UST: Unidades de Saúde Tradicionais; USF: Unidades de Saúde da Família; PCT: Programa de Controle da Tuberculose

OBS:

Unidades de Referência do PCT

Distrito Sanitário I: Policlínica Gouveia de Barros

Distrito Sanitário II: Policlínica Amaury Coutinho

Distrito Sanitário III: Policlínica Albert Sabin

Policlínica Clementino Fraga

Distrito Sanitário IV: Policlínica Lessa de Andrade

Distrito sanitário V: Policlínica Agamenon Magalhães

Distrito Sanitário VI: Policlínica Arnaldo Marques

Policlínica do Pina

Fonte: DEAB - Secretaria Municipal de Saúde 


\subsection{Técnica de coleta e análise dos dados}

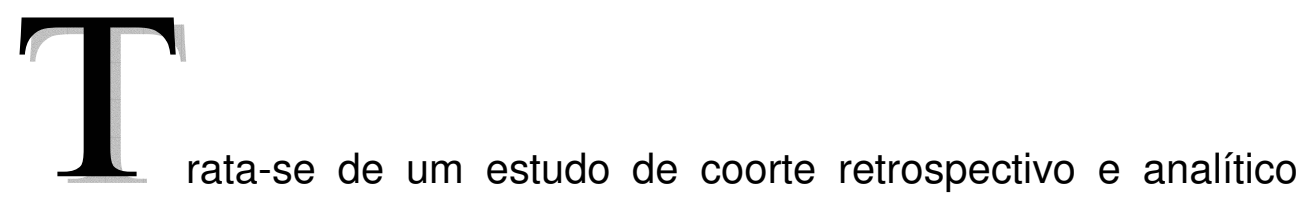

envolvendo o levantamento de dados disponíveis no SINAN (ambiente Windows), referentes aos casos de TB pulmonar, diagnosticados no período de 2001 a 2004 e residentes no município de Recife. Os dados foram obtidos junto à Vigilância Epidemiológica da Secretaria de Saúde do Recife, que é responsável pela operação do sistema no município.

Segundo o Guia de Vigilância Epidemiológica (BRASIL, 2005b), "dado" é definido como "um valor quantitativo referente a um fato ou circunstância", "número bruto que ainda não sofreu qualquer espécie de tratamento estatístico" ou "matéria-prima da produção de informação". Já "informação" é entendida como "o conhecimento obtido a partir dos dados", "o dado trabalhado" ou "resultado da análise e combinação de vários dados".

Foram selecionados para análise os dados disponíveis no SINAN que preencheram os seguintes requisitos:

- Respaldo de conhecimentos científicos sobre cada problema na literatura (tiveram relevância na literatura e foram julgadas importantes a priori);

- Relevância quanto aos objetivos do PNCT;

- Disponibilidade e facilidade de obtenção. 
Para o alcance do objetivo proposto, o processamento e análise de dados foram realizados em três fases distintas:

- Fase Exploratória

- Fase Univariada

- Fase Multivariada

\subsubsection{Fase Exploratória}

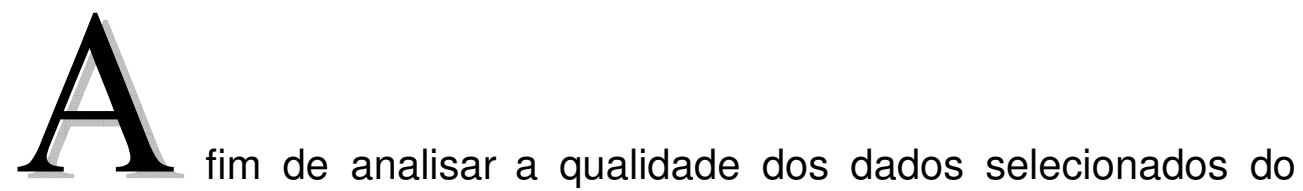
SINAN-WINDOWS, no agravo: tuberculose, foi realizado um estudo exploratório dos dados com o uso do programa Statistica 7.1 da Statsoft. A análise exploratória de dados seguiu a metodologia desenvolvida por Hair Jr. (2005) que propõe esta fase como ponto de partida essencial para qualquer análise multivariada. Esta fase consistiu em uma cuidadosa análise inicial de dados que permitiu examinar as categorias individuais dos dados selecionados e identificar "dados perdidos"9 - dados em branco, ignorados e inconsistentes (erros na entrada de dados que criam códigos inválidos, falhas em completar o banco de dados e respostas inaplicáveis).

Inicialmente, os dados sobre TB disponíveis no banco do SINAN foram importados para a planilha do programa Statistica 7.1 da Statsoft e

\footnotetext{
${ }^{9}$ Informação não disponível de um indivíduo ou caso sobre o qual outra informação está disponível (HAIR, Jr. 2005).
} 
armazenados em forma de tabela (dados $\mathrm{x}$ registro de casos). $\mathrm{O}$ banco do SINAN contém 63 dados e 22.864 registros de casos de TB no município de Recife, no período de 1992 e 1995 a 2005.

Posteriormente, foram selecionados para análise deste estudo, os seguintes dados (ANEXO A):

- NU_ANO (Ano do diagnóstico);

- ID_MN_RESI (Município de residência);

- SITUAÇÃO_2 (Situação no encerramento);

- NU_IDADE (Idade);

- CS_SEXO (Sexo);

- CS_ESCOLAR (Escolaridade);

- ID_OCUPACA (Ocupação);

- ID_DT_RESI (Distrito de residência);

- FORMA (Forma clínica);

- TRATAMENTO (Tipo de entrada);

- TRAT_SUPER (Tratamento supervisionado);

- DT_DIAG (Data do diagnóstico);

- DT_INIC_TR (Data do início do tratamento);

- DT_ENCERRA (Data do encerramento do tratamento);

- ID_UNIDA_1 (Unidade de saúde responsável pelo acompanhamento atual);

- $\quad \mathrm{HIV}(\mathrm{HIV})$;

- AGRAVOS_AS (Outros agravos). 
Foram considerados os casos de TB pulmonar, diagnosticados no período de 2001 a 2004 e residentes no município de Recife que corresponderam a 6.018 casos.

Nesta fase, foram construídas tabelas e histogramas com o objetivo de identificar e obter a distribuição de freqüência das categorias de cada dado selecionado. Para os dados que apresentaram categorias com registros em brancos, ignorados e/ ou inconsistentes foram construídas tabelas de freqüências de múltiplas respostas para verificar a aleatoriedade ou não de dados perdidos. Os dados perdidos foram quantificados em tabelas de freqüência absoluta e relativa.

\subsubsection{Fase Univariada}

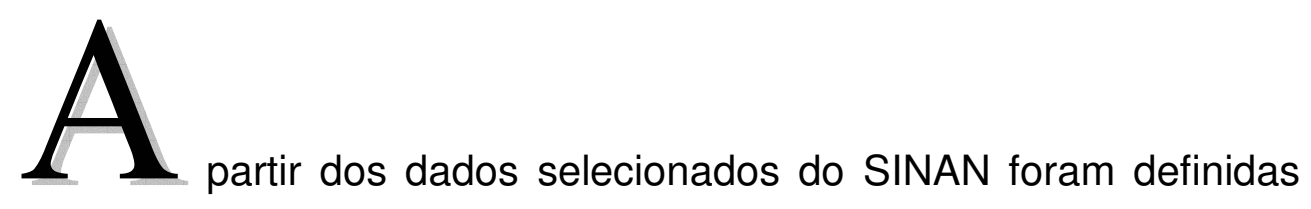
as variáveis dependentes e independentes e suas categorias.

Foi considerada variável dependente binária o resultado de tratamento da TB (situação no encerramento) usado pelo SINAN-Windows (FUNASA, 2001) (ANEXO B) categorizada em: resultado favorável e resultado desfavorável. Considerou-se como resultado favorável (1): cura e resultado desfavorável (0): abandono, óbito e TB-Multirresistente. Para esta fase foram excluídos os doentes que tiveram alta por transferência ou mudança de diagnóstico. Não foram considerados também, os casos que 
apresentaram campos/ variáveis de interesse em branco totalizando assim em 4.750 casos.

As variáveis independentes foram (ANEXO C):

- Ano de diagnóstico;

- Idade;

- Sexo;

- Escolaridade;

- Distrito de residência;

- Tipo de entrada;

- Tratamento supervisionado;

- Tempo 1 (Tempo do diagnóstico ao início do tratamento);

- Tempo 2 (Tempo do início do tratamento ao encerramento do tratamento);

- Distrito da Unidade de Saúde (Distrito a qual pertence a Unidade de Saúde responsável pelo acompanhamento atual do doente);

- HIV.

Algumas categorias das variáveis de interesse e pertencentes ao banco de dados foram redefinidas para atender aos objetivos propostos deste estudo (ANEXO D).

Foram criadas duas novas variáveis a partir dos dados disponíveis no banco do SINAN: DT_DIAG (Data do diagnóstico); DT_INIC_TR (Data do 
início do tratamento) e DT_ENCERRA. (Data do encerramento do tratamento). A variável "Tempo 1" consistiu na diferença entre a data do início do tratamento e a data do diagnóstico (em dias) e a variável "Tempo 2" consistiu na diferença entre a data do encerramento do tratamento e a data do início do tratamento (em meses). Os cálculos foram feitos com o auxílio do aplicativo Microsoft Office Excel 2003 e transferidos para a planilha do Programa Statistica da Statsoft. Os tempos obtidos foram categorizados.

Para a variável "Distrito da Unidade de Saúde" foi solicitada à Vigilância Epidemiológica da Secretaria de Saúde do Recife, a relação de Unidades de Saúde existentes no município com seus respectivos DS as quais pertencem. Assim, foi possível agrupar as unidades por DS.

A presença de associação entre o resultado favorável do tratamento e as variáveis independentes foi realizada por análise univariada com o uso do programa Statistical Package for the Social Sciences - SPSS, versão 11.5 for Windows, testando-se a significância estatística por meio do teste do quiquadrado Wald's. A razão de chance (odds ratio, OR), os intervalos de confiança de $95 \%$ (IC-95\%) e o teste do qui-quadrado Wald's foram determinados para cada categoria. 


\subsubsection{Fase Multivariada}

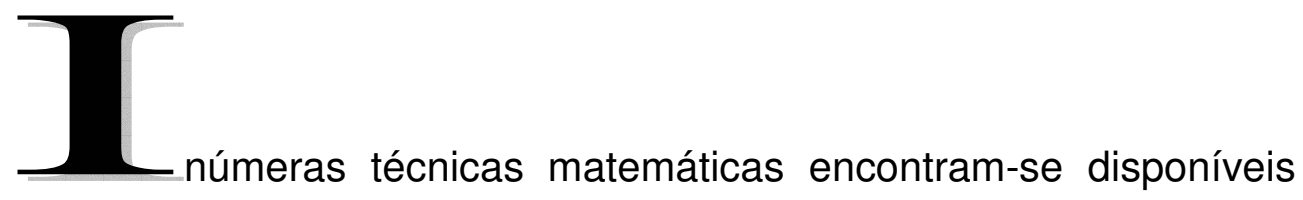
para a construção de modelos preditivos na área da saúde. A técnica mais simples consiste na análise univariada, assim denominada porque apenas uma variável preditiva é avaliada quanto à variável desfecho sob estudo. Contudo, esta análise não permite que sejam exploradas as relações das variáveis entre si com o desfecho. Para que essa informação seja obtida, a análise multivariada deve ser utilizada. A análise multivariada pode utilizar o modelo de regressão logística que é uma forma especializada de regressão que é formulada para prever e explicar uma variável categórica binária. A análise logística controla grande número de variáveis simultaneamente, permitindo que os dados sejam utilizados mais eficientemente.

A transformação logística fornece uma equação matemática:

$$
p=e^{\text {logit }} /\left(1+e^{\text {logit }}\right)
$$

onde:

$\mathrm{p}=$ probabilidade

$\mathrm{e}=2,718281828459$ (inverso do logaritmo natural)

logit $=y$, sendo:

$y=b_{0}+b_{1} x_{1}+b_{2} x_{2}+\ldots+b_{n} x_{n} ; y=$ variável resultado de tratamento

$\mathrm{b}_{0}=$ intercepto

$b_{1} \ldots b_{n}=$ constantes 
$\mathrm{X}_{1} \ldots \mathrm{X}_{\mathrm{n}}=$ variáveis preditoras

Realizou-se análise multivariada mediante modelo de regressão logística com o uso do programa SPSS, versão 11.5 for Windows. Cada variável independente foi testada individualmente, verificando-se o seguinte critério de inclusão no modelo multivariado: variáveis que apresentaram nível descritivo de significância menor ou igual a 0,20 na análise univariada.

Utilizou-se a técnica de seleção de variáveis backward- $L R$, sendo retiradas, uma a uma, aquelas variáveis que apresentaram menor grau de explicação para a variável dependente, conforme significância do logaritmo da razão de máxima verossimilhança.

O erro máximo fixado para rejeição da hipótese nula, adotado em todos os testes estatísticos, foi de $\alpha=5 \%$, ou seja, um nível de significância $p<0,05$.

Para as análises univariada e multivariada foi utilizada a metodologia desenvolvida por Kleinbaunm (1994), Hair, Jr. (2005) e Newson (2006).

\subsection{Aspectos éticos da pesquisa}

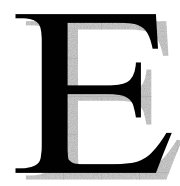

sta investigação se integra a um dos subprojetos do Projeto de âmbito nacional intitulado: "TUBERCULOSE. Implantação do DOTS em algumas regiões do Brasil: Histórico e peculiaridades regionais" que obteve a aprovação do Comitê de Ética em Pesquisa da Escola de Enfermagem de 
Ribeirão Preto da Universidade de São Paulo em 06 de dezembro de 2005 (ANEXO E). 
6. RESULTADOS 


\subsection{Fase Exploratória}

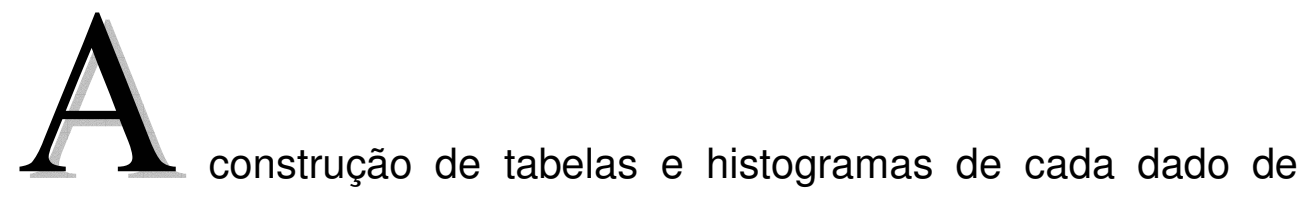
interesse para obter a distribuição de freqüência de suas categorias permitiu observar que alguns dados apresentaram categorias que impossibilitam a produção de informação e foram plotados para permitir a visualização e quantificação dessas categorias. No dado TRATAMENTO (Tipo de entrada) essas categorias foram: não sabe (7,59\%) e transferência (2,51\%) (Gráfico 1) e no dado HIV foram: em andamento (8,36\%) e não realizado $(76,79 \%)$ (Gráfico 2).

\section{Gráfico 1 - Distribuição das categorias do dado TRATAMENTO (Tipo de entrada). SINAN-TB, Recife-PE, 2001-2004}

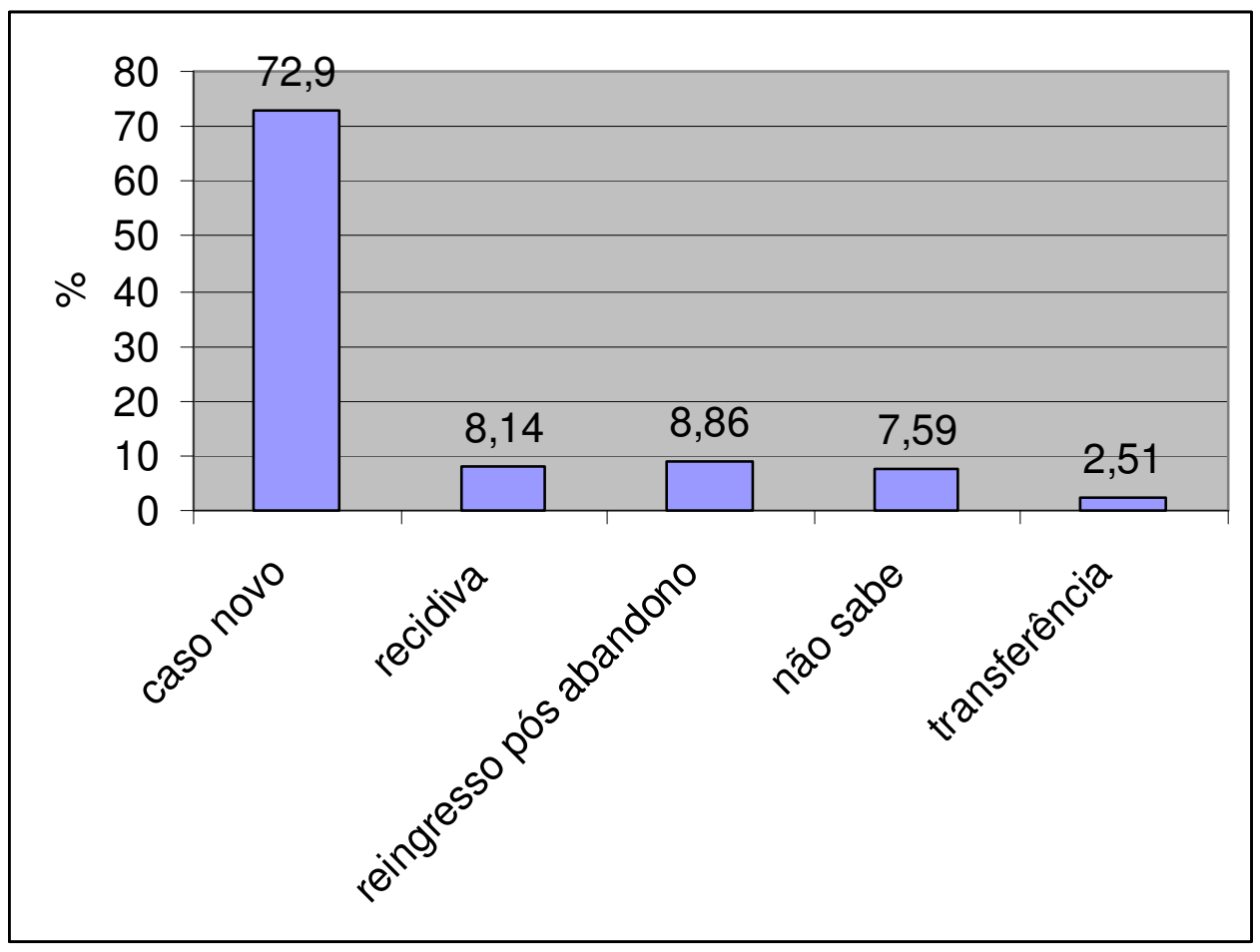


Gráfico 2 - Distribuição das categorias do dado HIV. SINAN-TB, RecifePE, 2001-2004

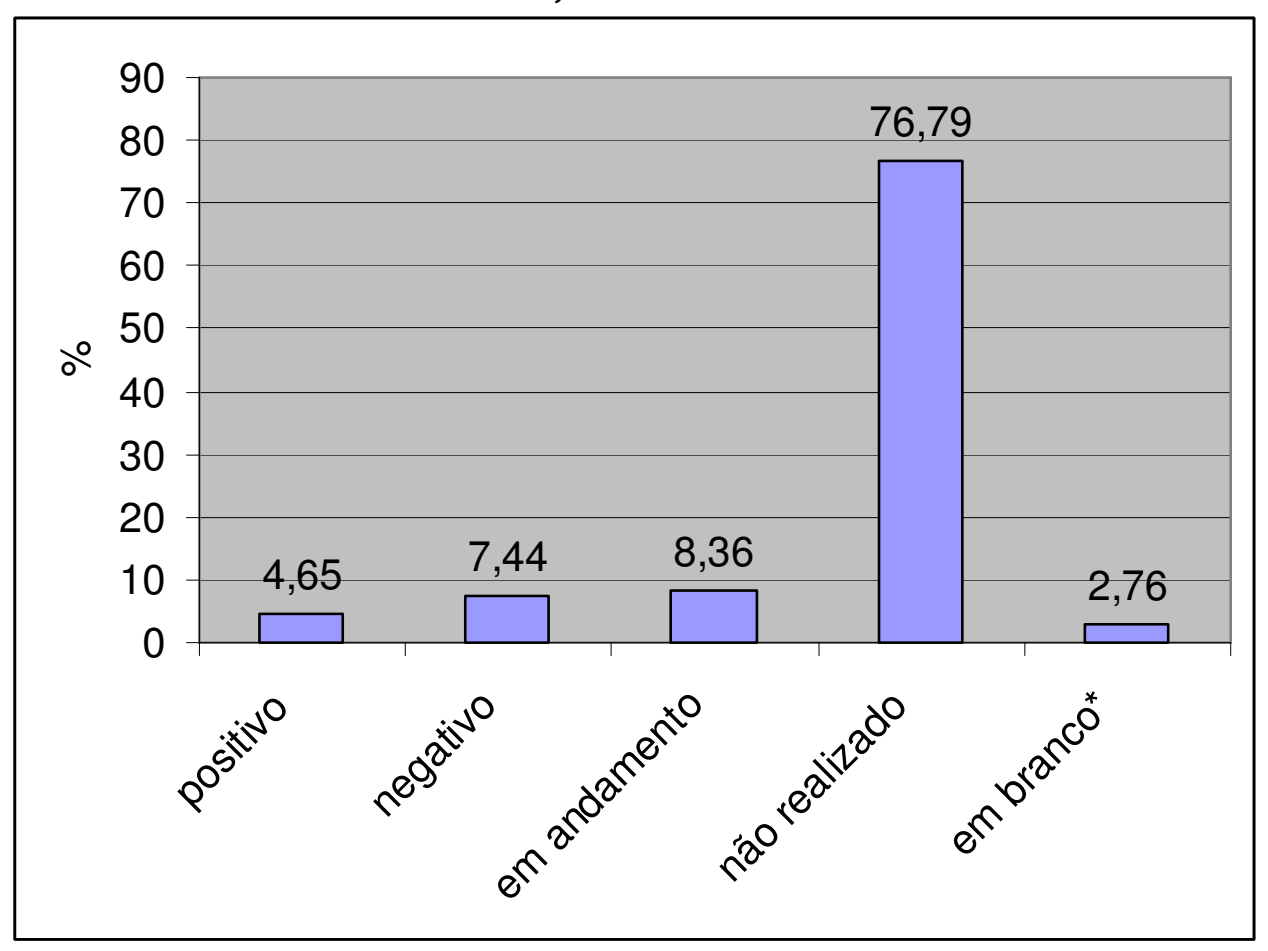

O registro nas categorias "não sabe", "transferência", "em andamento" e "não realizado" não representaram informações que permitiram ser analisadas, o que foi uma das limitações do estudo.

Os dados perdidos estão apresentados na Tabela 1, expressos em freqüência absoluta $(\mathrm{n})$ e relativa (porcentagem). Os dados NU_ANO (Ano do diagnóstico); ID_MN_RESI (Município de residência); FORMA (Forma clínica) e TRATAMENTO (Tipo de entrada) não apresentaram registros brancos, ignorados e/ ou inconsistentes. 
Tabela 1 - Freqüência de dados perdidos dos casos de TB pulmonar, diagnosticados no período de 2001 a 2004, residentes em Recife e registrados no banco de dados do SINAN

\begin{tabular}{|c|c|c|c|c|c|c|}
\hline \multirow[t]{3}{*}{ Dados em estudo } & \multicolumn{6}{|c|}{ Dados Perdidos } \\
\hline & \multicolumn{2}{|c|}{ Branco } & \multicolumn{2}{|c|}{ Ignorado } & \multicolumn{2}{|c|}{ Inconsistente } \\
\hline & $\mathbf{n}$ & $\%$ & $\mathbf{n}$ & $\%$ & $\mathbf{n}$ & $\%$ \\
\hline $\begin{array}{l}\text { Ano de diagnóstico } \\
\text { (NU_ANO) }\end{array}$ & 0 & 0 & 0 & 0 & 0 & 0 \\
\hline $\begin{array}{l}\text { Município de residência } \\
\text { (ID_MN_RESI) }\end{array}$ & 0 & 0 & 0 & 0 & 0 & 0 \\
\hline $\begin{array}{l}\text { Situação no encerramento/ } \\
\text { Resultado de tratamento } \\
\text { (SITUAÇÃO_2) }\end{array}$ & 221 & 3,67 & 0 & 0 & 0 & 0 \\
\hline Idade (NU_IDADE) & 0 & 0 & 0 & 0 & 2 & 0,03 \\
\hline Sexo (CS_SEXO) & 0 & 0 & 5 & 0,08 & 0 & 0 \\
\hline $\begin{array}{l}\text { Escolaridade } \\
\text { (CS_ESCOLAR) }\end{array}$ & 198 & 3,29 & 2.371 & 39,40 & 0 & 0 \\
\hline Ocupação (ID_OCUPACA) & 4.941 & 82,10 & 0 & 0 & 153 & 2,53 \\
\hline $\begin{array}{l}\text { Distrito de residência } \\
\text { (ID_DT_RESI) }\end{array}$ & 12 & 0,20 & 0 & 0 & 0 & 0 \\
\hline Forma clínica (FORMA) & 0 & 0 & 0 & 0 & 0 & 0 \\
\hline $\begin{array}{l}\text { Tipo de entrada } \\
\text { (TRATAMENTO) }\end{array}$ & 0 & 0 & 0 & 0 & 0 & 0 \\
\hline $\begin{array}{l}\text { Tratamento supervisionado } \\
\text { (TRAT_SUPER) }\end{array}$ & 3 & 0,05 & 3.849 & 63,96 & 0 & 0 \\
\hline $\begin{array}{l}\text { Data dō diagnóstico } \\
\text { (DT_DIAG) }\end{array}$ & 0 & 0 & 0 & 0 & 59 & 0,98 \\
\hline $\begin{array}{l}\text { Datā do início do tratamento } \\
\text { (DT_INIC_TR) }\end{array}$ & 0 & 0 & 0 & 0 & 599 & 9,94 \\
\hline $\begin{array}{l}\text { Data do encerramento do } \\
\text { tratamento (DT_ENCERRA) }\end{array}$ & 0 & 0 & 0 & 0 & 1.063 & 17,66 \\
\hline $\begin{array}{l}\text { Unidade de saúde } \\
\text { responsável pelo } \\
\text { acompanhamento atual } \\
\text { (ID_UNIDA_1) }\end{array}$ & 0 & 0 & 5 & 0,08 & 0 & 0 \\
\hline $\mathrm{HIV}(\mathrm{HIV})$ & 166 & 2,76 & 0 & 0 & 0 & 0 \\
\hline $\begin{array}{l}\text { Outros agravos } \\
\text { (AGRAVOS_AS) }\end{array}$ & 2.579 & 42,85 & 2.391 & 39,73 & 0 & 0 \\
\hline
\end{tabular}

Foi observado que o processo de dados perdidos ocorreu de um modo completamente aleatório, exceto para o dado DT_INIC_TR (Data de início de tratamento), ou seja, dos 599 casos com inconsistência no referido 
dado, $413(68,95 \%)$ correspondiam aos casos de óbito por TB (Gráfico 3) e $364(60,77 \%)$ foram registrados através do SIM.

Gráfico 3 - Distribuição dos casos com inconsistência no dado DT_INIC_TR (Data do início do tratamento) segundo resultado de tratamento. SINAN-TB, Recife-PE, 2001-2004

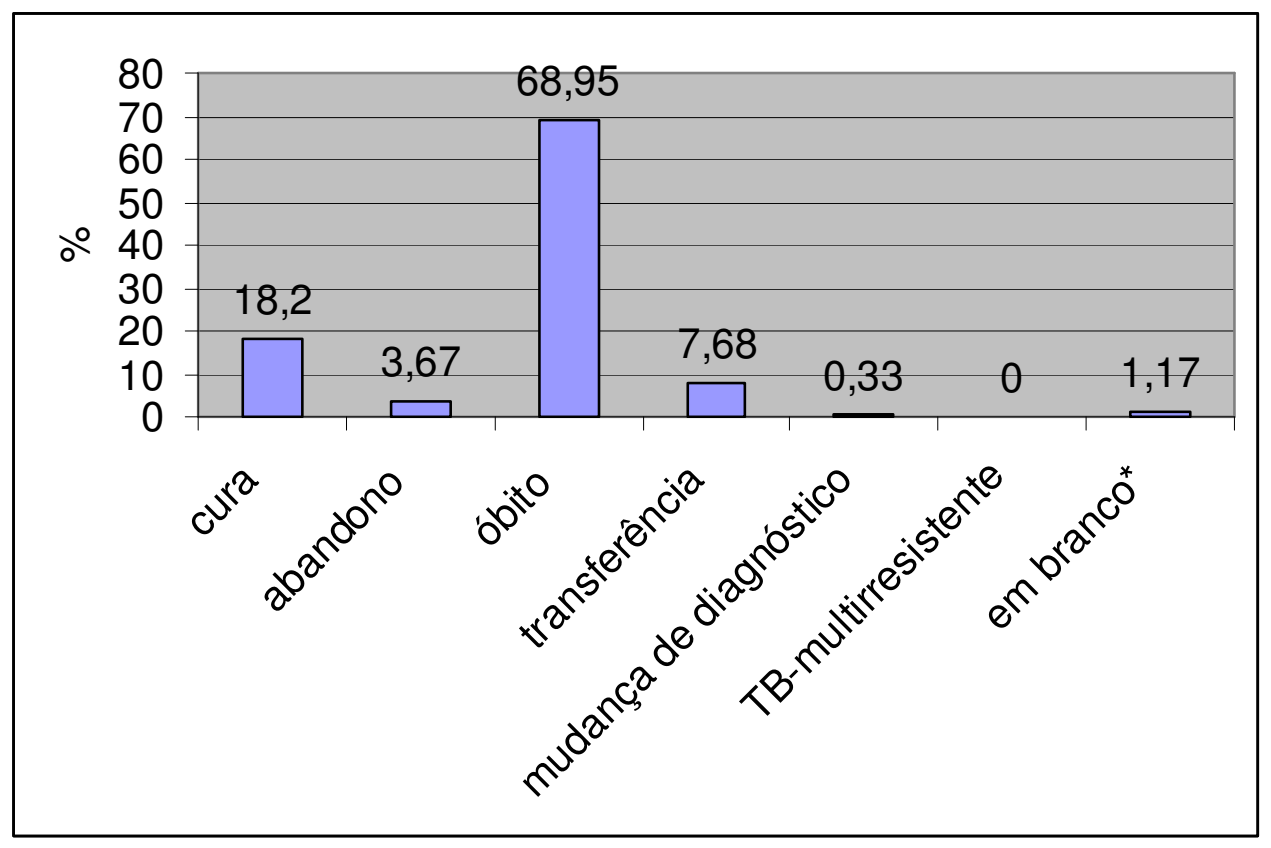

Os dados apresentados nesta fase permitem ser trabalhados nas próximas fases (uni e multivariada) desta investigação para gerar informações de qualidade, mas ainda, apresentam algumas falhas de preenchimento que necessitam ser revistas e solucionadas pelos órgãos competentes. 


\subsection{Fase Univariada}

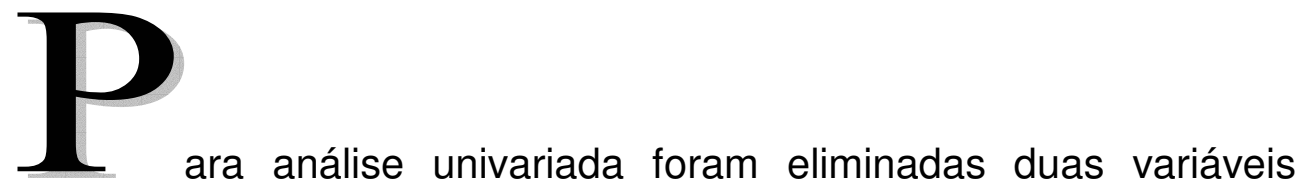

devido a dados em branco em mais de $40 \%^{13}$ : variável ocupação com $82,10 \%$ e variável outros agravos com $42,85 \%$ de dados em branco. Posteriormente, foram eliminados os casos que possuíam pelo menos uma variável de interesse em branco. Assim, dos 6.018 casos, foram eliminados $576(9,57 \%)$. Foram excluídos também, os casos com resultados de tratamento: Transferência (660 casos - 12,12\%) e Mudança de diagnóstico (32 casos $-0,59 \%)$ (Tabela 2$)$.

Tabela 2 - Distribuição dos casos de TB pulmonar, diagnosticados no período de 2001 a 2004 e residentes em Recife, segundo resultados de tratamento (cura, abandono, óbito e TB- multirresistente)
Resultados de Freqüência tratamento

n

\begin{tabular}{lcc}
\hline Cura & 3.268 & 68,80 \\
Abandono & 865 & 18,21 \\
Óbito & 605 & 12,74 \\
TB-multirresistente & 12 & 0,25 \\
\hline TOTAL & 4.750 & 100,00 \\
\hline
\end{tabular}

Os casos notificados de TB pulmonar, diagnosticados no período de 2001 a 2004, residentes em Recife e com todos os campos/ variáveis de interesse preenchidos corresponderam à 4.750 casos $(68,80 \%$ - resultado favorável e 31,20\% - resultado desfavorável).

\footnotetext{
${ }^{13}$ HAIR, Jr. (2005), em seus exemplos, sugeriu a exclusão de variáveis com $20 \%$ a $30 \%$ de dados em branco.
} 
A Tabela 3 mostra a freqüência absoluta e a porcentagem do número de casos com resultado favorável e desfavorável para cada categoria e os resultados da análise univariada.

Tabela 3 - Análise univariada da associação entre resultado favorável e variáveis independentes dos casos de TB pulmonar, diagnosticados no período de 2001 a 2004 e residentes em Recife

\begin{tabular}{|c|c|c|c|c|c|}
\hline Variáveis & $\begin{array}{c}\begin{array}{c}\text { Resultado } \\
\text { desfavorável } \\
(0)\end{array} \\
\mathbf{n}(\%)\end{array}$ & $\begin{array}{c}\begin{array}{c}\text { Resultado } \\
\text { favorável } \\
(1)\end{array} \\
\mathbf{n}(\%)\end{array}$ & $\begin{array}{c}\text { OR (IC } \\
95 \%)\end{array}$ & $\mathbf{p}$ & $\begin{array}{c}\text { Qui- } \\
\text { quadrado } \\
\text { Wald's }\end{array}$ \\
\hline Ano & & & & 0,051 & 3,814 \\
\hline 2001 & 327 (32,77\%) & $\begin{array}{c}671 \\
(67,23 \%)\end{array}$ & 1,00 & & \\
\hline 2002 & $355(31,70 \%)$ & $\begin{array}{c}765 \\
(68,30 \%)\end{array}$ & $\begin{array}{c}1,05(0,87 \\
-1,26)\end{array}$ & 0,599 & 0,276 \\
\hline 2003 & $401(32,11 \%)$ & $\begin{array}{c}848 \\
(67,89 \%)\end{array}$ & $\begin{array}{c}1,03(0,86 \\
-1,23)\end{array}$ & 0,740 & 0,110 \\
\hline $2004^{*}$ & $399(28,85 \%)$ & $\begin{array}{c}984 \\
(71,15 \%)\end{array}$ & $\begin{array}{c}1,20(1,01 \\
-1,43)\end{array}$ & 0,041 & 4,188 \\
\hline Sexo & & & & 0,006 & 7,444 \\
\hline Masculino & $1.024(32,51 \%)$ & $\begin{array}{c}2.126 \\
(67,49 \%)\end{array}$ & 1,00 & & \\
\hline Feminino* & $458(28,63 \%)$ & $\begin{array}{c}1.142 \\
(71,38 \%)\end{array}$ & $\begin{array}{c}1,20(1,05 \\
-1,37)\end{array}$ & 0,006 & 7,444 \\
\hline Idade & & & & 0,000 & 82,100 \\
\hline 0 a 9 anos* & $20(15,87 \%)$ & $\begin{array}{c}106 \\
(84,13 \%)\end{array}$ & $\begin{array}{c}4,29(2,59 \\
-7,10)\end{array}$ & 0,000 & 31,97 \\
\hline 10 a 19 anos* & $66(18,97 \%)$ & $\begin{array}{c}282 \\
(81,03 \%)\end{array}$ & $\begin{array}{c}3,46(2,53 \\
-4,73)\end{array}$ & 0,000 & 60,17 \\
\hline 20 a 39 anos* & $611(29,35 \%)$ & $\begin{array}{c}1.471 \\
(70,65 \%)\end{array}$ & $\begin{array}{c}1,95(1,61 \\
-2,35)\end{array}$ & 0,000 & 48,37 \\
\hline 40 a 59 anos* & $522(32,50 \%)$ & $\begin{array}{c}1.084 \\
(67,50 \%)\end{array}$ & $\begin{array}{c}1,68(1,38 \\
-2,04)\end{array}$ & 0,000 & 27,73 \\
\hline 60 ou mais & $263(44,73 \%)$ & $\begin{array}{c}325 \\
(55,27 \%)\end{array}$ & 1,00 & & \\
\hline Escolaridade & & & & 0,000 & 125,668 \\
\hline Nenhuma & $113(30,96 \%)$ & $\begin{array}{c}252 \\
(69,04 \%)\end{array}$ & 1,00 & & \\
\hline 1 a 3 anos & $100(28,99 \%)$ & $\begin{array}{c}245 \\
(71,01 \%)\end{array}$ & $\begin{array}{c}1,10(0,80 \\
-1,51)\end{array}$ & 0,566 & 0,329 \\
\hline 4 a 7 anos* & $300(23,73 \%)$ & $\begin{array}{c}964 \\
(76,27 \%)\end{array}$ & $\begin{array}{c}1,44(1,11 \\
-1,86)\end{array}$ & 0,005 & 7,76 \\
\hline 8 a 11 anos* & $122(20,54 \%)$ & $\begin{array}{c}472 \\
(79,46 \%)\end{array}$ & $\begin{array}{c}1,73(1,29 \\
-2,34)\end{array}$ & 0,000 & 13,12 \\
\hline 12 e mais* & $29(16,11 \%)$ & $\begin{array}{c}151 \\
(83,89 \%)\end{array}$ & $\begin{array}{c}2,33(1,48 \\
-3,68)\end{array}$ & 0,000 & 13,33 \\
\hline Não se aplica & $40(23,67 \%)$ & $\begin{array}{c}129 \\
(76,33 \%)\end{array}$ & $\begin{array}{c}1,45(0,95 \\
-2,20)\end{array}$ & 0,084 & 2,97 \\
\hline Ignorado & $778(42,44 \%)$ & $\begin{array}{c}1.055 \\
(57,56 \%)\end{array}$ & $\begin{array}{c}0,61(0,48 \\
-0,77)\end{array}$ & 0,000 & 16,44 \\
\hline
\end{tabular}


continuação

Tabela 3 - Análise univariada da associação entre resultado favorável e variáveis independentes dos casos de TB pulmonar, diagnosticados no período de 2001 a 2004 e residentes em Recife

\begin{tabular}{|c|c|c|c|c|c|}
\hline Variáveis & $\begin{array}{c}\begin{array}{c}\text { Resultado } \\
\text { desfavorável } \\
(0)\end{array} \\
\mathbf{n}(\%)\end{array}$ & $\begin{array}{c}\text { Resultado } \\
\text { favorável } \\
(1)\end{array}$ & $\begin{array}{c}\text { OR (IC } \\
95 \%)\end{array}$ & $\mathbf{p}$ & $\begin{array}{c}\text { Qui- } \\
\text { quadrado } \\
\text { Wald's }\end{array}$ \\
\hline Distrito & & & & 0,244 & 1,356 \\
\hline I & $148(30,64 \%)$ & $\begin{array}{c}335 \\
(69,36 \%)\end{array}$ & $\begin{array}{c}1,23(0,98 \\
-1,56)\end{array}$ & 0,076 & 3,15 \\
\hline II & 267 (33,75\%) & $\begin{array}{c}524 \\
(66,25 \%)\end{array}$ & $\begin{array}{c}1,07(0,88 \\
-1,30)\end{array}$ & 0,495 & 0,47 \\
\hline III & $268(30,35 \%)$ & $\begin{array}{c}615 \\
(69,65 \%)\end{array}$ & $\begin{array}{l}1,25(1,03 \\
-1,52)\end{array}$ & 0,023 & 5,19 \\
\hline IV & $149(22,71 \%)$ & $\begin{array}{c}507 \\
(77,29 \%)\end{array}$ & $\begin{array}{c}1,86(1,48 \\
-2,32)\end{array}$ & 0,000 & 29,30 \\
\hline V & 297 (31,70\%) & $\begin{array}{c}640 \\
(68,30 \%)\end{array}$ & $\begin{array}{c}1,18(0,97 \\
-1,42)\end{array}$ & 0,093 & 2,81 \\
\hline VI & $353(35,30 \%)$ & $\begin{array}{c}647 \\
(64,70 \%)\end{array}$ & 1,00 & & \\
\hline Tipo de Entrada & & & & 0,000 & 227,614 \\
\hline Caso novo* & $898(25,45 \%)$ & $\begin{array}{c}2.631 \\
(74,55 \%)\end{array}$ & $\begin{array}{c}3,48(2,81 \\
-4,30)\end{array}$ & 0,000 & 130,39 \\
\hline Recidiva* & $111(29,13 \%)$ & $\begin{array}{c}270 \\
(70,87 \%)\end{array}$ & $\begin{array}{c}2,89(2,14 \\
-3,89)\end{array}$ & 0,000 & 48,58 \\
\hline Não sabe & $240(69,77 \%)$ & $\begin{array}{c}104 \\
(30,23 \%)\end{array}$ & $\begin{array}{c}0,51(0,38 \\
-0,70)\end{array}$ & 0,000 & 18,29 \\
\hline Transferência & $23(21,10 \%)$ & $86(78,90 \%)$ & $\begin{array}{c}4,44(2,69 \\
-7,33)\end{array}$ & 0,000 & 33,88 \\
\hline $\begin{array}{l}\text { Reingresso } \\
\text { pós } \\
\text { abandono }\end{array}$ & $210(54,26 \%)$ & $\begin{array}{c}177 \\
(45,74 \%)\end{array}$ & 1,00 & & \\
\hline HIV & & & & 0,109 & 2,564 \\
\hline Positivo & $110(51,64 \%)$ & $\begin{array}{c}103 \\
(48,36 \%)\end{array}$ & 1,00 & & \\
\hline Negativo & $75(21,61 \%)$ & $\begin{array}{c}272 \\
(78,39 \%)\end{array}$ & $\begin{array}{c}3,87(2,67 \\
-5,61)\end{array}$ & 0,000 & 51,20 \\
\hline $\begin{array}{l}\text { Em } \\
\text { andamento }\end{array}$ & $94(25,07 \%)$ & $\begin{array}{c}281 \\
(74,93 \%)\end{array}$ & $\begin{array}{c}3,19(2,24 \\
-4,56)\end{array}$ & 0,000 & 40,84 \\
\hline Não realizado & $1.203(31,53 \%)$ & $\begin{array}{c}2.612 \\
(68,47 \%)\end{array}$ & $\begin{array}{c}2,32(1,76 \\
-3,06)\end{array}$ & 0,000 & 35,34 \\
\hline $\begin{array}{l}\text { Tratamento } \\
\text { Supervisionado }\end{array}$ & & & & 0,000 & 25,641 \\
\hline Sim & $201(19,80 \%)$ & $\begin{array}{c}814 \\
(80,20 \%)\end{array}$ & $\begin{array}{c}2,29(1,83 \\
-2,87)\end{array}$ & 0,000 & 52,42 \\
\hline Não & $225(36,17 \%)$ & $\begin{array}{c}397 \\
(63,83 \%)\end{array}$ & 1,00 & & \\
\hline Ignorado & $1.056(33,92 \%)$ & $\begin{array}{c}2.057 \\
(66,08 \%)\end{array}$ & $\begin{array}{c}1,10(0,92 \\
-1,32)\end{array}$ & 0,280 & 1,17 \\
\hline
\end{tabular}


continuação

Tabela 3 - Análise univariada da associação entre resultado favorável e variáveis independentes dos casos de TB pulmonar, diagnosticados no período de 2001 a 2004 e residentes em Recife

\begin{tabular}{|c|c|c|c|c|c|}
\hline Variáveis & $\begin{array}{c}\begin{array}{c}\text { Resultado } \\
\text { desfavorável } \\
(0)\end{array} \\
\mathrm{n}(\%)\end{array}$ & $\begin{array}{c}\text { Resultado } \\
\text { favorável } \\
(1)\end{array}$ & $\begin{array}{c}\text { OR (IC } \\
95 \%)\end{array}$ & $p$ & $\begin{array}{c}\text { Qui- } \\
\text { quadrado } \\
\text { Wald's }\end{array}$ \\
\hline Tempo 1 & & & & 0,000 & 389,190 \\
\hline 0 dias* & $920(26,29 \%)$ & $\begin{array}{c}2.580 \\
(73,71 \%)\end{array}$ & $\begin{array}{c}2,03(1,36 \\
-3,04)\end{array}$ & 0,001 & 11,80 \\
\hline 1 a 7 dias* & $115(24,78 \%)$ & $\begin{array}{c}349 \\
(75,22 \%)\end{array}$ & $\begin{array}{c}2,20(1,40 \\
-3,44)\end{array}$ & 0,001 & 11,78 \\
\hline 8 a 15 dias $^{*}$ & $19(13,87 \%)$ & $\begin{array}{c}118 \\
(86,13 \%)\end{array}$ & $\begin{array}{c}4,50(2,40 \\
-8,41)\end{array}$ & 0,000 & 22,13 \\
\hline 16 a 30 dias* $^{*}$ & $19(19,39 \%)$ & $79(80,61 \%)$ & $\begin{array}{c}3,01(1,59 \\
-5,70)\end{array}$ & 0,001 & 11,42 \\
\hline $\begin{array}{l}\text { Mais de } 30 \\
\text { dias }\end{array}$ & $42(42 \%)$ & $58(58 \%)$ & 1,00 & & \\
\hline Inconsistente & 367 (81,37\%) & $84(18,63 \%)$ & $\begin{array}{c}0,17(0,10 \\
-0,26)\end{array}$ & 0,000 & 58,02 \\
\hline Tempo 2 & & & & 0,000 & 324,002 \\
\hline 0 -1 mês & $128(82,05 \%)$ & $28(17,95 \%)$ & 1,00 & & \\
\hline $1-2$ meses & $82(91,11 \%)$ & $8(8,89 \%)$ & $\begin{array}{c}0,45(0,19 \\
-1,03)\end{array}$ & 0,058 & 3,608 \\
\hline $\begin{array}{l}2-13 \\
\text { meses }^{\star}\end{array}$ & $124(92,54 \%)$ & $10(7,46 \%)$ & $\begin{array}{c}0,37(0,17 \\
-0,79)\end{array}$ & 0,010 & 6,569 \\
\hline $3-4$ meses & $141(88,68 \%)$ & $18(11,32 \%)$ & $\begin{array}{c}0,58(0,31 \\
-1,10)\end{array}$ & 0,098 & 2,732 \\
\hline $\begin{array}{c}4-15 \\
\text { meses }^{*}\end{array}$ & 147 (66,82\%) & $73(33,18 \%)$ & $\begin{array}{c}2,27(1,38 \\
-3,73)\end{array}$ & 0,001 & 10,50 \\
\hline $\begin{array}{c}5-16 \\
\text { meses }\end{array}$ & $135(21,36 \%)$ & $\begin{array}{c}497 \\
(78,64 \%)\end{array}$ & $\begin{array}{c}16,83 \\
(10,72- \\
26,42)\end{array}$ & 0,000 & 150,53 \\
\hline $\begin{array}{l}6 \underset{19}{9} \\
\text { meses* }\end{array}$ & $259(11,39 \%)$ & $\begin{array}{c}2.015 \\
(88,61 \%)\end{array}$ & $\begin{array}{c}35,56 \\
(23,16- \\
54,61)\end{array}$ & 0,000 & 266,37 \\
\hline $\begin{array}{l}\text { Mais de } 9 \\
\text { meses }^{*}\end{array}$ & $89(14,42 \%)$ & $\begin{array}{c}528 \\
(85,58 \%)\end{array}$ & $\begin{array}{c}27,12 \\
(17,01- \\
43,24)\end{array}$ & 0,000 & 192,24 \\
\hline Inconsistente & 377 (80,56\%) & $91(19,44 \%)$ & $\begin{array}{c}1,10(0,69 \\
-1,76)\end{array}$ & 0,681 & 0,170 \\
\hline
\end{tabular}


continuação

Tabela 3 - Análise univariada da associação entre resultado favorável e variáveis independentes dos casos de TB pulmonar, diagnosticados no período de 2001 a 2004 e residentes em Recife

\begin{tabular}{|c|c|c|c|c|c|}
\hline Variáveis & $\begin{array}{c}\text { Resultado } \\
\text { desfavorável } \\
(0)\end{array}$ & $\begin{array}{c}\text { Resultado } \\
\text { favorável } \\
\text { (1) }\end{array}$ & $\begin{array}{c}\text { OR (IC } \\
95 \%)\end{array}$ & $\mathbf{p}$ & $\begin{array}{c}\text { Qui- } \\
\text { quadrado } \\
\text { Wald's }\end{array}$ \\
\hline & n (\%) & n (\%) & & & \\
\hline $\begin{array}{l}\text { Distrito da } \\
\text { Unidade de } \\
\text { Saúde }\end{array}$ & & & & 0,000 & 251,464 \\
\hline 00 & 379 (99,74\%) & $1(0,26 \%)$ & $\begin{array}{c}0,001 \\
(0,000- \\
0,008)\end{array}$ & 0,000 & 45,46 \\
\hline$I^{*}$ & $127(24,95 \%)$ & $\begin{array}{c}382 \\
(75,05 \%)\end{array}$ & $\begin{array}{c}1,33(0,99 \\
-1,79)\end{array}$ & 0,055 & 3,68 \\
\hline II & $198(27,42 \%)$ & $\begin{array}{c}524 \\
(72,58 \%)\end{array}$ & $\begin{array}{c}1,13(0,86 \\
-1,47)\end{array}$ & 0,381 & 0,77 \\
\hline III & 207 (27,79\%) & $\begin{array}{c}538 \\
(72,21 \%)\end{array}$ & $\begin{array}{c}1,11(0,85 \\
-1,44)\end{array}$ & 0,453 & 0,56 \\
\hline IV* & $156(16,79 \%)$ & $\begin{array}{c}773 \\
(83,21 \%)\end{array}$ & $\begin{array}{c}2,11(1,61 \\
-2,78)\end{array}$ & 0,000 & 28,65 \\
\hline V & $294(27,74 \%)$ & $\begin{array}{c}766 \\
(72,26 \%)\end{array}$ & $\begin{array}{c}1,11(0,86 \\
-1,43)\end{array}$ & 0,416 & 0,66 \\
\hline VI & $121(29,88 \%)$ & $\begin{array}{c}284 \\
(70,12 \%)\end{array}$ & 1,00 & & \\
\hline
\end{tabular}

Nível de referência - Categorias consideradas como de menor chance para obter resultado favorável: ano 2001; sexo masculino; idade 60 anos ou mais; escolaridade nenhuma; Distrito VI; tipo entrada reingresso após abandono; HIV positivo; TS não; Tempo 1 - mais de 30 dias; Tempo $2-0-11$ mês; Unidade pertencente ao Distrito VI.

* categorias que apresentaram associação com o resultado favorável.

As variáveis sexo, idade, escolaridade, tipo de entrada, tratamento supervisionado, Tempo 1, Tempo 2 e distrito da unidade de saúde apresentaram associação com o resultado favorável do tratamento de TB, na análise univariada, com nível de significância de 5\%. 


\subsection{Fase Multivariada}

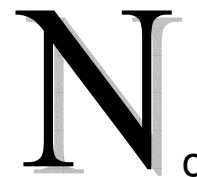

modelo multivariado foram incluídas as variáveis que apresentaram associação com $p<0,20$, na análise univariada (Tabela 3). Foram excluídas as variáveis: Distrito de residência $(\mathrm{p}=0,244)$; Tratamento Supervisionado por apresentar $65,54 \%$ dos dados com a categoria "ignorado" e HIV devido a $88,21 \%$ dos dados pertencerem as categorias "em andamento" ou "não realizado".

As variáveis que permaneceram no modelo multivariado ajustado final foram: Idade; Escolaridade, Tipo de entrada, Tempo 2 e Distrito da Unidade de Saúde (Tabela 4). 
Tabela 4 - Análise multivariada da associação entre resultado favorável e variáveis independentes dos casos de TB pulmonar, diagnosticados no período de 2001 a 2004 e residentes em Recife Variáveis OR (IC 95\%) p Quiquadrado Wald's

\section{Idade}

0 a 9 anos

10 a 19 anos

20 a 39 anos

40 a 59 anos

60 ou mais

Escolaridade

Nenhuma

1 a 3 anos

4 a 7 anos

8 a 11 anos

12 e mais

Não se aplica

Ignorado

Tipo de Entrada

Caso novo

Recidiva

Não sabe

Transferência

Reingresso pós abandono

\section{Tempo 2}
0 -1 1 mês
$1-12$ meses
$2-3$ meses
$3-14$ meses
$4-15$ meses
$5-16$ meses
$6-9$ meses

Mais de 9 meses

Inconsistente

Distrito da Unidade de Saúde 00

I

III

IV

V

VI

$\begin{array}{ccc}4,27(1,76-10,37) & 0,001 & 10,268 \\ 1,78(1,14-2,78) & 0,011 & 6,474 \\ 1,14(0,84-1,55) & 0,386 & 0,752 \\ 1,11(0,81-1,51) & 0,517 & 0,421 \\ 1,00 & 0,003 & 16,092 \\ & & \\ 1,00 & 0,000 & 28,218 \\ 1,06(0,68-1,66) & 0,799 & 0,065 \\ 0,99(0,69-1,41) & 0,960 & 0,003 \\ 1,52(1,00-2,29) & 0,049 & 3,883 \\ 1,55(0,85-2,85) & 0,154 & 2,030 \\ 0,45(0,23-0,88) & 0,019 & 5,471 \\ 0,75(0,52-1,07) & 0,112 & 2,531\end{array}$

$3,31(2,50-4,38) \quad 0,000 \quad 69,566$

$3,32(2,22-4,97) \quad 0,000 \quad 34,039$

$3,05(1,75-5,31) \quad 0,000 \quad 15,500$

$5,58(2,88-10,83) \quad 0,000 \quad 25,919$

$\begin{array}{lll}1,00 & 0,000 & 75,459\end{array}$

$1,00 \quad 0,000 \quad 858,182$

$0,26(0,11-0,62) \quad 0,002 \quad 9,204$

$0,27(0,12-0,58) \quad 0,001 \quad 10,816$

$0,43(0,22-0,84) \quad 0,014 \quad 6,097$

$1,31(0,77-2,22) \quad 0,323 \quad 0,979$

$9,15(5,65-14,84) \quad 0,000 \quad 80,719$

$27,28(17,21-\quad 0,000 \quad 198,107$ $43,23)$

$24,78(15,00-\quad 0,000 \quad 156,915$ $40,95)$

$10,80(5,80-\quad 0,000 \quad 56,312$ $20,10)$

$0,001(0,000-\quad 0,000 \quad 40,283$ $0,011)$

$1,60(1,09-2,36) \quad 0,018 \quad 5,639$

$1,26(0,89-1,79) \quad 0,185 \quad 1,756$

$0,88(0,62-1,25) \quad 0,489 \quad 0,478$

$2,87(2,01-4,11) \quad 0,000 \quad 33,138$

$1,23(0,89-1,71) \quad 0,206 \quad 1,602$

$\begin{array}{lll}1,00 & 0,000 & 106,583\end{array}$


7. ANÁLISE E DISCUSSÃO DOS DADOS 


\subsection{Fase Exploratória}

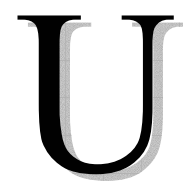

$\mathrm{m}$ dos cinco pilares que compõe a estratégia DOTS é o sistema de registro e informação que permite a avaliação do resultado do tratamento e do desempenho geral dos PCT (OMS, 2002).

O cumprimento das funções de vigilância epidemiológica depende da disponibilidade de dados que sirvam para subsidiar o processo de produção de informação para implementar processos de decisões, planejamento, organização, bem como para a normatização de atividades técnicas correlatas.

Segundo o Plano de Ação de Tuberculose 2004/ 2005 de Recife, o banco de dados sobre TB no município apresentava alta proporção de casos com mau preenchimento das fichas, inconsistências entre variáveis, falta de registro de encerramento e duplicidade de registro. Nesse cenário, sentiu-se a necessidade de promover atividades para a validação do banco de dados de TB notificados no Recife, no período de 1996 a 2003, visando melhorar a qualidade dos dados para ações de programação e planejamento em saúde no município. Neste sentido, foram traçadas as atividades a serem desenvolvidas nos anos 2004 e 2005:

- Identificar no banco de dados sobre tuberculose do SINAN, as variáveis essenciais não preenchidas e/ ou ignoradas, as inconsistências entre variáveis, a ausência de registro de 
encerramento e duplicidade de registro, utilizando-se o aplicativo TABWIN e Relatório de Conferência do SINAN, sendo agrupados e impressos os casos, por unidade de atendimento;

- Contratar recursos humanos (1 coordenador, 1 digitador, 6 pessoas de nível superior e 6 de nível médio) para a execução das atividades;

- Resgatar as informações necessárias por Unidade de Atendimento, utilizando Livros de Registros dos Programas; prontuário do paciente e Boletins Mensais de Acompanhamento;

- Realizar digitação dos dados coletados no primeiro nível hierárquico informatizado (Unidade de Saúde ou Distrito Sanitário);

- Realizar conferência do banco quanto à incorporação dos dados validados;

- Realizar transferência dos dados digitados de acordo com o fluxo estabelecido (Unidade de Saúde para o Distrito Sanitário e Distrito Sanitário para o Nível Central Municipal);

- Identificar os possíveis registros duplicados, através do Relatório de duplicidade do SINAN;

- Analisar os possíveis registros duplicados no nível central municipal; 
- Realizar exclusão das duplicidades e procedimento de vinculação nos casos de duplo registro no primeiro nível informatizado;

- Realizar compatibilização do banco de dados de tuberculose com os bancos de AIDS e meningite e notificar os casos não conhecidos no sistema de tuberculose;

- Realizar correção do banco de tuberculose quanto aos casos notificados pelo Sistema de Informação sobre Mortalidade SIM.

Apesar dos esforços empreendidos, observou-se neste estudo, uma alta porcentagem de registros em branco nos dados ID_OCUPACA (Ocupação) - 82,10\% e AGRAVOS_AS (Outros Agravos) - 42,85\%; registros ignorados nos dados CS_ESCOLAR (Escolaridade) - 39,40\%, AGRAVOS_AS (Outros Agravos) - 39,73\% e TRAT_SUPER (Tratamento Supervisionado) - 63,96\% e inconsistentes nos dados ID_OCUPACA (Ocupação) - 2,53\%, DT_INIC_TR (Data do início do tratamento) - 9,94\% e DT_ENCERRA (Data do encerramento do tratamento) - $17,66 \%$.

Tais achados mostram a dificuldade das equipes de saúde e da gerência das unidades de saúde em priorizar, no conjunto de atividades, o sistema de registro e informação, expresso pelas falhas e inconsistências no preenchimento do banco de dados do SINAN.

A identificação de dados perdidos na fase exploratória deste estudo mostra aspectos relacionados à organização dos serviços de saúde local, 
evidenciando questões que merecem ser refletidas, tais como: - Será que o preenchimento incompleto dos dados está relacionado à disponibilidade (quanti e qualitativa) de pessoal de saúde para atualizar os registros em fichas de notificação e banco de dados informatizados? - Será que os profissionais de saúde estão sensibilizados e conscientes de suas responsabilidades em preencher corretamente uma ficha de notificação compulsória e o registro sistemático e oportuno no SINAN? - Será que o fator disponibilidade de pessoal e tempo seria suficiente para o registro completo dessas informações?

Alguns dados perdidos também foram identificados em um estudo realizado em Cuiabá-MT que analisou os fatores preditivos para o abandono do tratamento da TB pulmonar de doentes inscritos no PCT. As variáveis relacionadas à ocupação e indicadores socioeconômicos não estavam presentes na maioria dos registros dos prontuários (FERREIRA; SILVA; BOTELHO, 2005).

Destaca-se a importância da obtenção de informações sobre aspectos socioeconômicos na identificação, por exemplo, de grupos populacionais de risco para o desfecho desfavorável do tratamento, os quais exigem uma abordagem especial dos PCT que devem minimizar os entraves no decorrer do processo de tratamento e cura da TB.

No presente estudo foram identificados 4.941 casos $(82,10 \%)$ com o dado ID_OCUPACA (Ocupação) em branco e 153 casos (2,53\%) com o referido dado inconsistente. Alguns estudos mostraram associação significativa entre ser desempregado com o desfecho desfavorável de 
tratamento da TB (RIBEIRO, 1993; DIEL; NIEMANN, 2003; BERGEL; GOUVEIA, 2005; BRITO et al., 2004; VENDRAMINI et al., 2005; BARROSO et al., 2003). É preciso reconhecer quais condições que predispõem ao não cumprimento correto do esquema terapêutico e quais intervenções complementares às médicas são necessárias em situações de desemprego, alcoolismo, desnutrição, entre outros.

No dado AGRAVOS_AS (Outros Agravos - AIDS, alcoolismo, diabetes e doença mental) também foi observado uma não valorização desta informação durante o preenchimento apresentando 2.579 casos $(42,85 \%)$ e 2.391 casos $(39,73 \%)$ com o referido dado em branco e ignorado, respectivamente, ou seja, $82,58 \%$ de dados perdidos. Em relação ao agravo alcoolismo, vários estudos o identificaram como um dos principais fatores de risco para a não cura do doente de TB (FERRER et al., 1991; DEHEINZELIN et al., 1996; PABLOS-MÉNDEZ et al., 1997; RIBEIRO et al., 2000; LIMA et al., 2001; ALBUQUERQUE et al., 2001; DIEL; NIEMANN, 2003; BARROSO et al., 2003; LINDOSO, 2004; BRAGA et al., 2004; BERGEL; GOUVEIA, 2005). Tais indivíduos devem ser identificados no início do tratamento para que sejam implementados procedimentos de acompanhamento diferenciados.

Em Recife, a partir de 2004, iniciou-se uma articulação da Atenção Básica com o Centro de Atenção Psicossocial (CAPS) que oferece acolhimento e tratamento aos doentes de TB etilistas, com transtorno mental e usuários de drogas, garantindo assim, a integralidade do cuidado. O CAPS é um serviço de saúde mental, formado por médico, enfermeiro, assistente 
social, psicólogo, terapeuta ocupacional e outros profissionais (PREFEITURA DO RECIFE, 2004).

Dentro do universo composto por doentes de TB existe uma diversidade de características individuais de diferentes naturezas que estão associadas ao resultado de tratamento da doença (HARGREAVES et al., 2001; SANTHA et al., 2002; SINGLA, et al., 2005; MORSY et al., 2003; DIEL; NIEMANN, 2003; BUSTAMANTE-MONTES et al., 2000; PRITCHARD et al., 2003). Cada doente tem seus problemas específicos que devem ser identificados pelos profissionais de saúde a fim de priorizar a atenção e enfatizar ações específicas satisfazendo suas necessidades durante o processo de tratamento.

Vale destacar que os serviços de saúde não predizem com segurança quais casos vão abandonar o tratamento (WHO, 1997). Este foi um dos motivos que levou a OMS a recomendar que o TS fosse empregado para todos os casos de TB.

No entanto, a alta porcentagem de dados ignorados no que se refere ao TS $(63,96 \%)$ não permitirá futuros estudos que analisem o impacto da atividade no controle da TB no município de Recife. A atividade de TS não era realizada de forma sistematizada pelos serviços de saúde do município até o ano de 2004 e está sendo implantada de forma gradual a partir do Plano Municipal de Tuberculose (2004-2005).

Para Muniz (1999) o TS no controle da TB desponta no espaço da saúde como capaz de gerar mudanças na prática dos agentes envolvidos, configurando um novo modo de agir em saúde. 
Neste sentido, sugere-se investir na capacitação das equipes em relação à atividade do TS e melhor esclarecimento aos trabalhadores de saúde sobre a precisão dos dados a serem informados de modo a oferecerem dados que permitam avaliar a efetividade do TS no controle da doença.

Além da identificação de registros em brancos e ignorados na fase exploratória deste estudo, observou-se categorias de alguns dados que não representam informações que permitam ser analisadas, tais como: não sabe e transferência (TRATAMENTO - Tipo de entrada) e em andamento (HIV). O dado HIV em particular, apresentou 04 categorias, sendo que 76,79\% dos casos correspondiam à categoria "não realizado", ou seja, a utilização dos exames laboratoriais de sorologia anti-HIV recomendados pela OMS é baixa e as normas do MS não são cumpridas pelos PCT local.

No estudo de Selig et al. (2004) sobre óbitos atribuídos à TB no Estado do Rio de Janeiro, os resultados mostraram que a sorologia anti-HIV foi solicitada em apenas 24,9\% dos casos de TB registrados no ano de 1998 e foi positiva em $26,5 \%$.

Devido à alta prevalência da co-infecção TB/ HIV e pela dificuldade de identificar pela história clínica os pacientes co-infectados, há indicação de fazer o teste anti-HIV para todos os pacientes com TB ativa. Os profissionais de saúde devem estar atentos ao fato de que o diagnóstico precoce da infecção pelo HIV no paciente com TB tem implicações terapêuticas importantes na evolução das duas patologias. 
As medidas de prevenção e controle do HIV e da TB não podem ser pensadas separadamente ao se considerar que a co-infecção pode elevar em 25 vezes o risco de desenvolver a TB doença e que as pessoas portadoras de ambas doenças têm um risco significativamente maior de morte (KEIT-PONTES et al., 1997; BRASIL, 2004).

A questão da capacitação dos recursos humanos para ações de prevenção e infra-estrutura para solicitação de exame para detectar coinfecção TB-HIV e realizar a vigilância epidemiológica do caso notificado devem ser considerados nos programas de educação permanente.

Em relação à inconsistência dos registros no SINAN, foram observadas nos seguintes dados: NU_IDADE (Idade); ID_OCUPACA (Ocupação); DT_DIAG (Data do diagnóstico); DT_INIC_TR (Data do início do tratamento) e DT_ENCERRA (Data do encerramento do tratamento). O dado DT_INIC_TR (Data do início do tratamento) foi o único que não apresentou aleatoriedade no processo de dados perdidos, ou seja, os casos com inconsistência no referido dado correspondiam aos casos de óbitos por TB $(68,95 \%)$ e notificados através do SIM $(60,77 \%)$. Ao realizar a correção do banco de TB quanto aos casos registrados pelo SIM, não foram resgatadas as informações necessárias para o preenchimento do SINAN. É possível que o profissional capacitado e comprometido o faça utilizando Livros de Registros dos Programas; prontuário do paciente e boletins mensais de acompanhamento.

Destaca-se a importância na interface de comunicação com outros sistemas de informação, no sentido de agilizar no desenvolvimento de 
análises e ações imediatas. O SINAN ao tentar englobar as funções de um sistema de notificação resulta em um produto com muitas lacunas de informação, num nível de desagregação incompatível com as necessidades dos serviços locais de saúde (BRASIL, 1997).

A OMS define Sistema de Informação em Saúde como um conjunto de componentes que atuam de forma integrada, por meio de mecanismos de coleta, processamento, análise e transmissão da informação necessária e oportuna para implementar processos de decisões no sistema de saúde. Define, também, Sistema de Informação de Serviços de Saúde como aquele cujo propósito é selecionar os dados pertinentes a esses serviços, transformando-os em informação para aqueles que planejam, financiam, provêem e avaliam os serviços de saúde (FIOCRUZ, 1998).

A formulação das políticas e os processos de tomada de decisão sobre a organização do sistema local de saúde requerem sistemas de informação disponíveis que exerçam um efeito sensibilizador alertando para novos problemas e oferecendo possibilidades alternativas de soluções (COHN et al., 2005).

Neste sentido, destaca-se a necessidade e importância de registros de dados consistentes e atualizados sobre os doentes de TB para a identificação das necessidades individuais e redistribuição da oferta de ações e serviços por critérios de necessidades. Além disso, tais dados auxiliam no processo de planejamento, regulação, programação pactuada e integrada da atenção à saúde, monitoramento e avaliação das ações de controle da TB. 


\subsection{Fases Univariada e Multivariada}

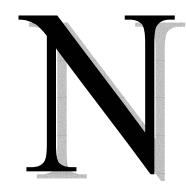

a análise univariada, as variáveis sexo, idade, escolaridade, tipo de entrada, tratamento supervisionado, Tempo 1, Tempo 2 e distrito da unidade de saúde apresentaram associação com o resultado favorável do tratamento de TB $(p<0,05)$.

A variável Sexo esteve significativamente associada ao resultado favorável de tratamento da TB $(p=0,006)$ sendo que as mulheres tiveram maior chance de cura que os homens $(O R=1,20)$ na análise univariada, mas não constituiu-se como fator preditivo para a cura no modelo ajustado final.

No universo composto por homens e mulheres solteiros e separados, os primeiros têm, aparentemente, preocupações mais diluídas sobre a doença e aderem menos às recomendações médicas. Na grande maioria, eles entendem que uma vez cessados os sintomas da doença estão, se não totalmente, quase curados. Alegam ainda que os medicamentos são em grande quantidade e que provocam efeitos colaterais causando-Ihes tanto ou mais problemas do que os sintomas iniciais. Em relação às mulheres, a necessidade e o desejo de cura, quando as sensações desagradáveis se intensificam, fazem com que superem as sensações desagradáveis dos medicamentos, aderindo melhor ao tratamento (GONÇALVES et al., 1999).

No estudo de Johansson et al. (2000) realizado no Vietnam, observaram que entre os homens, uma característica típica do 
comportamento foi que eles negligenciaram os sintomas da TB até que a doença alcançasse um estágio sério, e só então, buscaram os serviços de saúde públicos.

$\mathrm{Na}$ análise univariada, a variável ldade esteve significativamente associada ao resultado favorável de tratamento da TB $(p<0,0001)$ e também, todas as suas categorias. Os indivíduos pertencentes às categorias com menos de 60 anos tiveram maior chance de cura que os indivíduos com 60 anos ou mais. Após os ajustes feitos mediante análise multivariada, apenas, as crianças e adolescentes nas faixas etárias de 0 a 9 e 10 a 19 anos tiveram chance, respectivamente, 4,27 e 1,78 vezes maior de cura do que os indivíduos com 60 anos ou mais e constituíram-se em fatores preditivos para o resultado favorável de tratamento entre os indivíduos estudados.

Alguns autores justificam a menor chance de cura de pacientes com mais de 60 anos devido à: maior vulnerabilidade aos efeitos adversos do esquema terapêutico; dificuldade no acesso ao serviço de saúde para o diagnóstico e/ ou tratamento da TB; dificuldade de reconhecimento do quadro clínico que, muitas vezes, é confundido com as alterações próprias do envelhecimento atrasando seu diagnóstico e com outras doenças como bronquite crônica do fumante e enfisema por terem sintomatologias semelhantes, tais como: tosse, perda de peso, fraqueza e dispnéia (DUBE et al., 1987; LITUAK, 1990; YOSHIKAWA, 1992; CARVALHO FILHO; ALENCAR, 1994; RAJAGOPALAN; YOSHIKAWA, 2000; CHAIMOWICZ, 2001; RAJAGOPALAN, 2001; VENDRAMINI et al., 2003). 
Dentre outros fatores responsáveis por uma maior morbidade e letalidade da TB no idoso são apontados os antecedentes: má alimentação, moradia em instituições para idosos, as doenças associadas, alcoolismo, tabagismo e drogas (VENDRAMINI et al., 2003).

O coeficiente de incidência de TB para a população geriátrica no município de Recife, em 2002, foi de 135/ 100.000 habitantes, maior que o coeficiente para a população geral que foi de 104/ 100.000 habitantes (PERNAMBUCO, 2004).

Vale destacar que o Brasil passa por uma transição demográfica, cuja conseqüência tem sido o aumento do segmento da população de idosos, apresentando características que os diferenciam do resto da população (BALDESSIN, 1996). O processo de envelhecimento é dinâmico, apresentando modificações tanto morfológicas como funcionais, bioquímicas e psicológicas, que determinam a progressiva perda da capacidade de adaptação do indivíduo ao meio ambiente, ocasionando maior vulnerabilidade e maior incidência de processos patológicos que terminam por levá-lo à morte (CARVALHO FILHO; ALENCAR, 1994).

A variável escolaridade mostrou associação com o resultado favorável $(p<0,0001)$ na análise univariada. As categorias 1 a 3 anos de escolaridade e não se aplica (crianças que não atingiram a idade escolar) não apresentaram associação com o resultado favorável. O modelo ajustado final revelou uma associação entre a categoria "8 a 11 anos" de estudos concluídos e o resultado favorável de tratamento da TB. Estes indivíduos tiveram chance 1,52 vezes maior de cura do que aqueles com nenhuma 
escolaridade. A baixa escolaridade em doentes com resultado desfavorável de tratamento está de acordo com os achados de outros trabalhos (CAMPOS et al., 2000; RIBEIRO, 1993; DEHEINZELIN et al., 1996).

Dos 4.750 casos em estudo, apenas $774(16,29 \%)$ tinham o registro de 8 anos ou mais de estudos concluídos. Ribeiro (1993) reforça a importância da orientação dada ao doente, afirmando que "os indivíduos de baixa escolaridade, na ausência de informação, apresentam uma interação aditiva, se constituindo em uma categoria de maior risco para o abandono".

Ribeiro et al. (2000) sugerem modelos escalonados que incluam grupos educativos de sala de espera, associando-se TS diário ou duas vezes por semana com apadrinhamento e visitas domiciliares em grupos com maior risco de resultado desfavorável de tratamento.

Santos Filho (2006) sugere que os membros das comunidades mais afetadas pela TB devam participar da criação de materiais sobre a doença, que sejam precisos e sensíveis aos contextos social e cultural locais, uma vez que a escassez de informação e de recursos educacionais claros, acessíveis e não-científicos disponíveis para o setor comunitário é um obstáculo ao início da implementação de iniciativas de conscientização.

$\mathrm{Na}$ análise univariada, a variável Tipo de entrada esteve significativamente associada ao resultado favorável de tratamento da TB $(p<0,0001)$ e também, todas as suas categorias. Os resultados encontrados após os ajustes no modelo multivariado, monstraram que os "casos novos" e "recidiva" constituíram-se também como fatores preditivos para o resultado favorável entre os indivíduos estudados. Os "casos novos" e "recidiva" 
tiveram chance, respectivamente, 3,31 e 3,32 vezes maior de cura do que os casos de "reingresso pós abandono" do tratamento da TB.

Os casos novos têm praticamente $100 \%$ de chance de cura desde que os princípios da quimioterapia sejam seguidos (BRASIL, 2002a). Já os casos de retratamento (reingresso por abandono anterior, recidiva ou falência prévia), apenas $47 \%$ obtiveram sucesso ao final do tratamento, na coorte brasileira de 2001 (WHO, 2004).

Campos et al. (2000) verificaram no município de Recife-PE, em 1997, que o abandono do tratamento anterior foi o principal motivo para o retratamento $(55,8 \%)$, seguido por casos de recidiva da doença $(39,2 \%)$. Os casos que voltaram a tratar-se após recidiva apresentaram maior percentual de resultado favorável (64\%) quando comparados com os casos que voltaram a tratar-se após abandono ou falência do tratamento anterior.

Para alguns autores a menor chance de cura para os casos de reingresso pós abandono pode ser explicado por se tratar de pacientes que já apresentaram história de abandono ao tratamento anterior por diferentes motivos: sensação de estar curado; reações colaterais à medicação; patologias associadas à TB, como a AIDS e o alcoolismo; baixa ou nenhuma escolaridade; trabalho sem vínculo empregatício; falta de estruturação familiar; ou ainda, aspectos atribuídos ao próprio serviço de saúde que acompanha o caso, tais como, demora no atendimento ao doente, dificuldade de acesso ao profissional de saúde, inexistência da ação de busca de faltosos, deficiência na relação entre doente e profissional de saúde e falhas na orientação sobre o tratamento (RIBEIRO, 1993; 
OLIVEIRA, 1995; DINIZ et al., 1995; OLIVEIRA; MOREIRA FILHO, 2000; SANTHA et al., 2002; OLIVEIRA; MARIN-LEÓN; GARDINAL, 2005). Segundo Santos Filho (2006) os doentes que não compreendem as implicações do tratamento têm mais possibilidade de negligenciá-la.

$\mathrm{Na}$ análise univariada, a variável Tratamento Supervisionado mostrou associação com o resultado favorável de tratamento da TB $(p<0,0001)$ sendo que os casos em TS tiveram maior chance de cura $(\mathrm{OR}=2,29)$.

Um estudo realizado no município de Jacareí-SP mostrou um aumento de casos de doentes em TS acompanhado de um acréscimo no número de curas e diminuição dos abandonos de tratamento. No início da ampliação da equipe do PCT, em 1998, nenhum paciente realizou o TS. Os índices de cura e abandono foram de $74 \%$ e 9,20\%, respectivamente. Em 2003, cerca de $45 \%$ dos pacientes realizaram o TS. Os índices de cura e de abandono foram de $87,8 \%$ e 1,20\%, respectivamente, alcançando os índices preconizados pelo MS (SILVA; BARBOSA, 2004).

Um outro estudo realizado na cidade do Rio de Janeiro, os autores concluíram que pacientes que receberam TS tiveram uma chance 1,6 vezes maior de cura do que aqueles que receberam tratamento auto-administrado (TA) e que a implantação da estratégia DOTS melhorou a qualidade do PCT (CAVALCANTE et al., 2003).

No entanto, não foi possível incluir a variável Tratamento Supervisionado no modelo multivariado, uma vez que $3.113(65,54 \%)$ casos apresentaram o registro ignorado na referida variável. 
Na análise univariada, a variável Tempo 1 (do diagnóstico ao início do tratamento) esteve significativamente associada ao resultado favorável de tratamento da TB $(p<0,0001)$ e também, todas as suas categorias, no entanto, não se constituíram como fatores preditivos para a cura após ajustes feitos mediante análise multivariada.

A responsabilidade principal pelo tempo transcorrido desde 0 primeiro atendimento até o início do tratamento, depende da habilidade e capacidade do sistema de serviço de saúde de diagnosticar e instituir o tratamento (SHERMAN et al., 1999).

Lienhard et al. (2001) consideram que o conhecimento da demora para o tratamento da TB tem um papel importante como medida de avaliação sobre qualidade e efetividade de um programa de controle.

Quanto mais rápido for o diagnóstico e início do tratamento da TB, menor a possibilidade de agravamento do quadro clínico e maior a chance de cura sugerindo um bom desempenho do pessoal médico e paramédico nas rotinas de colheita, leitura do exame e início do tratamento dos pacientes matriculados no serviço (JOB et al., 1986).

Um estudo realizado por Torres e Pérez (2000) sobre o tempo percorrido da identificação, ao diagnóstico e ao tratamento de pacientes com TB pulmonar no Hospital Santa María Del Socorro de Ica (Peru), observaram que o tempo transcorrido do diagnóstico até o início do tratamento foi de 0 dias $(82,4 \%)$.

Penna (1988) avaliou a efetividade epidemiológica dos PCTs baseados na descoberta de casos e seu tratamento. Considerou serem 
tardias as intervenções, como o tratamento, no sentido de se evitar a infecção dos comunicantes, que são infectados antes do diagnóstico do caso índice. Estimou que o período de tempo mínimo necessário para o início do tratamento a partir do início dos sintomas, dentro do que é factível para o programa brasileiro, é de oito semanas.

$\mathrm{Na}$ análise univariada, a variável Tempo 2 (do início ao encerramento do tratamento) também mostrou associação com o resultado favorável do tratamento da TB $(p<0,0001)$. Após os ajustes feitos mediante análise multivariada, as categorias $5-16$ meses, $6-19$ meses e Mais de 9 meses constituíram-se como fatores preditivos para cura. Os doentes de TB que realizaram o tratamento em $5-6$ meses tiveram chance 9,15 vezes maior de cura do que aqueles que o fizeram em tempo menor. $O$ tempo de tratamento $5-16$ meses pode ser devido à falhas no registro das datas de início e encerramento do tratamento. Os indivíduos que o realizaram em 6 - 9 meses e mais de 9 meses tiveram respectivamente 27,28 e 24,78 vezes maior chance de cura. O tempo maior que o estipulado para 0 tratamento da TB pode ser devido às irregularidades durante a terapêutica relacionada a questões envolvendo paciente, medicação e/ ou organização do serviço de saúde.

São comuns intercorrências acontecerem ao longo do tratamento, ocasionando desvios como o não-cumprimento do esquema terapêutico, aumentando o tempo de tratamento. No entanto, vale destacar que quanto maior o tempo do tratamento, maior o risco de abandono com suas implicações biológicas, econômicas, psicológicas e sociais (SUMARTOJO, 
1993; PERINI, 1998; OLIVEIRA; MOREIRA FILHO, 2000; REIGOTA, 2001; SASSAKI et al., 2002; WORKSHOP - REDE BRASILEIRA DE PESQUISA EM TUBERCULOSE, 2002).

Para alcançar o objetivo de produzir impacto epidemiológico, o processo de descoberta-tratamento de casos bacilíferos deve atingir a maior cobertura possível e a máxima regularidade de tratamento (AZUMA, 1975). Uma vez iniciado, o tratamento não deve ser interrompido, salvo após rigorosa revisão clínica e laboratorial que o determine (BRASIL, 2000b).

O controle do tratamento consiste na avaliação periódica da evolução da doença e a utilização correta dos medicamentos. Para que isso ocorra, é fundamental que o profissional de saúde garanta as condições básicas para o êxito do tratamento. Na oportunidade, a equipe de saúde, além de conscientizar o paciente da importância de sua colaboração no tratamento, estabelece com ele uma relação de cooperação mútua, orientando-o em relação à: doença; duração do tratamento prescrito; importância da regularidade no uso das drogas; graves conseqüências advindas da interrupção ou abandono do tratamento (BRASIL, 2000a).

É de fundamental importância a adoção de medidas intersetoriais de promoção e vigilância da saúde, capazes de atuar nos fatores condicionantes de forma articulada, que não apenas monitore casos, mas também alie a estratégia DOTS visando eliminar, principalmente, a baixa aderência ao tratamento e o surgimento de cepas resistentes (WHO, 2001).

A variável Distrito da Unidade de Saúde mostrou associação com o resultado favorável $(p<0,0001)$ na análise univariada. O modelo ajustado 
final revelou que os casos acompanhados pelas unidades de saúde que pertenciam aos Distritos Sanitários (DS) I e IV tiveram chance, respectivamente, 1,60 e 2,87 vezes maior de cura do que àqueles acompanhados pelas unidades que pertenciam ao DS VI.

O DS VI é um dos distritos que concentra maior número de ZEIS (Zonas Especiais de Interesse Social). No município de Recife existem 66 ZEIS que englobam cerca de $80 \%$ de 490 favelas, sendo que $40 \%$ dos habitantes do Recife estão nessas áreas. (PREFEITURA DO RECIFE, 2004). A menor chance de cura pode estar relacionada às áreas carentes com precárias condições de vida.

Os elevados coeficientes de morbi-mortalidade de velhos problemas de saúde pública, como é o caso da TB, em determinadas áreas urbanas revelam a necessidade de entender as relações entre ambiente urbano/ pobreza urbana e a existência de quadros sanitários superpostos (SOUZA et al., 2000; SOUZA, 2003). Os moradores de favelas, trabalhadores do sexo e população em situação de rua nem sempre têm acesso aos serviços de saúde, ou se têm, não lhes é garantida a integralidade das ações segundo suas necessidades específicas e mais urgentes, necessitando para isso reformulação e adaptação de programas e ações em saúde (CARNEIRO JÚNIOR et al., 2000; CARNEIRO JÚNIOR; SILVEIRA, 2003; MARSIGLIA; SILVEIRA; CARNEIRO JÚNIOR, 2005). 


\section{CONSIDERAÇÕES FINAIS}


s dados selecionados para este estudo, disponíveis no SINAN, apresentam algumas falhas de preenchimento, tais como: registros em branco, ignorados e/ ou inconsistentes e categorias de dados que não representam informações que permitam ser analisadas (não sabe, transferência e em andamento). Isso mostra a dificuldade da equipe de saúde local em priorizar, no conjunto de atividades, o sistema de registro e informação, evidenciando também, sua não utilização no planejamento das ações do PCT dirigidas a grupos específicos (doentes com baixa escolaridade, desempregados, co-infectados TB/ HIV, etc.) e em outras intervenções como o TS. Tais dificuldades necessitam ser solucionadas a fim de melhor contribuir na identificação das necessidades individuais, redistribuição da oferta de ações e na redefinição do perfil dessa oferta, de modo a priorizar a atenção e enfatizar ações específicas para determinados grupos de doentes.

É necessário maior atenção dos serviços para o sistema de registro e informação e melhor esclarecimento aos trabalhadores de saúde sobre a precisão dos dados a serem informados. A sensibilidade e o envolvimento de todos os profissionais de saúde no registro sistemático e oportuno de dados resultam em maior consistência e melhor qualidade das informações.

Para que seja ampliado o uso do SINAN de forma adequada, é necessária uma política de gestão da informação e capacitação técnica do profissional de saúde. A valorização do papel da informação epidemiológica 
na definição das políticas públicas da saúde se reflete, diretamente, na qualidade dos sistemas de informação.

O instrumental estatístico utilizado, modelo de regressão logística multivariado, permitiu identificar os fatores preditivos ao resultado favorável do tratamento da TB. A partir da análise desses fatores foi possível identificar como grupos prioritários, os indivíduos com mais de 60 anos, nenhuma escolaridade e reingressos pós abandono. O não cumprimento ao tempo de tratamento preconizado e unidades de saúde pertencentes à DS com áreas carentes constituíram-se como os principais obstáculos ao sucesso do tratamento.

O sistema de vigilância epidemiológica da TB precisa ser implementado para responder às diversas demandas do atual quadro epidemiológico da doença. Sugere-se atenção especial aos idosos com um enfoque diferenciado no seu diagnóstico, tratamento e cuidado, devido às características clínicas específicas que os diferenciam dos adultos, seus antecedentes e os eventos conseqüentes da TB. Além disso, é importante a formação e educação permanente dos profissionais de saúde da rede de Atenção Básica na área do envelhecimento e saúde da pessoa idosa e apoio ao desenvolvimento de estudos e pesquisas sobre a TB no idoso.

Ao consideramos a baixa (ou nenhuma) escolaridade e a ausência de informação, uma interação aditiva para menor chance de cura da TB, sugere-se investir na capacitação dos profissionais de saúde de modo que estes possam oferecer, principalmente a este grupo, maiores orientações e esclarecimentos sobre a doença utilizando materiais educativos em termos 
claros, acessíveis e não-científicos. A importância da terapia medicamentosa é um conceito científico que nem sempre pode ser compreendido e aceito pelas pessoas que não compartilham desse paradigma. A educação em TB deve ter como objetivo propiciar o conhecimento sobre a doença e tratamento, promover esclarecimentos e estabelecer o vínculo que favoreça a confiança no saber científico. Além disso, os membros das comunidades mais afetadas pela TB devem ser estimulados a participarem da criação de materiais sobre a doença, que sejam precisos e sensíveis aos contextos social e cultural locais.

Os indivíduos em retratamento para TB, especialmente, os casos de reingresso pós abandono também devem ser considerados como grupo de risco nos PCT, uma vez que estes tendem a abandonar o tratamento com freqüência permanecendo doentes e estão mais expostos para a transmissão de bacilos resistentes às drogas. Esforços devem ser dirigidos para melhorar a eficiência dos serviços de saúde no atendimento a este grupo de doentes certificando-se da ingestão do medicamento através do tratamento supervisionado diário durante o tratamento e oferecendo atividades de educação e acolhimento. Deve-se considerar que todas as pessoas têm um potencial para mudanças de comportamento e estilos de vida, desde que conheçam e compreendam as razões e os benefícios dessas mudanças. Além disso, nos PCT é importante o acolhimento multidisciplinar do paciente e de seus familiares de modo integrá-los junto às equipes, minimizar os entraves no decorrer do processo de tratamento e 
cura da doença e propiciar o conhecimento mútuo das impressões sobre a TB e sua terapêutica.

Além de contribuir para a humanização e melhoria da qualidade da atenção, o acolhimento é uma estratégia de reorientação da atenção ao doente que pode ter efeitos significativos nas relações dos profissionais e dos doentes de TB e até mudanças nas concepções destes acerca das suas necessidades de saúde (TEIXEIRA, 2002b; CAMPINAS; ALMEIDA, 2004).

Em relação ao obstáculo para o sucesso do tratamento, identificado a partir da variável Tempo 2, é necessário o esclarecimento do paciente sobre a duração do tempo de tratamento da TB, pois a utilização correta e regular do regime terapêutico permite que a maioria dos pacientes seja curada. Considerando-se que o não cumprimento do tratamento pode se apresentar sob diferentes formas e graus (do esquecimento eventual ou da interrupção intencional periódica e/ ou intermitente ao abandono), é preciso reconhecer quais condições que o predispõem e quais intervenções são indispensáveis perante aos problemas identificados. O não cumprimento de um esquema terapêutico e suas ligações com os fatores de irregularidade ao tratamento pode estar relacionado tanto ao doente quanto à medicação e/ ou à organização do serviço de saúde. Na avaliação do cumprimento ao esquema terapêutico, pode-se utilizar a regularidade com que são ingeridos os medicamentos contando-se as drágeas da cartela.

Para uma análise mais aprofundada da relação entre o resultado de tratamento da TB e áreas carentes com precárias condições de vida são 
necessários estudos que associem a distribuição espacial da TB, as condições socioeconômicas e de saneamento da população envolvida.

Sugere-se desenvolver nos serviços de saúde uma organização de assistência à TB voltada às necessidades individuais do doente priorizando os grupos com menor chance de cura garantindo não só a universalidade no acesso aos serviços de saúde, mas também a equidade no acesso às ações. Portanto, é necessário a elaboração de protocolos de regulação visando garantir o acesso às ações por critérios de necessidades. A assistência a esse grupo deve se basear no modelo da promoção, proteção e recuperação da saúde.

Desta forma, acredita-se numa melhora na eficiência do atendimento aos grupos prioritários e conseqüentes transformações nos indicadores epidemiológicos da doença no município de Recife.

Destaca-se que esta pesquisa representa apenas o ponto de partida para novas investigações que abordem de uma forma mais ampla o problema da TB. Sugere-se que sejam incluídas, em futuras investigações, outras variáveis que não foram abordadas neste estudo visando intervir nos fatores condicionantes para a cura da doença, assim como, garantir o acesso aos recursos e serviços de forma justa, ou seja, implica reformulação e adaptação de programas e ações em saúde, de modo a garantir a integralidade das ações segundo suas necessidades específicas e mais urgentes.

A saúde é uma questão social, econômica, política e, acima de tudo, um direito humano fundamental. Proporcionar condições de saúde para 
todos implica mudar as prioridades políticas e econômicas. Trabalhar a eqüidade é uma forma de aumentarmos a potência do SUS como política de inclusão social. 
REFERÊNCIAS BIBLIOGRÁFICAS 
ALBUQUERQUE, M. F. M.; LEITÃO, C. C. S.; CAMPELO, A. R. L.; SOUZA, W. V.; SALUSTIANO, A. Fatores prognósticos para desfecho do tratamento da tuberculose pulmonar em Recife, Pernambuco, Brasil. Revista Panamericana de Salud Publica, Washington, v. 9, n. 6, p. 368-374, 2001.

ALMEIDA, C.; TRAVASSOS, C.; PORTO, S. M.; FARIAS, T. A Reforma Sanitária Brasileira: Em Busca da Equidade. In: CONGRESSO BRASILEIRO DE CIÊNCIAS SOCIAIS EM SAÚDE, 2., 1999, São Paulo. Anais... São Paulo, 1999.

AZUMA, Y. A simple simulation model of tuberculosis epidemiology for use without large-scale computers. Bulletin of the World Health Organization, Geneva, v. 52, p. 313-22, 1975.

BALDESSIN, A. O idoso: viver e morrer com dignidade. In: PAPALÉO NETO, M. Manual de gerontologia. São Paulo: Atheneu, 1996. p. 491-8.

BARNHOORN, F.; ADRIANSE, $\mathrm{H}$. In search of factors responsible for non-compliance among tuberculosis patients in Warha District, India. Social Science and Medicine, Oxford, v. 34, n. 2, p. 291-306, 1992.

BARROSO, E. C.; MOTA, R. M. S.; MORAIS, M. F. M.; CAMPELO, C. L.; BARROSO, J. B.; RODRIGUES, J. L. N. Fatores associados aos tratamentos inadequados em grupo de portadores de tuberculose multirresistente. Jornal de Pneumologia, São Paulo, v. 29, n. 6, 2003.

BERGEL, F. S.; GOUVEIA, N. Retornos freqüentes como nova estratégia para adesão ao tratamento de tuberculose. Revista de Saúde Pública, São Paulo, v. 39, n. 6, 2005.

BRAGA, E. C.; FERREIRA, L. R.; VELANO, C. E. E.; DEL GUERRA, D. C.; FOGAROLLI, L. P. C.; CARDOSO, C. M. Tuberculose, patologia reemergente: incidência e fatores associados. Revista da Sociedade Brasileira de Clínica Médica, São Paulo, v. 2, n. 1, p. 15, 2004. 
BRASIL, Lei $n^{\circ}$ 8.080, de 19 de setembro de 1990. Dispõe sobre as Condições para a Promoção, Proteção e Recuperação da Saúde, a organização e o Funcionamento dos Serviços Correspondentes, e dá outras providências. Lei Orgânica da Saúde, Brasília, DF, 19 de setembro de 1990.

BRASIL, Lei ํ 8.142, de 28 de dezembro de 1990. Dispõe sobre a participação da comunidade na gestão do Sistema Único de Saúde (SUS) e sobre as transferências intergovernamentais de recursos financeiros na área da saúde e dá outras providências. Lei Orgânica da Saúde, Brasília, DF, 28 de dezembro de 1990.

BRASIL. Ministério da Saúde. Departamento de Informática do Sistema Único de Saúde - DATASUS. Sistema de informações hospitalares, arquivos reduzidos: manual de preenchimento de autorização de internação hospitalar. Brasília: Ministério da Saúde, 1997.

BRASIL. Ministério da Saúde. Secretaria de Políticas Públicas. Departamento de Atenção Básica. Coordenação Nacional de Pneumologia Sanitária. Plano de controle da Tuberculose no Brasil no período de 2001-2005. Brasília, 2000a.

BRASIL. Ministério da Saúde. Secretaria de Políticas Públicas. Departamento de Atenção Básica. Normas para o Programa de Controle da Tuberculose. Brasília, 2000b.

BRASIL. Ministério da Saúde. Secretaria de Políticas de Saúde. Departamento de Atenção Básica. Manual técnico para o controle da tuberculose. 6. ed. Brasília: Ministério da Saúde, 2002a.

BRASIL. Ministério da Saúde. Fundação Nacional de Saúde. Centro de Referência Professor Hélio Fraga. Sociedade Brasileira de Pneumologia e Tisiologia. Controle da Tuberculose: uma proposta de integração ensino-serviço. 5. ed. Rio de Janeiro: FUNASA/ CRPHF/ SBPT, 2002b.

BRASIL. Ministério da Saúde. Secretaria de Vigilância em Saúde. Departamento de Vigilância Epidemiológica. Coordenação Geral de Doenças Endêmicas. Área Técnica de Pneumologia Sanitária. Programa nacional de controle da Tuberculose. Brasília, 2004. 
BRASIL. Ministério da Saúde. Secretaria de Vigilância em Saúde. Sistema nacional de vigilância em saúde: relatório de situação. Brasília: Ministério da Saúde, 2005a.

BRASIL. Ministério da Saúde. Secretaria de Vigilância em Saúde. Guia de vigilância epidemiológica. 6. ed. Brasília: Ministério da Saúde, 2005b. 816 p.

BRASIL. Ministério da Saúde. Secretaria-Executiva. Departamento de Apoio à Descentralização. Regulamento dos pactos pela vida e de gestão. Brasília: Ministério da Saúde, 2006.

BRITO, L. S. F. Sistema de Informações de Agravos de Notificação SINAN. In: SEMINÁRIO DE VIGILÂNNCIA EPIDEMIOLÓGICA, 1993, Brasília. Anais... Brasília: Ministério da Saúde/ Fundação Nacional de Saúde, 1993. p. 145-146.

BRITO, R. C.; GOUNDER, C.; LIMA, D. B.; SIQUEIRA, H.; CAVALCANTI, H. R.; PEREIRA, M. M.; KRITSKY, A. L. Resistência aos medicamentos anti-tuberculose de cepas de Mycobacterium tuberculosis isoladas de pacientes atendidos em hospital geral de referência para tratamento de AIDS no Rio de Janeiro. Jornal Brasileiro de Pneumologia, Ribeirão Preto, v. 30, n. 4, 2004.

BUSTAMANTE-MONTES, L. P.; ESCOBAR-MESA, A.; BORJAABURTI, V. H.; GOMEZ-MONOZ, A.; BECERRA-POSADA, F. Predictors of death from pulmonary tuberculosis: the case of Veracruz, Mexico. The International Journal of Tuberculosis and Lung Disease, França, v. 4, p. 208-215, 2000.

CAMPINAS, L. L. S. L.; ALMEIDA, M. M. M. B. Agentes comunitários de saúde e 0 acolhimento aos doentes com tuberculose no Programa Saúde da Família. Boletim de Pneumologia Sanitária, Rio de Janeiro, v. 12, n. 3, p. 145-154, 2004.

CAMPOS, H. M. A.; ALBUQUERQUE, M. F. M.; CAMPELO, A. R. L.; SOUZA, W. V.; BRITO, A. M. O retratamento da tuberculose no município do Recife, 1997: uma abordagem epidemiológica. Jornal de Pneumologia, São Paulo, v. 26, n. 5, p. 235-40, 2000. 
CARNEIRO JUNIOR, N. et al. A construção da eqüidade no acesso às políticas públicas: uma experiência de articulação intersetorial e interinstitucional na área central do município de São Paulo. Revista Brasileira de Administração Pública, Rio de Janeiro, v. 34, n. 6, p. 95-104, 2000.

CARNEIRO JUNIOR, N.; SILVEIRA, C. Organização das práticas de atenção primária em saúde no contexto dos processos de exclusão/inclusão social. Cadernos de Saúde Pública, Rio de Janeiro, v. 19, n. 6, p. 1827-1835, 2003.

CARVALHO, D.M. Grandes sistemas nacionais de saúde: revisão e discussão da situação atual. Informe Epidemiológico do SUS, Brasília, v. 6, n. 4, p. 7-45, 1997.

CARVALHO FILHO, E. T.; ALENCAR, Y. M. G. de. Teorias do envelhecimento. In: CARVALHO FILHO, E. T.; PAPALÉO NETO, M. Manual de geriatria: fundamentos, clínica e terapêutica. São Paulo: Atheneu; 1994. p. 1-8.

CASTELLANOS, P. L. A Epidemiologia e a organização dos Serviços de Saúde. In: ROUQUAYROL, M.Z. Epidemiologia \& Saúde. 4. ed. Rio de Janeiro: Medsi, 1994. p. 477-84.

CAVALCANTE, S. C.; SOARES, E. C. C.; ROCHA, M. S.; OLIVEIRA, J. R.; DIAS, S. M. O.; PACHECO, A. G. F.; CHAISSON, R. E.; DUROVNI, B. A implantação da estratégia DOTS na cidade do Rio de Janeiro. Pulmão, Rio de Janeiro, v. 12, n. 2, 2003.

CENTER FOR HEALTH EQUITY, TRAINING, RESEARCH AND EVALUATION (CHETRE). What is equity? In: An area health service taking action to achieve health for all. Newsletter 1. Center for Health Equity, Training, Research and Evaluation. The University of New South Wales. School of Public Health \& Community Medicine, Austrália. 2000.

CHAIMOWICZ, F. Transição etária de incidência e mortalidade por tuberculose no Brasil. Revista de Saúde Pública, São Paulo, v. 35, n. 1, p. 817, 2001. 
COHN, A.; WESTPHAL, M. F.; ELIAS, P. E. Informação e decisão política em saúde. Revista de Saúde Pública, São Paulo, v. 39, n. 1, p. 114-21, 2005.

DAVIDSON, P. T. Drug resistance and the selection of therapy for tuberculosis. The American review of respiratory disease, Baltimore, v. 136, n. 2, p. 255-7, 1987.

DEHEINZELIN, D.; TAKAGAKI, T. Y.; SARTORI, A. M. C.;LEITE, O. H. M.; AMATO NETO, V.; CARVALHO, C. R. R. Fatores preditivos de abandono de tratamento por pacientes com tuberculose. Revista do Hospital das Clínicas, São Paulo, v. 51, p. 131-135, 1996.

DIEL, R.; NIEMANN, S. Outcome of tuberculosis treatment in Hamburg: a survey, 1997 - 2001. The International Journal of Tuberculosis and Lung Disease, França, v. 7, n. 2, p. 124-131, 2003.

DINIZ, L. S.; GERHARDT, G.; MIRANDA, J. A.; MANCEAU, J. N. Efetividade do tratamento em oito municípios de capitais brasileiras. Boletim de Pneumologia Sanitária, Rio de Janeiro, v. 3, p. 6-18, 1995.

DUBE, D.; FEATHER, J.; KATZ, P. R.; REICHMAN, W. Clinical features of pulmonary tuberculosis in young and old veterans. Journal of the American Geriatrics Society, Los Angeles, v. 35, n. 6 , p. 512-5, 1987.

FERREIRA, S. M. B.; SILVA, A. M. C.; BOTELHO, C. Abandono do tratamento da tuberculose pulmonar em Cuiabá-MT-Brasil. Jornal Brasileiro de Pneumologia, Ribeirão Preto, v. 31, n. 5, p. 427-435, 2005.

FERRER, X.; KIRSCHBAUM, A.; TORO, J.; JADUE, J.; MUÑOZ, M.; ESPINOZA, A. Adherencia al tratamiento de la tuberculosis del adulto em Santiago, Chile. Boletín de la Oficina Sanitaria Panamericana, Washington, v. 111, n. 5, p. 423-31, 1991. 
FUNDAÇÃO OSWALDO CRUZ. Universidade de Brasília. FINATEC. Sistema de informações. Rio de Janeiro: FIOCRUZ, 1998. Série Gestão Operacional de Sistemas e Serviços de Saúde.

GIOVANELLA, L.; DRUMOND, J.; SKABA, M.; SÁ, V.; OLIVEIRA, R. Eqüidade em saúde no Brasil. Saúde em Debate, Rio de Janeiro, $v$. 49, p. 13-22, 1996.

GOLDBAUM, M. Vigilância da saúde. In: SEMINÁRIO DE VIGILÂNCIA EPIDEMIOLÓGICA, 1993, Brasília. Anais... Brasília: Ministério da Saúde/ Fundação Nacional de Saúde, 1993. p. 57-62.

GONÇALVES, H.; COSTA, J. S. D.; MENEZES, A. M. B.; KNAUTH, D.; LEAL, O. F. Adesão à terapêutica da tuberculose em Pelotas, Rio Grande do Sul: na perspectiva do paciente. Cadernos de Saúde Pública, Rio de Janeiro, v. 15, p. 1-17, 1999.

HAIR JR., J. F.; ANDERSON, R. E.; TATHAM, R. L.; BLACK, W. C. Análise multivariada de dados. 5. ed. Porto Alegre: BOOKMAN, 2005.

HARGREAVES, N. J.; KADZAKUMANJA, O.; WHITTY, C. J. M.; SALANIPONI, F. M. L.; HARRIES, A. D.; SQUIRE, S. B. 'Smearnegative' pulmonary tuberculosis in a DOTS programme: poor outcomes in an area of high HIV seroprevalence. The International Journal of Tuberculosis and Lung Disease, França, v. 5, n. 9, p. 847-854, 2001.

JACOBI, P. Habitat e saúde na periferia. São Paulo em Perspectiva, São Paulo, n. 4, p. 121-130, 1990.

JOB, J. R. P. P.; GOZZANO, J. O. A.; BERNARDES JÚNIOR, O. R.; GARCIA, R. H.; MIRALHES, O. J. C.; MIRANDA, M. A. P. Informações que antecederam 0 diagnóstico de tuberculose pulmonar e tempo decorrido até o início do tratamento em pacientes matriculados em Centro de Saúde, São Paulo (Brasil). Revista de Saúde Pública, São Paulo, v. 20, n. 1, p. 21-25, 1986. 
JOHANSSON, E.; LONG, N. H.; DIWAN, V.; WINKVIST, A. Gender and tuberculosis control: health seeking behavior among men and women in Vietnam. Health Policy, New York, v. 52, p. 33-51, 2000.

KEIT-PONTES, L. R. S. et al. Tuberculose associada à AIDS: situação da região nordeste brasileiro. Revista de Saúde Pública, São Paulo, v. 31, n. 4, 1997.

KLEINBAUM, D. G. Logistic regression: a self-learning text. New York: Springer, 1994.

LAGUARDIA, J.; DOMINGUES, C. M. A.; CARVALHO, C.; LAUERMAN, C. R.; MACÁRIO, E.; GLATT, R. Sistema de Informação de Agravos de Notificação (SINAN): desafios no desenvolvimento de um sistema de informação em saúde. Epidemiologia e Serviços de Saúde, Brasília, v. 13, n. 3, p. 135147, 2004.

LE GRAND, D. J. Equidad, salud y atención sanitaria. In: JORNADAS DE ECONOMIA DE LA SALUD, 8., Espanha. Anais... Espanha: 1988.

LESSA, F. J. D.; MENDES, A. C. G.; FARIAS, S. F.; SÁ, D. A.; DUARTE, P. O.; MELO FILHO, D. A. Novas metodologias para vigilância epidemiológica: uso do Sistema de Informações Hospitalares - SIH/SUS. Informe Epidemiológico do SUS, Brasília, v. 9, Supl. 1, 2000.

LIENHARDT, C.; ROWLEY, J.; MANNEH, K.; LAHAI, G.; NEEDHAM, D.; MILLIGAN, P.; MCADAM, K. P. W. J. Factors affecting time delay to treatment in a tuberculosis control programme in a sub-Saharan African country: the experience of the Gambia. The International Journal of Tuberculosis and Lung Disease, Paris, v. 5, n. 3, p. 233-239, 2001.

LIMA, M. B. M. da; MORAIS, A. P. P.; SILVA, W. C. Estudo de casos sobre abandono de tratamento da tuberculose: avaliação do atendimento, percepção e conhecimentos sobre a doença na perspectiva dos clientes (Fortaleza, Ceará, Brasil). Cadernos de Saúde Pública, Rio de Janeiro, v. 17, n. 4, p. 877-885, 2001. 
LINDOSO, A. A. B. P. Fatores preditivos para morte por tuberculose pulmonar no município de São Paulo, SP, 2002. 2004. Tese (Doutorado) - Faculdade de Medicina da Universidade de São Paulo, São Paulo, 2004. 79p.

LITUAK J. El envejecimiento de la población: un desafío que va más allá del año 2000. Boletín de la Oficina Sanitaria Panamericana, Washington, v. 109, n. 1, p. 1-5, 1990.

MANGTANI, P.; JOLLEY, D. J.; WATSON, J. M.; RODRIGUES, L. C. Socioeconomic deprivation and notification rates for tuberculosis in London during 1982-91. British Medical Journal, London, v. 310, n. 5, p. 963-6, 1995.

MARMOT, M. G. et al. Social-economic status and health. Annual Review Public Health, California, n. 8, p. 111-135, 1987.

MARSIGLIA, R. M. G.; SILVEIRA, C.; CARNEIRO JÚNIOR, N. Políticas sociais: desigualdade, universalidade e localização na saúde no Brasil. Saúde e Sociedade, São Paulo, v. 14, n. 2, p. 6976, 2005.

MORSY, A. M.; ZAHER, H. H.; HASSAN, M. H.; SHOUMAN, A. Predictors of treatment failure among tuberculosis patients under DOTS strategy in Egypt. Eastern Mediterranean Health Journal, Alexandria, v. 9, n. 4, 2003.

MOTA, E.; CARVALHO, D. M. T. Sistemas de informação em saúde. In: ROUQUAYROL, M.Z.; ALMEIDA FILHO, N. Epidemiologia \& Saúde. 6. ed. Rio de Janeiro: MEDSI, 2003. p. 605-628.

MUNIZ, J. N. O tratamento supervisionado no controle da tuberculose em Ribeirão Preto sob a percepção da equipe de saúde. 1999. 155 f. Dissertação (Mestrado) - Escola de Enfermagem de Ribeirão Preto, Universidade de São Paulo, Ribeirão Preto, 1999.

NEWSON, J. T. Logistic regression. Escola de Saúde Comunitária da Universidade Estadual de Portland, 2006. 
OLIVEIRA, H. B. Estudo da tuberculose notificada entre presidiários. In: CONGRESSO BRASILEIRO DE EPIDEMIOLOGIA, 3., 1995. Salvador. Anais... Salvador,1995. p. A667.

OLIVEIRA, H. B.; MARIN-LEÓN, L.; GARDINALI, J. Análise do Programa de Controle da Tuberculose em relação ao tratamento em Campinas-SP. Jornal Brasileiro de Pneumologia, Ribeirão Preto, v. 3 n. 2, p. 133-8, 2005.

OLIVEIRA, H. B.; MOREIRA FILHO, D. C. Abandono de tratamento e recidiva da tuberculose : aspectos de episódios prévios, Campinas, SP, Brasil, 1993-1994. Revista de Saúde Pública, São Paulo, v. 34, n. 5 , p. $437-443,2000$.

ORGANIZAÇÃO PANAMERICANA DA SAÚDE. Organização Mundial de Saúde. Reunion regional de directores nacionales de programas de control de la tuberculosis: informe final. Guayaquil: Organización Panamericana de la Salud, 1997.

ORGANIZACIÓN MUNDIAL DE LA SALUD. Un Marco Ampliado de DOTS para el Control Eficaz de la Tuberculosis: alto a la tuberculosis enfermedades transmisibles. Ginebra: OMS, 2002.

ORGANIZACIÓN PANAMERICANA DE LA SALUD. Organización Mundial de la Salud. Usos y perspectivas de la epidemiologia. Documentos del Seminario. Buenos Aires, Argentina, 7-10 noviembre, 1984, Publicación PNSP 84-47, Washington, D.C., 1984, $243 p$.

PABLOS-MÉNDEZ, A.; KNIRSCH, C. A.; BARR, R. G.; LERNER, B. H.; FRIEDEN, T. R. Nonadherence in tuberculosis treatment: predictors and consequences in New York city. The American journal of medicine, New York, v. 102, n. 2, p. 164-170, 1997.

PENNA, M. L. F. Tuberculose: Assistência ou Controle? Revisão dos dados que apóiam a existência de efetividade epidemiológica dos programas de controle baseados no diagnóstico e tratamento de casos. Boletim da Campanha Nacional Contra a Tuberculose, Rio de Janeiro, v. 2, n. 1, p. 5-14, 1988. 
PERINI, E. $O$ abandono do tratamento da tuberculose: transgredindo regras, banalizando conceitos. 1998. 218 f. Tese (Doutorado) - Escola de Veterinária, Universidade Federal de Minas Gerais, Belo Horizonte, 1998.

PERNAMBUCO. Governo do Estado. Secretaria Estadual de Saúde. Coordenação de Tuberculose do Estado de Pernambuco. Indicadores e informações em saúde. Ano. Disponível em: <http://www. saúde.gov.br>. Acesso em: 27 dez. 2004.

PREFEITURA DO RECIFE. Secretaria de Saúde. Política de controle da Tuberculose: Plano de Ação de Tuberculose - Ano: 2004/ 2005. Recife, 2004. Versão Preliminar.

PREFEITURA DO RECIFE. Secretaria de Saúde. Recife: Mais trabalho, melhor qualidade de vida. Recife, 2005. Plano Plurianual 2006-2009. v. 1. Lei 17.111/ 2005.

PRITCHARD, A. J. et al. Risk factors for drug resistant tuberculosis in Leicestershire - poor adherente to treatment remains an important cause of resistance. Epidemiology and infection, Cambridge, v. 130, n. 3, p. 481-483, 2003.

RAJAGOPALAN, S. Tuberculosis and aging: a global health problem. Clinical infectious diseases, Chicago, v. 33, p. 1034-39, 2001.

RAJAGOPALAN, S.; YOSHIKAWA, T. T. Tuberculosis in long-termcare facilities. Infection control and hospital epidemiology, Chicago, v. 21, n. 9, p. 611-5, 2000.

RAWLS, J. Uma Teoria da Justiça. São Paulo: Martins Fontes, 1997.

RECIFE. Secretaria de Saúde. Diretoria Geral de Atenção à Saúde. Diretoria Executiva de Atenção Básica. Coordenação de Tuberculose. Ações de controle da Tuberculose: relatório anual (2004). Recife, 2005. 
REIGOTA, R. M. S. Avaliação do Controle da Tuberculose pulmonar no município de Bauru - SP: implantação do tratamento supervisionado, 1999/2000. Dissertação (Mestrado) Faculdade de Medicina de Botucatu, Universidade Estadual Paulista, Botucatu, 2001.

RIBEIRO, A. S.; AMADO, V. M.; CAMELIER, A. A.; FERNANDES, M. M. A.; SCHENKMAN, S. Estudo caso-controle de indicadores de abandono em doentes com tuberculose. Jornal de Pneumologia, São Paulo, v. 26, n. 6, 2000.

RIBEIRO. S. N. Abandono do tratamento da tuberculose: aspectos do tratamento mal conduzido: discussão dos possíveis fatores como causa do abandono do tratamento específico da tuberculose e a situação bacteriológica após o abandono. 1993. Dissertação (Mestrado em Medicina Social) - Universidade do Estado do Rio de Janeiro, Rio de janeiro, 1993.

RUFFINO-NETTO, A. Tuberculose: a calamidade negligenciada. Revista da Sociedade Brasileira de Medicina Tropical, v. 35, n. 1, 2002.

RUFFINO-NETTO, A.; VILLA, T. C. S. Tuberculose, implantação do DOTS em algumas regiões do Brasil: histórico e peculiaridades regionais. Ribeirão Preto: Instituto Milênio REDE TB, 2006. 210 p.

SANTHA, T.; GARG, R.; FRIEDEN, T. R.; CHANDRASEKARAN, V.; SUBRAMANI, R.; GOPI, P. G.; SELVAKUMAR, N.; GANAPATHY, S.; CHARLES, N.; RAJAMMA, J.; NARAYANAN, P. R. Risk factors associated with default, failure and death among tuberculosis patients treated in a DOTS programme in Tiruvallur District, South India, 2000. The International Journal of Tuberculosis and Lung Disease, França, v. 6, n. 9, p. 780-788, 2002.

SANTOS FILHO, É. T. dos. Tempos de mudanças para o controle da tuberculose no Brasil. Rio de Janeiro: Public Health Watch Open Society Institute, 2006. 85p.

SASSAKI, C. M.; ARCÊNCIO, R. A.; COSTA JÚNIOR, M. L.; PALHA, P. F.; CARDOZO-GONZALES, R. I.; VILLA, T. C. S. Tempo 
de tratamento de pacientes inscritos no Programa de Controle da Tuberculose: Ribeirão Preto-SP (1998-1999). Boletim de Pneumologia Sanitária, Rio de Janeiro, v. 10, n. 2, p. 27-34, 2002.

SELIG, L.; BELO, M.; CUNHA, A. J. L. A.; TEIXEIRA, E. G.; BRITO, R.; LUNA, A. L.; TRAJMAN, A. Óbitos atribuídos à tuberculose no Estado do Rio de Janeiro. Jornal Brasileiro de Pneumologia, Ribeirão Preto, v. 30, n. 4, p. 417-24, 2004.

SEN, A. An Essay on Entitlement and Deprivation. Oxford: Clarendon Press, 1997.

SHERMAN, L. F.; FUJIWARA, P. I.; COOK, S. V.; BAZERMAN, L. B.; FRIEDEN, T. R. Patient and health care system delays in the diagnosis and treatment of tuberculosis. The International Journal of Tuberculosis and Lung Disease, França, v. 3, n. 12, p. 10881095, 1999.

SILVA, A. C. A.; BARBOSA, E. C. Ampliação da equipe do Programa de Controle da Tuberculose e Implantação do Tratamento Supervisionado - Município de Jacareí-SP. Boletim Epidemiológico Paulista, São Paulo, v. 1. n. 10, 2004.

SINGLA, R.; SINGLA, N.; SARIN, R.; ARORA, V. K. Influence of pretreatment bacillary load on treatment outcome of pulmonary tuberculosis patients receiving DOTS under revised national tuberculosis control programme. The Indian journal of chest diseases \& allied sciences, Delhi, v. 47, p. 19-23, 2005.

SOUZA, W. V. A epidemiologia da tuberculose em uma cidade brasileira na última década do século $\mathbf{X X}$ : uma abordagem espacial. 2003. 156f. Tese (Doutorado em Saúde Pública), Centro de Pesquisas Aggeu Magalhães, Escola Nacional de Saúde Pública da FIOCRUZ, Recife, 2003.

SOUZA, W. V.; XIMENES, R.; ALBUQUERQUE, M. F. M.; LAPA, T. M.; PORTUGAL, J. L.; LIMA, M. L. C.; MARTELLI, C. M. T. The use of socioeconomic factors in mapping tuberculosis risk areas in a city of northeastern Brazil. Revista Panamericana de Salud Publica, United States, v. 8, n. 6, 2000. 
SUMARTOJO, E. When tuberculosis treatment fails: a social behavioral account of patient adherence. American Review of Respiratory Disease, Baltimore, v. 147, p. 1311-1320, 1993.

TEIXEIRA, C. F. O Sistema Único de Saúde e a Vigilância da Saúde. Rio de Janeiro: FIOCRUZ, 2002a. 22 p. Texto didático.

TEIXEIRA, C. F. Promoção e vigilância da saúde no contexto da regionalização da assistência à saúde no SUS. Cadernos de Saúde Pública, Rio de Janeiro, 18 (suplemento), p. 153-162, 2002b.

TEIXEIRA, C. F. Epidemiologia e planejamento de saúde. In: ROUQUAYROL, M.Z.; ALMEIDA FILHO, N. Epidemiologia \& saúde. 6. ed. Rio de Janeiro: MEDSI, 2003. 728p.

TORRES, E.; PÉREZ, R. Tiempo empleado en la captación, diagnóstico y tratamiento en pacientes con tuberculosis pulmonar frotis positivo en el Hospital Santa María del Socorro de Ica, 2000. Informe 2000-Tuberculosis en el Perú. Capítulo III: Investigaciones operacionales. Ministerio de Salud. Perú, 2000.

TURNER, B. Equality. Nova York: Ellis Horwood Limited-Tavistock Publications, 1986.

VENDRAMINI, S. H. F.; GAZETTA, C. E.; CHIARAVALOTTI NETTO, F.; CURY, M. R.; MEIRELLES, E. B.; KUYUMJIAN, F. G.; VILLA, T. C. S. Tuberculose em município de porte médio do sudeste do Brasil: indicadores de morbidade e mortalidade, de 1985 a 2003. Jornal Brasileiro de Pneumologia, Ribeirão Preto, v. 31, n. 3, p. 237-43, 2005.

VENDRAMINI, S. H. F.; VILLA, T. C. S.; CARDOZO-GONZALES, R. I.; MONROE, A. A. Tuberculose no idoso: análise do conceito. Revista Latino-Americana de Enfermagem, Ribeirão Preto, v. 11, n. 1, 2003. 
WHITEHEAD, M. The concepts and principles of equity and health. International Journal of Health Services, Westport, v. 22, p. 429445, 1992.

WORKSHOP-REDE BRASILEIRA DE PESQUISA EM TUBERCULOSE, 1., 2002, Rio de Janeiro. Anais... Rio de Janeiro: UFRJ, 2002. $116 \mathrm{p}$.

WORLD HEALTH ORGANIZATION. WHO report on the tuberculosis epidemic, 1997: use dots more widely. Geneva, 1997. (WHO, TB/97.224).

WORLD HEALTH ORGANIZATION (WHO). Global Tuberculosis control: surveillance, planning, financing. WHO Report 2001. Geneva, 2001.

WORLD HEALTH ORGANIZATION (WHO). Global Tuberculosis control: surveillance, planning, financing. WHO Report 2003. Geneva, 2003.

WORLD HEALTH ORGANIZATION (WHO). Global Tuberculosis control: surveillance, planning, financing. WHO Report 2004. Geneva, 2004.

WORLD HEALTH ORGANIZATION (WHO). Global Tuberculosis control: surveillance, planning, financing. WHO Report 2005. Geneva, 2005.

WORLD HEALTH ORGANIZATION (WHO). Global tuberculosis control: surveillance, planning, financing. WHO Report 2006. Geneva, 2006.

YOSHIKAWA, T. T. Tuberculosis in aging adults. Journal of the American Geriatrics Society, Los Angeles, v. 40, p. 178-87, 1992. 
ANEXOS 
ANEXO A

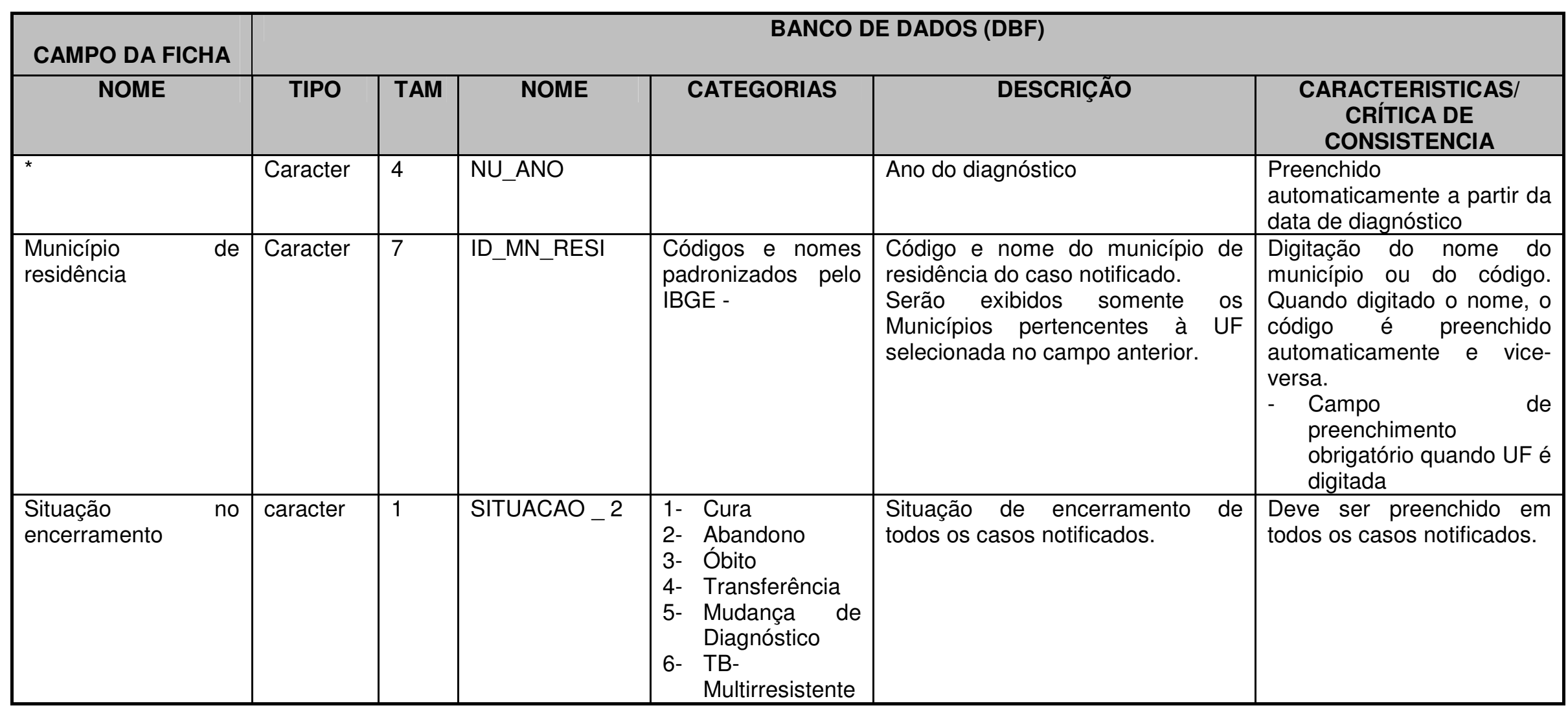




\begin{tabular}{|c|c|c|c|c|c|c|}
\hline Idade & Caracter & 4 & NU_IDADE & $\begin{array}{l}\text { A composição da } \\
\text { variável obedece } \\
\text { ao seguinte critério: } \\
4^{\circ} \text { dígito: } \\
\text { ANOS (A), MESES } \\
\text { (M), DIAS (D) } \\
\text { Ex. 09 M - nove } \\
\text { meses, } 18 \text { A - } \\
\text { dezoito anos }\end{array}$ & $\begin{array}{l}\text { Idade do paciente por ocasião da } \\
\text { data do diagnóstico. } \\
\text { OBS: quando não há data de } \\
\text { nascimento a idade deve ser } \\
\text { digitada segundo informação } \\
\text { fornecida pelo paciente como } \\
\text { aquela referida por ocasião da data } \\
\text { do diagnóstico e se o paciente não } \\
\text { souber informar sua idade, anotar a } \\
\text { idade aparente. }\end{array}$ & $\begin{array}{l}\text { Preenchida } \\
\text { automaticamente, a partir } \\
\text { da diferença entre data do } \\
\text { diagnóstico e data do } \\
\text { nascimento. } \\
\text { Campo de preenchimento } \\
\text { obrigatório caso a data de } \\
\text { nascimento não seja } \\
\text { preenchida }\end{array}$ \\
\hline Sexo & Caracter & 1 & CS_SEXO & $\begin{array}{l}\text { M - masculino } \\
\text { F - feminino } \\
\text { I - ignorado }\end{array}$ & Sexo do paciente & Preenchimento obrigatório \\
\hline $\begin{array}{lr}\text { Escolaridade } & (\mathrm{em} \\
\text { anos de } & \text { estudos } \\
\text { concluídos) } & \end{array}$ & Caracter & 1 & CS_ESCOLAR & $\begin{array}{l}\text { 1- nenhuma } \\
2 \text { - De } 1 \text { a } 3 \\
3 \text { - De } 4 \text { a } 7 \\
4 \text { - De } 8 \text { a } 11 \\
5 \text { - De } 12 \text { e mais } \\
\text { 6 - Não se aplica } \\
9 \text { - Ignorado }\end{array}$ & $\begin{array}{l}\text { Anos de estudo concluídos. A } \\
\text { classificação é obtida em função da } \\
\text { série e do grau que a pessoa está } \\
\text { freqüentando ou freqüentou } \\
\text { considerando a última série } \\
\text { concluída com aprovação. A } \\
\text { correspondência é feita de forma } \\
\text { que cada série concluída com } \\
\text { aprovação corresponde a um ano } \\
\text { de estudo. }\end{array}$ & $\begin{array}{l}\text { - Categoria padronizada } \\
\text { segundo definição da } \\
\text { RIPSA } \\
\text { Categoria } 6 \text { - não se } \\
\text { aplica é preenchida } \\
\text { automaticamente } \\
\text { quando caso notificado } \\
\text { é }<7 \text { anos. }\end{array}$ \\
\hline
\end{tabular}




\begin{tabular}{|c|c|c|c|c|c|c|}
\hline $\begin{array}{l}\text { Ocupação/ Ramo de } \\
\text { Atividade Econômica }\end{array}$ & Caracter & 5 & ID_OCUPACA & & $\begin{array}{l}\text { Informar a atividade exercida pelo } \\
\text { paciente no setor formal, informal } \\
\text { ou autônomo ou sua última } \\
\text { atividade exercida quando paciente } \\
\text { for desempregado. O ramo de } \\
\text { atividade econômica do paciente } \\
\text { refere-se às atividades econômicas } \\
\text { desenvolvidas nos processos de } \\
\text { produção do setor primário } \\
\text { (agricultura e extrativismo); } \\
\text { secundário (indústria) ou terciário } \\
\text { (serviços e comércio). }\end{array}$ & \\
\hline Distrito & caracter & 4 & ID_DT_RESI & $\begin{array}{l}\text { Códigos e nomes } \\
\text { padronizados } \\
\text { segundo Tabela } \\
\text { disponibilizada pelo } \\
\text { sistemar para } \\
\text { cadastramento pelo } \\
\text { usuário - r } \\
\end{array}$ & $\begin{array}{l}\text { Nome e respectivo código do } \\
\text { distrito de residência do paciente } \\
\text { por ocasião da notificação. }\end{array}$ & $\begin{array}{l}\text { Serão exibidos apenas os } \\
\text { distritos pertencentes ao } \\
\text { Município selecionado no } \\
\text { campo anterior. }\end{array}$ \\
\hline Forma & caracter & 1 & FORMA & $\begin{array}{l}\text { 1-pulmonar } \\
\text { 2-extrapulmonar } \\
\text { 3-pulmonar }+ \\
\text { extrapulmonar }\end{array}$ & $\begin{array}{l}\text { Forma clínica da tuberculose, por } \\
\text { ocasião da notificação, segundo a } \\
\text { sua localização. }\end{array}$ & $\begin{array}{l}\text { Preenchimento obrigatório. } \\
\text { Se a categoria = } 1 \text {, campo } \\
\text { "Se extrapulmonar" é } \\
\text { preenchido } \\
\text { automaticamente com } \\
\text { categoria } 9 \text { (não se aplica) e } \\
\text { o cursor pula para campo } \\
\text { Agravos associados. Se } \\
\text { categoria }=2 \text { ou } 3 \text {, campo } \\
\text { "Se extrapulmonar" é de } \\
\text { preenchimento obrigatório. }\end{array}$ \\
\hline
\end{tabular}




\begin{tabular}{|c|c|c|c|c|c|c|}
\hline Tipo de Entrada & Caracter & 1 & TRATAMENTO & $\begin{array}{ll}\text { 1- } & \text { Caso Novo } \\
\text { 2- } & \text { Recidiva } \\
\text { 3- } & \text { Reingresso } \\
& \text { após-abandono } \\
\text { 4- } & \text { Não Sabe } \\
\text { 5- } & \text { Transferência }\end{array}$ & $\begin{array}{l}\text { Preencher com o código } \\
\text { correspondente a situação de } \\
\text { entrada do paciente na Unidade de } \\
\text { Saúde. O item TRANSFERËNCIA } \\
\text { se refere àquele paciente que } \\
\text { comparece a esta Unidade de } \\
\text { Saúde para dar continuidade ao } \\
\text { tratamento iniciado em outra } \\
\text { Unidade de Saúde, desde que não } \\
\text { tenha havido interrupção do uso da } \\
\text { medicação por mais de } 30 \text { dias. } \\
\text { Neste último caso, o tipo de } \\
\text { entrada deve ser "Reingresso após } \\
\text { abandono". Os conceitos de "Caso } \\
\text { Novo" e "Recidiva" estão referidos } \\
\text { no Manual de Normas Técnicas da } \\
\text { Tuberculose. A opção "Não Sabe" } \\
\text { deve ser assinalada quando o } \\
\text { paciente não souber fornecer } \\
\text { informações. }\end{array}$ & Preenchimento obrigatório \\
\hline $\begin{array}{l}\text { Tratamento } \\
\text { supervisionado }\end{array}$ & Caracter & 1 & TRAT_SUPER & $\begin{array}{l}\text { 1-sim } \\
\text { 2-não } \\
\text { 9-Ignorado }\end{array}$ & $\begin{array}{l}\text { Se o paciente está em tratamento } \\
\text { supervisionado para Tuberculose } \\
\text { (conforme norma técnica) }\end{array}$ & \\
\hline Data do Diagnóstico & Data & 10 & DT_DIAG & $\mathrm{dd} / \mathrm{mm} / \mathrm{aaaa}$ & $\begin{array}{l}\text { Data em que foi realizado } 0 \\
\text { diagnóstico do caso notificado. }\end{array}$ & $\begin{array}{l}\text { Preenchimento obrigatório. } \\
\leq \text { data de notificação }\end{array}$ \\
\hline $\begin{array}{l}\text { Data de início do } \\
\text { tratamento atual }\end{array}$ & Data & 10 & DT_INIC_TR & - & $\begin{array}{l}\text { Data de início do tratamento atual } \\
\text { na Unidade de Saúde que está } \\
\text { notificando o caso. }\end{array}$ & $\begin{array}{l}\text { Data do tratamento atual } \geq \\
\text { data do diagnostico. }\end{array}$ \\
\hline $\begin{array}{ll}\text { Data } & \text { de } \\
\text { encerramento }\end{array}$ & Data & 10 & DT_ENCERRA & $\mathrm{dd} / \mathrm{mm} /$ aaaa & $\begin{array}{l}\text { Data da alta por cura, abandono, } \\
\text { óbito, transferência, mudança de } \\
\text { diagnóstico ou data do diagnóstico } \\
\text { da TB multirresistente. }\end{array}$ & $\begin{array}{l}\text { Campo de preenchimento } \\
\text { essencial }\end{array}$ \\
\hline
\end{tabular}




\begin{tabular}{|c|c|c|c|c|c|c|}
\hline $\begin{array}{l}\text { Estabelecimento de } \\
\text { saúde atual }\end{array}$ & Caracter & 7 & ID_UNIDA_1 & $\begin{array}{l}\text { Cadastro de } \\
\text { estabelecimentos } \\
\text { de saúde do SINAN }\end{array}$ & $\begin{array}{l}\text { Unidade de Saúde atualmente } \\
\text { responsável pelo acompanhamento } \\
\text { do paciente. }\end{array}$ & $\begin{array}{l}\text { Preenchimento automático } \\
\text { no momento da digitação da } \\
\text { ficha de notificação/ } \\
\text { investigação. O campo será } \\
\text { alterado quando da } \\
\text { vinculação de } 2 \text { registros } \\
\text { devido a transferência do } \\
\text { caso de uma unidade para } \\
\text { outra. }\end{array}$ \\
\hline HIV & Caracter & 1 & HIV & $\begin{array}{l}\text { 1-positivo } \\
\text { 2-negativo } \\
\text { 3-em andamento } \\
\text { 4- não realizado }\end{array}$ & $\begin{array}{l}\text { Resultado da sorologia para o vírus } \\
\text { da imunodeficiência adquirida }\end{array}$ & \\
\hline Agravos associados & Caracter & 1 & $\begin{array}{l}\text { AGRAVOS - } \\
\text { AS }\end{array}$ & $\begin{array}{l}\text { 1- AIDS } \\
\text { 2- Alcoolismo } \\
\text { 3- Diabetes } \\
\text { 4- Doença Mental } \\
\text { 5- Outros } \\
\text { 9- Ignorado }\end{array}$ & $\begin{array}{l}\text { Informar se } \text { existe agravos } \\
\text { associados à tuberculose por } \\
\text { ocasião da notificação. }\end{array}$ & \\
\hline
\end{tabular}




\begin{abstract}
ANEXO B
Em relação ao resultado de tratamento da $\mathrm{TB}$, foi considerada a situação no encerramento (SITUACAO_2) descrita no Dicionário de Dados do SINAN - Ambiente WINDOWS (FUNASA, 2001) e definida no Livro de Registro e Controle de Tratamento dos Casos de Tuberculose.:
\end{abstract}

- Cura: será dada com base em critérios clínico-radiológicos, nos casos pulmonares inicialmente negativos ou extrapulmonares, ao completarem o tratamento;

- Abandono: será dada ao doente que deixou de comparecer à unidade de saúde por mais de 30 dias consecutivos, após a data aprazada para seu retorno;

- Óbito: será dada quando do conhecimento da morte do paciente, durante $\mathrm{o}$ tratamento $\mathrm{e}$ independentemente da causa;

- TB-Multirresistente: será dada aos casos que apresentem bacilo resistente a pelo menos rifampicina + isoniazida. 


\section{ANEXO C}

Em relação às variáveis independentes, foram definidas a partir do Dicionário de Dados do SINAN - ambiente WINDOWS, da Fundação Nacional de Saúde (FUNASA) - 2001:

- Ano de diagnóstico: ano que foi diagnosticado a TBpulmonar;

- Idade: idade do paciente por ocasião da data do diagnóstico;

- Sexo: sexo do paciente;

- Escolaridade: anos de estudo concluídos. A classificação é obtida em função da série e do grau que a pessoa está freqüentando ou freqüentou considerando a última série concluída com aprovação. A correspondência é feita de forma que cada série concluída com aprovação corresponde a um ano de estudo;

- Distrito de residência: distrito de residência do paciente por ocasião da notificação;

- Tipo de entrada: situação de entrada do paciente na Unidade de Saúde. O item TRANSFERËNCIA se refere àquele paciente que comparece a esta Unidade de Saúde para dar continuidade ao tratamento iniciado em outra Unidade de Saúde, desde que não tenha havido interrupção do uso da medicação por mais de 30 dias. Neste último caso, o tipo de 
entrada deve ser "Reingresso após abandono". Os conceitos de "Caso Novo" e "Recidiva" estão referidos no Manual de Normas Técnicas da Tuberculose. A opção "Não Sabe" deve ser assinalada quando o paciente não souber fornecer informações;

- Tratamento supervisionado: tratamento supervisionado, se o paciente está em tratamento supervisionado para Tuberculose (conforme norma técnica);

- Tempo 1: Data do início do tratamento - Data do diagnóstico (em dias);

- Tempo 2: Data do encerramento do tratamento - Data do início do tratamento (em meses);

Sendo:

- Data do diagnóstico: data em que foi realizado o diagnóstico do caso notificado;

- Data do início do tratamento: data de início do tratamento atual na Unidade de Saúde que está notificando o caso;

- Data do encerramento do tratamento: data da alta por cura, abandono, óbito, transferência, mudança de diagnóstico ou data do diagnóstico da TB multirresistente. 
- Distrito da Unidade de Saúde: Distrito a qual pertence a Unidade de Saúde responsável pelo acompanhamento atual do paciente;

- HIV: resultado da sorologia para o vírus da imunodeficiência adquirida. 
ANEXO D

\begin{tabular}{|c|c|}
\hline VARIÁVEIS & CATEGORIAS \\
\hline Resultado do tratamento & $\begin{array}{l}\text { Desfavorável (abandono, } \\
\text { óbito e TB-multirresistente) } \\
\text { Favorável (cura) }\end{array}$ \\
\hline Idade & $\begin{array}{l}0 \text { a } 9 \text { anos } \\
10 \text { a } 19 \text { anos } \\
20 \text { a } 39 \text { anos } \\
40 \text { a } 59 \text { anos } \\
60 \text { ou mais }\end{array}$ \\
\hline $\begin{array}{l}\text { Tempo } 1 \text { = Data do início do } \\
\text { tratamento - Data do diagnóstico (em } \\
\text { dias) }\end{array}$ & $\begin{array}{l}0 \text { dias } \\
1 \text { a } 7 \text { dias } \\
8 \text { a } 15 \text { dias } \\
16 \text { a } 30 \text { dias } \\
\text { mais de } 30 \text { dias } \\
\text { inconsistente }\end{array}$ \\
\hline $\begin{array}{l}\text { Tempo } 2 \text { = Data do encerramento do } \\
\text { tratamento - Data do início do } \\
\text { tratamento (em meses) }\end{array}$ & $\begin{array}{l}0-11 \text { mês } \\
1-12 \text { meses } \\
2-13 \text { meses } \\
3-14 \text { meses } \\
4-15 \text { meses } \\
5-16 \text { meses } \\
6-19 \text { meses } \\
\text { mais de } 9 \text { meses } \\
\text { inconsistente }\end{array}$ \\
\hline Distrito da Unidade de Saúde & $\begin{array}{l}\text { Sistema de Informações } \\
\text { de Mortalidade } \\
\text { Distrito I } \\
\text { Distrito II } \\
\text { Distrito III } \\
\text { Distrito IV } \\
\text { Distrito V } \\
\text { Distrito VI } \\
\end{array}$ \\
\hline
\end{tabular}




\section{ANEXO E}
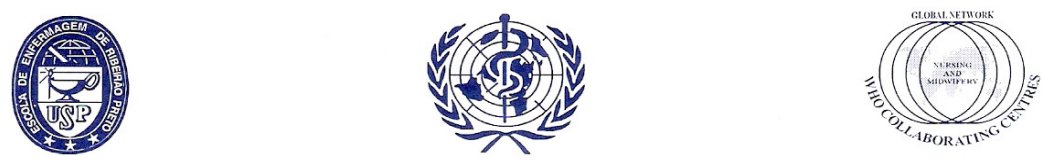

ESCOLA DE ENFERMAGEM DE RIBEIRÃO PRETO - UNIVERSIDADE DE SÃO PAULO

CENTRO COLABORADOR DA ORGANIZAÇÃo MUNDIAL DA SAÚDE PARA

O DESENVOLVIMENTO DA PESQUISA EM ENFERMAGEM

Avenida Bandeirantes, 3900 - Campus Universitário - Ribeirão Preto - CEP 14040-902 - São Paulo - Brasil FAX: $55-16-633-3271 / 55-16-630-2561$ - TELEFONES: 55 - 16 - 633-0379/602-3382

COMITÊ DE ÉTICA EM PESQUISA DA EERPIUSP

Of.CEP-EERP/USP - 169/2005

Ribeirão Preto, 6 de dezembro de 2005

Prezada Senhora,

Comunicamos que o projeto de pesquisa, abaixo especificado, foi analisado e considerado APROVADO AD REFERENDUM pelo Comitê de Ética em Pesquisa da Escola de Enfermagem de Ribeirão Preto da Universidade de São Paulo, em 6 de dezembro de 2005.

Protocolo:

$n^{\circ} 0584 / 2005$

Projeto:

Implantação do DOTS em algumas Regiões do Brasil: Histórico e Peculiaridades de Acordo com Características Regionais.

Pesquisador: $\quad$ Antônio Ruffino Netto

Tereza Cristina Scatena Villa

Em atendimento à Resolução 196/96, deverá ser encaminhado ao CEP o relatório final da pesquisa e a publicação de seus resultados, para acompanhamento, bem como comunicada qualquer intercorrência ou a sua interrupção.

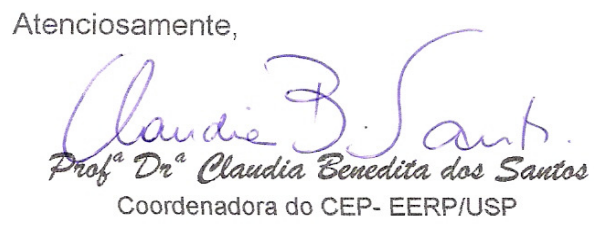

IIma. Sra.

Profa. Dra. Tereza Cristina Scatena Villa

Departamento de Enfermagem Materno-Infantil e Saúde Pública

Escola de Enfermagem de Ribeirão Preto-USP 